\title{
USING THE ELABORATION LIKELIHOOD MODEL TO DESIGN AND EVALUATE POLICE RECRUITMENT MESSAGES
}

\author{
A thesis submitted to \\ the Faculty of Graduate Studies and Research \\ in Partial Fulfillment of the requirements for the degree \\ Masters of Arts
}

by

Rebecca Mugford

Department of Psychology

Carleton University

September 2009

(C) 2009 Rebecca Mugford 


$\begin{array}{ll}\begin{array}{l}\text { Library and Archives } \\ \text { Canada }\end{array} & \begin{array}{l}\text { Bibliothèque et } \\ \text { Archives Canada }\end{array} \\ \begin{array}{l}\text { Published Heritage } \\ \text { Branch }\end{array} & \begin{array}{l}\text { Direction du } \\ \text { Patrimoine de l'édition }\end{array} \\ \begin{array}{l}\text { 395 Wellington Street } \\ \text { Ottawa ON K1A 0N4 } \\ \text { Canada }\end{array} & \begin{array}{l}395, \text { rue Wellington } \\ \text { Ottawa ON K1A ON4 } \\ \text { Canada }\end{array}\end{array}$

Your file Votre reference

ISBN: 978-0-494-58439-2

Our file Notre rétérence

ISBN: 978-0-494-58439-2

NOTICE:

The author has granted a nonexclusive license allowing Library and Archives Canada to reproduce, publish, archive, preserve, conserve, communicate to the public by telecommunication or on the Internet, loan, distribute and sell theses worldwide, for commercial or noncommercial purposes, in microform, paper, electronic and/or any other formats.

The author retains copyright ownership and moral rights in this thesis. Neither the thesis nor substantial extracts from it may be printed or otherwise reproduced without the author's permission.
AVIS:

L'auteur a accordé une licence non exclusive permettant à la Bibliothèque et Archives Canada de reproduire, publier, archiver, sauvegarder, conserver, transmettre au public par télécommunication ou par l'Internet, prêter, distribuer et vendre des thèses partout dans le monde, à des fins commerciales ou autres, sur support microforme, papier, électronique et/ou autres formats.

L'auteur conserve la propriété du droit d'auteur et des droits moraux qui protège cette thèse. Ni la thèse ni des extraits substantiels de celle-ci ne doivent être imprimés ou autrement reproduits sans son autorisation.
In compliance with the Canadian Privacy Act some supporting forms may have been removed from this thesis.

While these forms may be included in the document page count, their removal does not represent any loss of content from the thesis.
Conformément à la loi canadienne sur la protection de la vie privée, quelques formulaires secondaires ont été enlevés de cette thèse.

Bien que ces formulaires aient inclus dans la pagination, il n'y aura aucun contenu manquant. 


\begin{abstract}
In the near future, police agencies across Canada are expected to experience a serious staffing crisis. One way to help alleviate this crisis is to encourage more young people to consider policing as a profession, particularly since research has shown that many youth are not interested in policing as a career. The primary goal of this thesis was to explore the possibility of using the Elaboration Likelihood Model of persuasion to guide the development and evaluation of police recruitment messages. Across two studies, the Elaboration Likelihood Model was tested by examining the effects of message quality, source credibility, and argument quantity on attitudes towards policing as a career under different conditions of elaboration likelihood (i.e., message processing). In contrast to what was predicted, the studies failed to find any of the expected effects. While these results do not suggest that the ELM generalizes to the domain of police recruitment, it is still too early to abandon the possibility that this model of persuasion may have value in this applied context. Potential explanations for the null findings are discussed as well as important avenues for future research.
\end{abstract}




\section{Acknowledgements}

Above all, I must first thank the person who made it possible for me to accomplish everything I have throughout the course of my time at Carleton, my supervisor, Craig Bennell. Without your guidance and hard work, I know this thesis would not have been possible. Your patience and support have not gone unnoticed, and simply saying 'thank you' does not even begin to express how much I truly appreciate everything you have done for me over the years.

I would also like to thank my committee members, Dr. Kevin Nunes, Dr. Shelley Brown, Dr. Ron Saunders, and Dr. Connie Kristiansen for offering their time, effort, and feedback on this thesis. I am also thankful to have had the remarkable administrative support provided by those in the Department of Psychology over the past few years.

I must also thank the other graduate students that are a part of the Police Research Lab -Alyssa, Karla, Shevaun, and Tamara. Not only have all of you been great friends over the past two years, but you were always there to answer any questions I had throughout the program. I would especially like to thank each of you for helping me with the seemingly never-ending rounds of data collection that were needed to finish this thesis. Without your help and support, it would have been very difficult for me to stick to my timeline.

Finally, thank you to everyone else in my life that has helped me get through the past few years with my sanity still intact, especially Megan, Sara, and my parents Ron and Sheila. The past few years would have been much more difficult without your continual encouragement and understanding, and for that I am grateful. 


\section{Table of Contents}

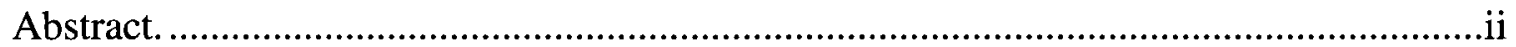

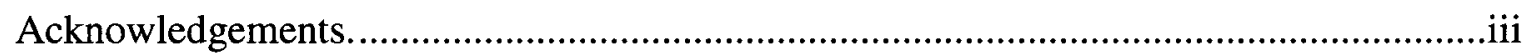

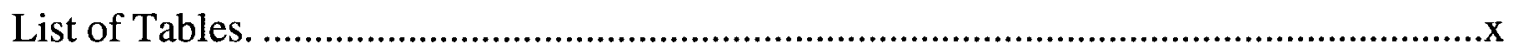

List of Figures. .................................................................................................

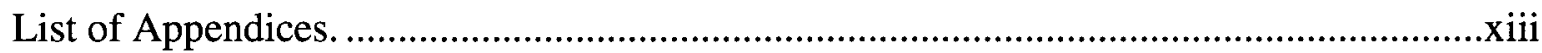

Using the Elaboration Likelihood Model to Design and Evaluate Police Recruitment

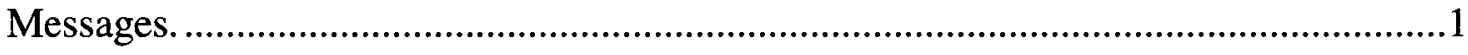

Current Recruitment Concerns in the Policing Sector...............................................2

Supply Concerns: Shrinking Labour Pool and Aging Workforce. ......................2

Demand Concerns: Lack of Interest in Policing as a Career ...............................

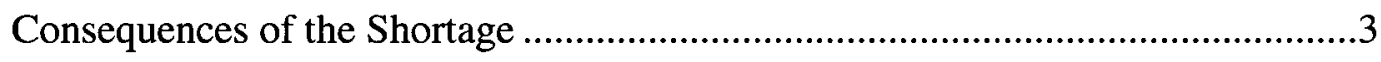

Recommended Solutions .......................................................................

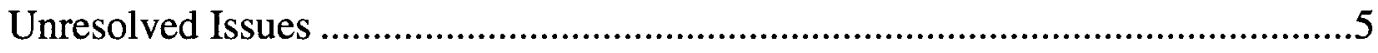

The Elaboration Likelihood Model.......................................................................6

The Elaboration Likelihood Construct.......................................................

Different Routes to Attitude Influence .......................................................

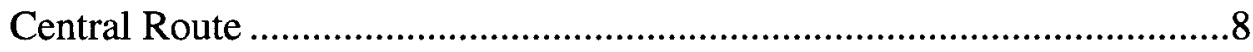

Peripheral Route........................................................................

Influencing the Extent of Elaboration .......................................................

Factors Influencing the Effectiveness of Persuasive Communications ..................11

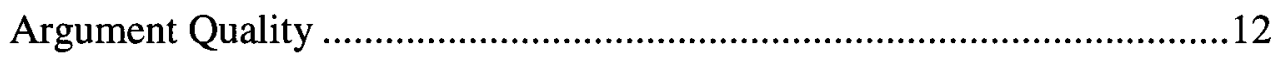

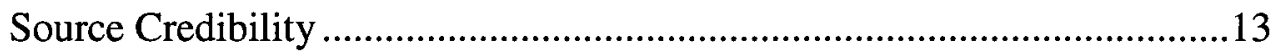




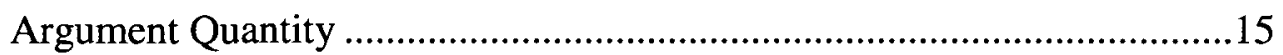

Implications of the Route to Persuasion ...............................................................

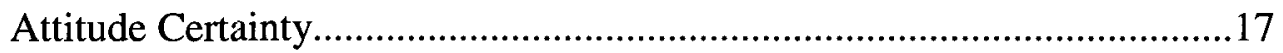

Importance of the Elaboration Likelihood Model to the Police Recruitment

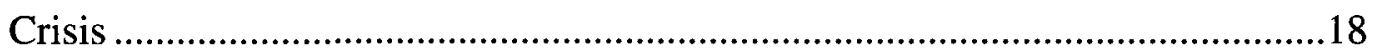

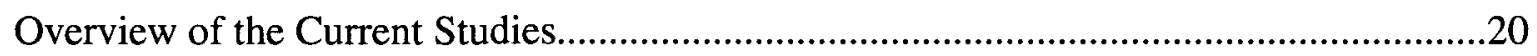

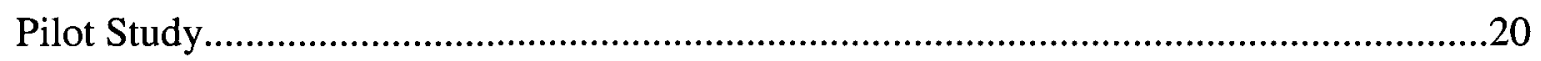

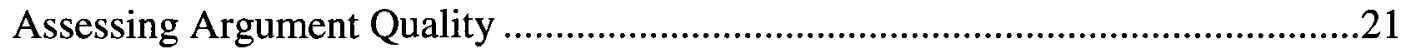

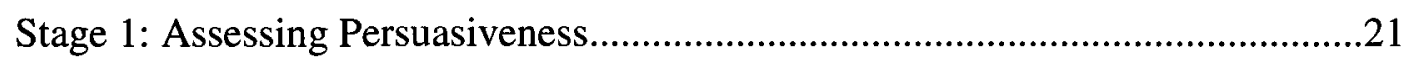

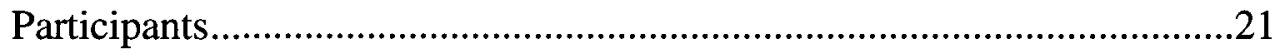

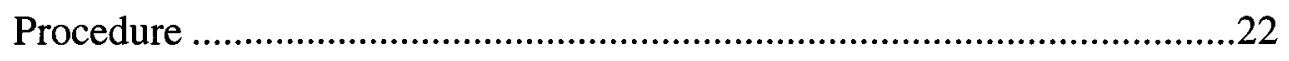

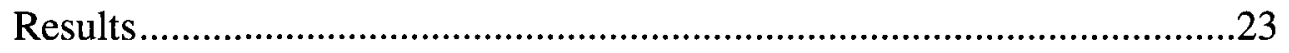

Stage 2 and 3: Assessing Cognitive Responses and the Role of Extraneous

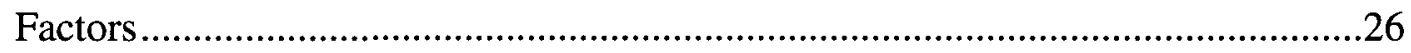

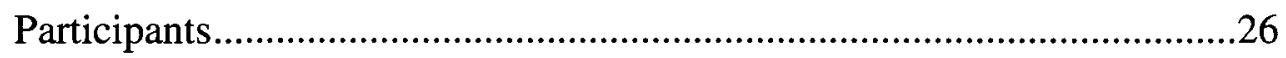

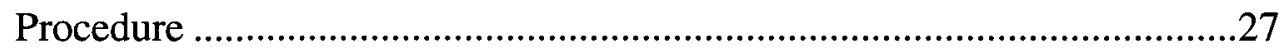

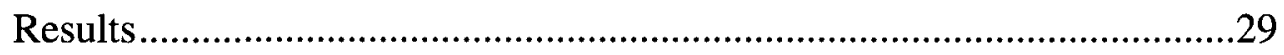

Manipulation Checks for Source Credibility and Personal Relevance ....................29

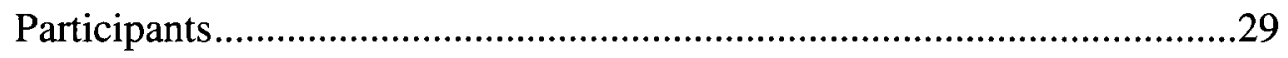

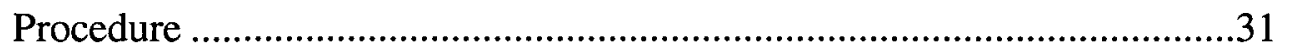

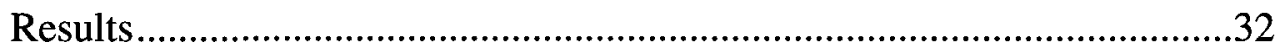

Study 1: Personal Relevance, Argument Quality, and Source Credibility ..........................33

Purpose 


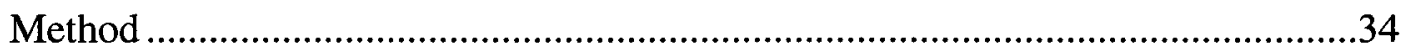

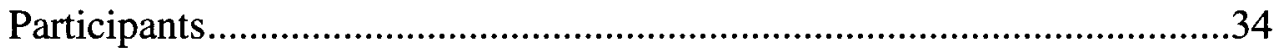

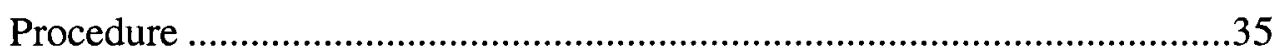

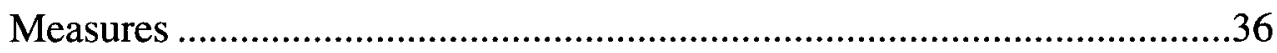

Attitudes Towards Policing as a Career.........................................36

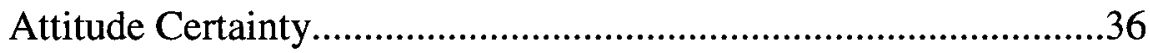

Cognitive Responses to Recruitment Messages ...............................37

Manipulation Checks ........................................................................

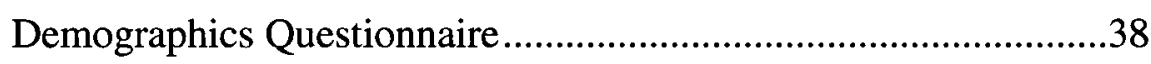

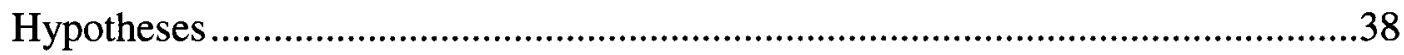

Attitudes Towards Policing as a Career.......................................................39

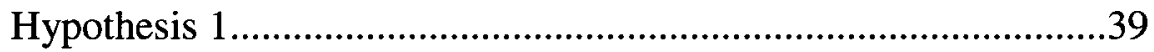

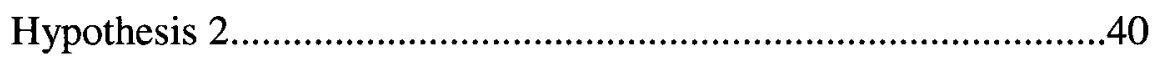

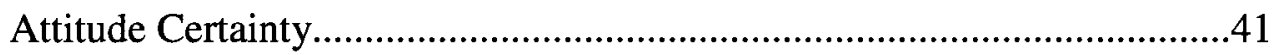

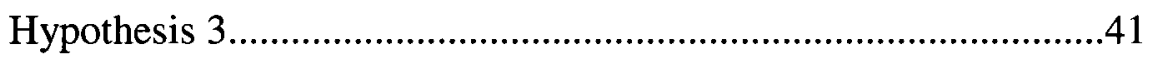

Cognitive Responses to Recruitment Messages ........................................41

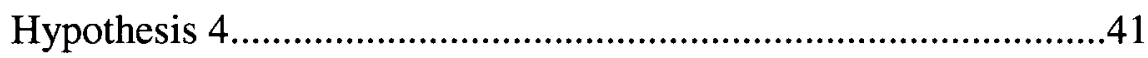

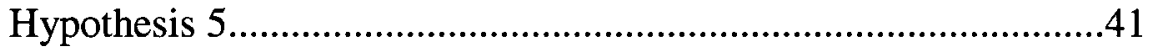

Mediating Role of Cognitive Responses....................................................42

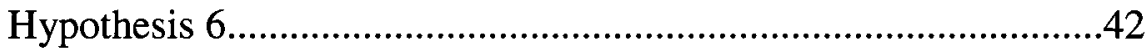

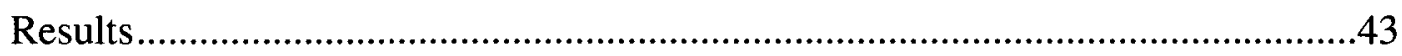

Preliminary Screening and Analyses .......................................................43

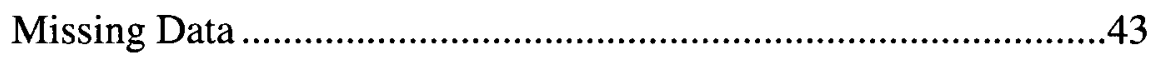


Manipulation Checks ..................................................................

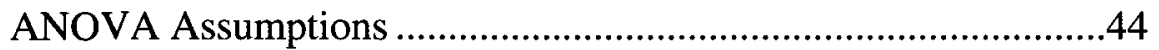

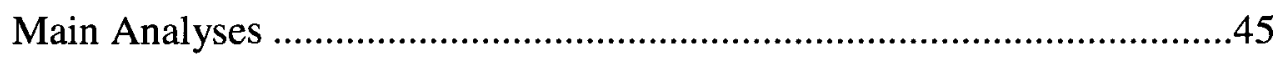

Attitudes Towards Policing as a Career (H1 and H2) .....................45

Attitude Certainty (H3) ................................................................

Cognitive Responses (H4 and H5)...............................................49

Mediating Role of Cognitive Responses (H6) ..............................52

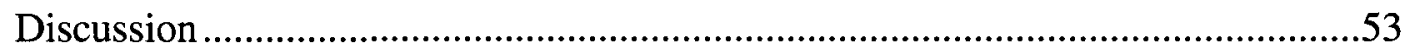

Study 2: Personal Relevance, Argument Quality, and Argument Quantity .......................55

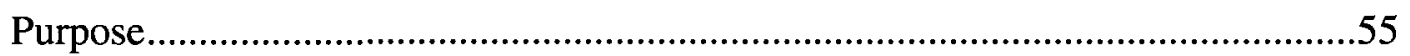

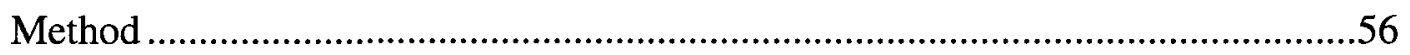

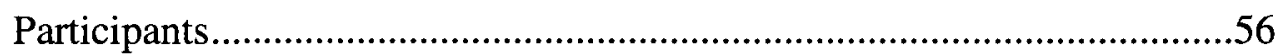

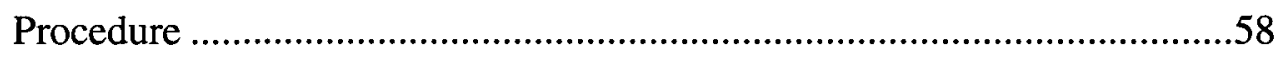

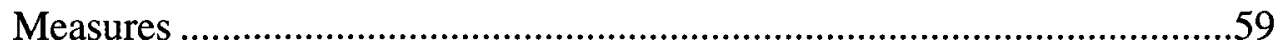

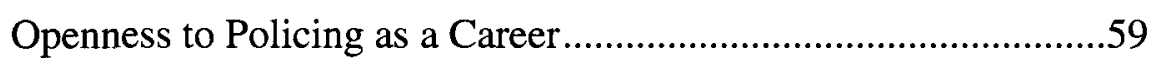

Attitudes Towards Policing as a Career........................................59

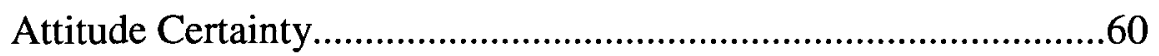

Cognitive Responses to Recruitment Messages ............................60

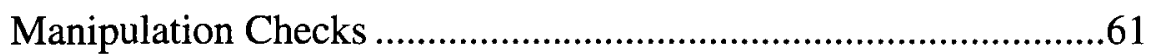

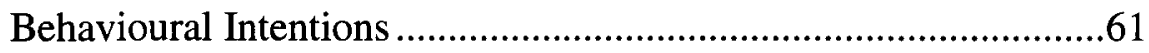

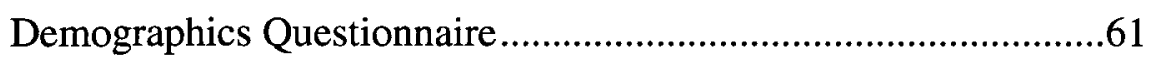

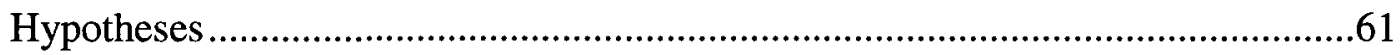

Attitudes Towards Policing as a Career....................................................62 


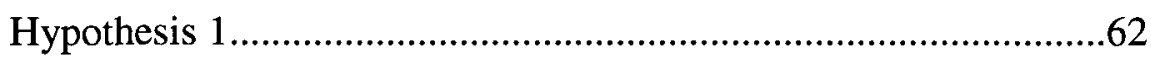

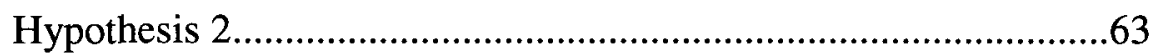

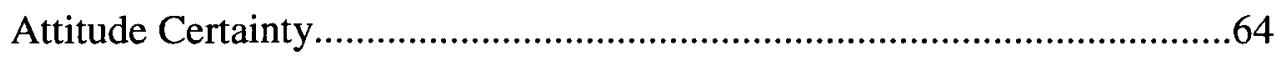

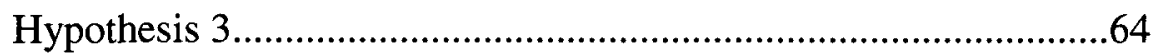

Cognitive Responses to Recruitment Messages ……………………..........64

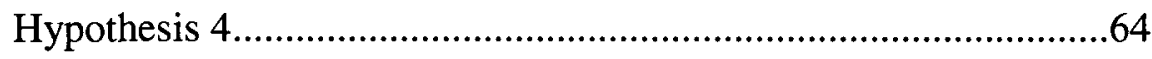

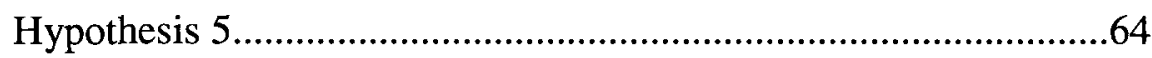

Mediating Role of Cognitive Responses.....................................................65

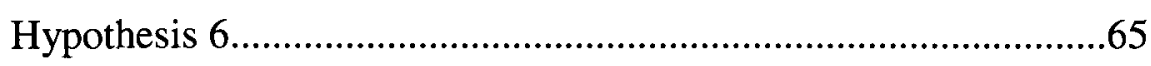

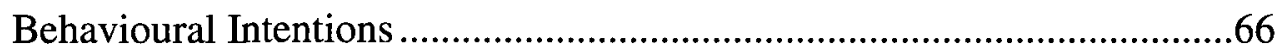

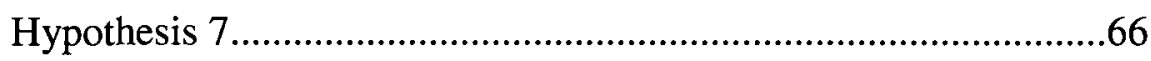

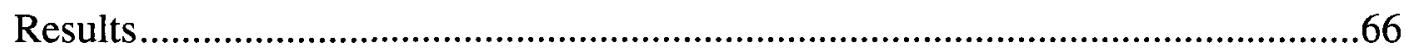

Preliminary Screening and Analyses ....................................................66

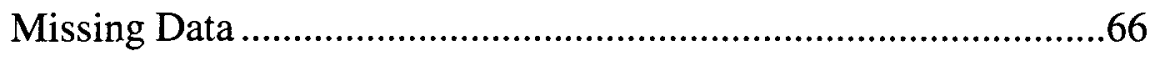

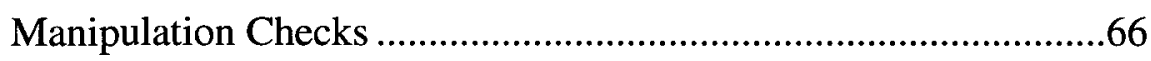

ANCOVA Assumptions.................................................................67

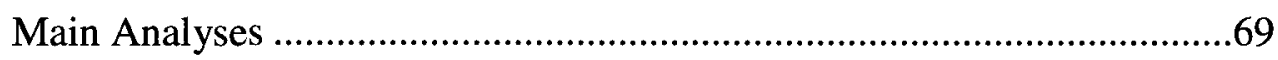

Attitudes Towards Policing as a Career ( $\mathrm{H} 1$ and $\mathrm{H} 2)$......................70

Attitude Certainty (H3) ...............................................................

Cognitive Responses (H4 and H5)...............................................

Mediating Role of Cognitive Responses (H6) ................................77

Behavioural Intentions (H7) ..........................................................77

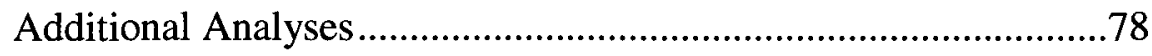




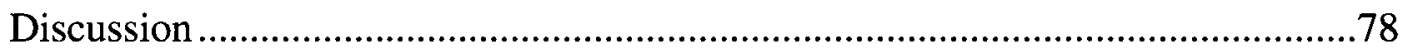

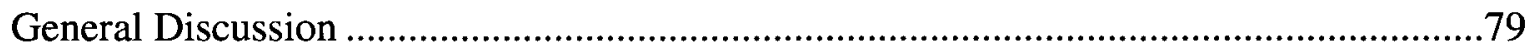

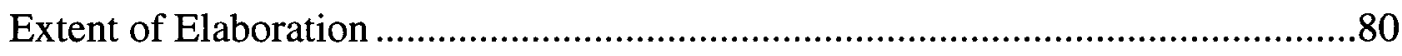

Attitude-Relevant Knowledge, Initial Attitudes, and Biased Processing ................82

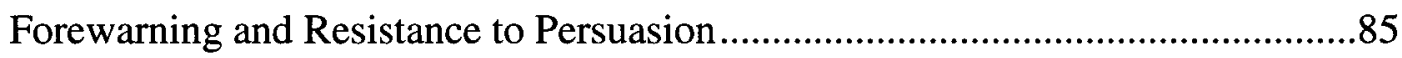

Significance of the Attitude Targeted for Change ....................................................86

Experimental Environment .................................................................................

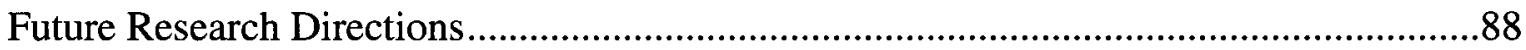

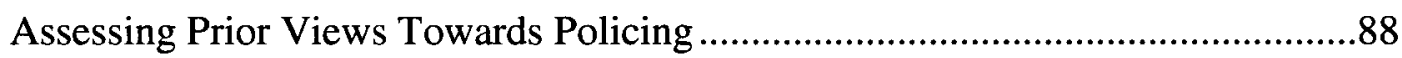

Personal Relevance Manipulation..........................................................................90

Refining Strong and Weak Messages ..................................................................91

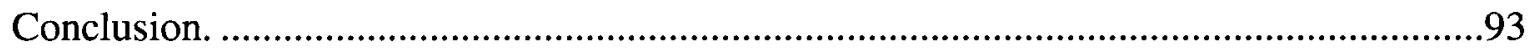

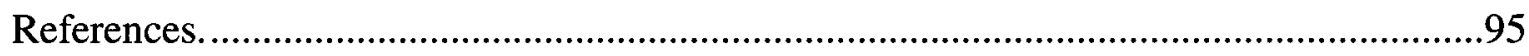

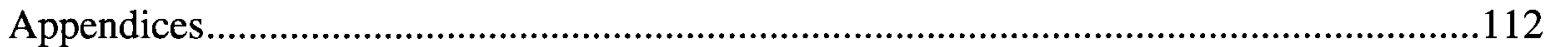




\section{List of Tables}

Table 1. Summary of Stage 1 participants' field of study and career aspirations .....22

Table 2. Means and associated standard deviations of arguments rated highest in persuasiveness ................................................................................24

Table 3. Means and associated standard deviations of arguments rated lowest in

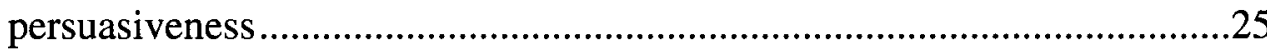

Table 4. Summary of Stage 2 and 3 participants' field of study and career aspirations

Table 5. Summary of manipulation check participants' field of study and career aspirations

Table 6. Summary of Study 1 participants' field of study and career aspirations ......35

Table 7. Study 1 group sizes, cell means, standard errors, and associated confidence intervals for attitudes towards policing as a career

Table 8. Study 1 group sizes, cell means, standard errors and associated confidence intervals for attitude certainty......

Table 9. Study 1 group sizes, cell means, standard errors and associated confidence intervals for total number of relevant thoughts .50

Table 10. Study 1 group sizes, cell means, standard errors and associated confidence intervals for thought favourability. .52

Table 11. Summary of Study 2 participants' field of study and career aspirations ....58

Table 12. Correlations between each dependent variable and openness to policing as a career 
Table 13. Group sizes, cell means, standard errors, and associated confidence intervals for the covariate, openness to policing as a career. .70

Table 14. Group sizes, cell means, standard errors, and associated confidence intervals for attitudes after adjusting for openness to policing as a career

Table 15. Group sizes, cell means, standard errors, and associated confidence intervals for attitude certainty after adjusting for openness to policing as a career .73

Table 16. Study 2 group sizes, cell means, standard errors, and associated confidence intervals for total relevant thoughts .75

Table 17. Group sizes, cell means, standard errors, and associated confidence intervals for thought favourability after adjusting for openness to policing as a career. . .76

Table 18. Correlations between attitudes and behavioural intentions for high and low relevance conditions 


\section{List of Figures}

Figure 1. Processes underlying the central and peripheral route to persuasion and their related consequences for attitudes and behaviour. Adopted from

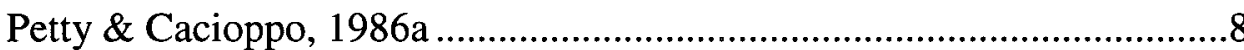

Figure 2. Expected interaction between personal relevance and argument quality on attitudes towards policing as a career. Adopted from Petty et al.

Figure 3. Expected interaction between personal relevance and source credibility on attitudes towards policing as a career. Adopted from Petty et al.

Figure 4. Expected interaction between personal relevance and argument quality on thought favourability scores

Figure 5. Proposed direct and indirect effects of argument quality on attitudes under conditions of high personal relevance

Figure 6. Expected interaction between personal relevance and argument quality on attitudes towards policing as a career. Adopted from Petty \& Cacioppo (1984b) .63

Figure 7. Expected interaction between personal relevance and argument quantity on attitudes towards policing as a career. Adopted from Petty \& Cacioppo (1984b)

Figure 8. Expected interaction between personal relevance and argument quality on thought favourability scores 


\section{List of Appendices}

Appendix A. Informed Consent Form (Pilot Study Stage 1) …………………............112

Appendix B. Questionnaire (Pilot Study Stage 1) ......................................................114

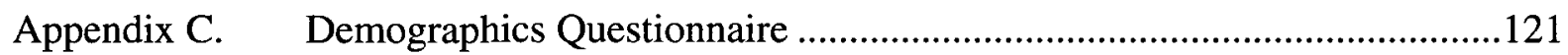

Appendix D. Debriefing Form (Pilot Study Stage 1) …….............................................123

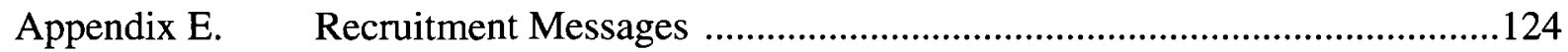

Appendix F. Thought Listing and Extraneous Factors (Pilot Study Stage 2 and 3)......127

Appendix G. Introduction to Messages ……….....................................................128

Appendix H. Pilot Study Manipulation Checks........................................................129

Appendix I. Informed Consent Form (Study 1) .......................................................130

Appendix J. Attitude and Attitude Certainty Measures (Study 1 and Study 2)............132

Appendix K. Manipulation Checks (Study 1 and Study 2) ...........................................133

Appendix L. Debriefing Form (Study 1) ……………..............................................

Appendix M. Study 1 Power and Effect Size Tables........................................................136

Appendix N. Sets of Arguments for Three Argument Conditions ………….................138

Appendix O. Questions Assessing Openness to a Career in a Variety of

Employment Sectors

Appendix P. Behavioural Intention Questions.......................................................141

Appendix Q. Study 2 Power and Effect Size Tables ................................................142 
Using the Elaboration Likelihood Model to Design and Evaluate Police Recruitment Messages

Recruitment refers to all organizational practices that are carried out in an attempt to identify and attract prospective employees (Barber, 1998; Orrick, 2008). The process of recruitment is extremely important to all organizations, as the quality and quantity of applicants attracted through the recruitment process is integral to the success of agency operations as a whole (Carlson, Connerley, \& Mecham, 2002). Although various methods of recruitment exist, all recruitment efforts have the overarching goal of influencing: (1) job applicant attitudes towards the career in question and (2) subsequent applicant behaviour (i.e., actually applying for the job; Barber, 1998).

Currently in Canada, the United States, and Australia, the recruitment of police personnel has become the focus of much concern (Hay Group, 2007; McKeever \& Kranda, 2006; Myers, 2006; Police Sector Council, 2006). Indeed, over the past few years, the Police Sector Council (PSC) of Canada has made recruitment one of their top priorities, calling for immediate action to develop evidence-based recruitment strategies in an effort to prevent a future shortage of police resources across the country (PSC, 2006). As a result, the Government of Canada recently established a national Police Officers Recruitment Fund, dispersing a total of 400 million dollars to provincial and territorial governments in order to sustain local law enforcement efforts in recruiting qualified police personnel (Public Safety Canada, 2008).

Although many recommendations have been made in an attempt to improve police recruitment strategies (e.g., Hay Group, 2007; Orrick, 2008), these recommendations tend to overlook a potentially crucial aspect of recruitment effectiveness - the effect that message, source, and recipient factors may have on the 
attitudes formed in response to recruitment messages (e.g., Jones, Sinclair, \& Courneya, 2003; Petty, Cacioppo, \& Goldman, 1981; Petty, Cacioppo, \& Haugtvedt, 1992). In an attempt to address this issue, this thesis will draw on the Elaboration Likelihood Model of persuasion (ELM; Petty \& Cacioppo, 1986a) to determine how certain persuasion factors impact attitudes towards a career in policing when these factors are embedded in recruitment messages. As such, this research may provide police agencies with a useful way of increasing interest amongst the general public towards pursuing a policing career, which may help alleviate current recruitment concerns.

Current Recruitment Concerns in the Policing Sector

\section{Supply Concerns: Shrinking Labour Pool and Aging Workforce}

The challenge of effectively recruiting law enforcement personnel has emerged as a central issue nationwide (Hay Group, 2007; PSC, 2006). Indeed, a survey of Canadian police chiefs in 2007 indicated that attracting the next generation of talent is the most important issue facing their organizations in the next 5 to 10 years (Hay Group, 2007). Contributing to this problem is the fact that the number of young people entering the workforce is shrinking, which can be partially attributed to Canada's lower birthrates over the past few decades (Martel, Caron-Malenfant, Vezina, \& Belanger, 2007). Resulting from this workforce shrinkage is a 'war of talent' between employment sectors that is expected to continue into the foreseeable future (Michaels, Handfield-Jones, \& Axelrod, 2001).

Not only are police agencies competing with other public and private employment sectors for fewer potential employees, but the retirement of a large portion of Canadian police officers magnifies this concern. For example, 38 percent of police officers surveyed in 2007 indicated that they intend to leave their job in the next two years or 
retire within the next five years (Hay Group, 2007). Similarly, human resource employees across Canadian police forces expect a substantial increase in turnover rates, with most forces who responded to a recent survey reporting that potentially 55 to 75 percent of their senior positions will be vacant within the next five years (Hay Group, 2007).

Demand Concerns: Lack of Interest in Policing as a Career

Also contributing to current recruitment concerns is the realization that a large majority of the youth population are becoming less interested in, and willing to consider, a career in law enforcement (Hay Group, 2007). For instance, although the Ontario Provincial Police attracted 20,000 applicants between the period of 1993 to 1997, the number of applicants decreased to 5,300 between 1998 and 2002 (Jones, 2004). This lack of interest in policing is more directly evident in recent survey results of youth employment preferences. For example, in a 2005 survey of young Canadians, policing was ranked sixth out of twelve job sectors in terms of field of choice, and fell to ninth place in 2007 (PSC, 2005, 2007). Moreover, only 36 percent of youths surveyed in 2005 indicated that they would even consider a career in law enforcement (PSC, 2005). Clearly this is a cause for concern, as recent estimates indicate that the annual number of police officers recruited in 2010 would need to be double that of current recruitment levels just to maintain the present level of police officer strength nation-wide (PSC, 2006).

\section{Consequences of the Shortage}

Although a visible shortage in Canadian police personnel has yet to occur, law enforcement organizations across the United States are presently dealing with the consequences of an increasingly competitive labour market, an aging workforce, and uninterested youth (Orrick, 2008; Whetstone, Reid, \& Turner, 2006; Woska, 2006). The 
situation across the United States provides a window into what may happen in Canada in the event that a similar shortage occurs. For example, from 1989 to 2002, the average number of individuals applying to U.S. police agencies with 500 or more officers declined 37 percent (Taylor et al., 2005). Consequently, police agencies across the U.S. are having a difficult time filling positions (White \& Escobar, 2008), with some estimates revealing that approximately 80 percent of law enforcement agencies in the U.S. currently have vacant positions (Woska, 2006). This shortage may manifest itself in several ways, including fewer officers available to patrol areas, slower response rates to non-emergency situations, and increased overtime, which can lead to officer burnout.

\section{Recommended Solutions}

As indicated above, a variety of recommendations have been made in an attempt to improve police recruitment strategies (e.g., Hay Group, 2007; Orrick, 2008). As supply concerns are unalterable, most of these recommendations attempt to increase the demand in policing as a career. For instance, in the National Diagnostic on Human Resources in Policing, the Hay Group (2007) recommended that the policing sector engage in a country-wide recruitment campaign. It was argued that this would allow for the pooling of resources and prevent wasting valuable resources on competition between law enforcement agencies themselves. It was further recommended that police agencies jointly employ as many identifiable best practices in recruiting as possible, including advertising on television, radio, billboards, and the Internet, and that police agencies continue to utilize community outreach programs (Hay Group, 2007). Other groups and individuals have offered similar solutions to increasing recruitment effectiveness, while also emphasizing the importance of canvassing schools and taking part in career fairs to provide the public with accurate information about the policing profession (HRDC 
Steering Committee, 2000; McKeever \& Kranda, 2006; Orrick, 2008; White \& Escobar, 2008). Although these recommendations may be useful as an initial step towards increasing recruitment efforts, many important questions still remain concerning the ways in which these efforts can be improved.

Unresolved Issues

Given the fact that a substantial amount of fiscal resources have now been allocated to national recruitment efforts, empirical research examining the effectiveness of police recruitment strategies is valuable. Indeed, in a recent survey, 64 percent of Canadian police organizations stated that although they employ some type of recruitment strategy, they do not formally evaluate the success of their recruitment efforts (Hay Group, 2007). Although the use of multiple recruitment techniques (e.g., using television, radio, and the Internet) may be helpful in terms of reaching a broader target audience, the above recommendations do not provide answers to some crucial questions that arise when considering the ultimate goal of recruitment efforts: to influence attitudes and subsequent behaviour.

For instance, it is currently unclear how best to motivate prospective applicants to carefully consider the content of the recruitment messages being presented by police agencies. In addition, while it is clear that recruitment messages must emphasize the positive aspects of policing, police agencies currently do not know what benefits to highlight in order to make a compelling case to the public that policing is an attractive career option. Furthermore, when interacting with potential applicants (e.g., during career fairs), it is not currently clear how features of the setting (e.g., the characteristics of the recruiter) influence attitudes towards policing. 
Overall, regardless of the number of recruitment techniques employed, recruitment efforts may be unsuccessful if they fail to take into account relevant aspects of the target audience, the recruitment message, and the police recruiter. Research in other domains has clearly shown that each of these factors can influence how people respond to messages that are intended to persuade, both at the level of attitudes and behaviours, and therefore a systematic examination of these issues may help to inform police recruitment practices in Canada. Much of this other research is based on the Elaboration Likelihood Model (ELM; Petty \& Cacioppo, 1986a), a popular and well supported model of persuasion that will be discussed next.

The Elaboration Likelihood Model

As previously mentioned, the ultimate goal of a police recruitment message is to foster positive appraisals of policing as a career in order to motivate prospective applicant behaviour (Orrick, 2008). Thus, when developing recruitment communications, it is essential to consider the importance of attitudes, as they are often assumed to be the driving force behind behaviour (e.g., Fazio \& Zanna, 1978; Fishbein \& Ajzen, 1975). One social psychological framework that acknowledges the importance of attitudes and their relationship with behaviour is the ELM (Petty \& Cacioppo, 1986a). The ELM is a contemporary model of persuasion, which attempts to account for the multitude of processes involved in attitude formation and change, the strength of the attitudes resulting from these processes, and the subsequent influence of attitudes on behaviour (Petty, Wheeler, \& Tormala, 2003). The ELM has been used as a framework for developing effective communications in many fields, including job advertising (Jones, Shultz, \& Chapman, 2006), but has yet to be applied to the police recruitment domain. The main components of the ELM will be described in the following sections. 


\section{The Elaboration Likelihood Construct}

Fundamental to the ELM is the concept of elaboration likelihood, referring to the extent to which an individual has both the motivation and ability to attend to the merits of the arguments presented within a message (Petty et al., 2003). When an individual is motivated and able to assess the arguments supporting a particular issue (i.e., elaboration likelihood is high), they are likely to use a great deal of their cognitive resources to evaluate (i.e., elaborate upon) all available information pertinent to that issue. In contrast, when an individual does not possess the motivation and/or the ability to thoroughly scrutinize message arguments (i.e., elaboration likelihood is low), they are likely to employ little cognitive effort to elaborate upon such information.

The extent of elaboration is represented on an elaboration likelihood continuum ranging from no thought about issue-relevant arguments included within a message to complete elaboration of every argument contained within a message (Petty, Wheeler, \& Bizer, 1999). Although attitudes can be influenced regardless of elaboration, it is the extent of elaboration (i.e., whether an individual falls lower or higher on the elaboration likelihood continuum) that is the key determinant of the route by which attitude change occurs. In turn, the route that is employed determines how different message and source factors will influence the attitudes formed as a result of the persuasive communication (Petty, Wegener, \& Fabrigar, 1997).

\section{Different Routes to Attitude Influence}

The ELM is commonly referred to as a dual process model, as it proposes two routes to persuasion that correspond to whether an individual falls high or low on the elaboration likelihood continuum: (1) the central route and (2) the peripheral route (see Figure 1). 


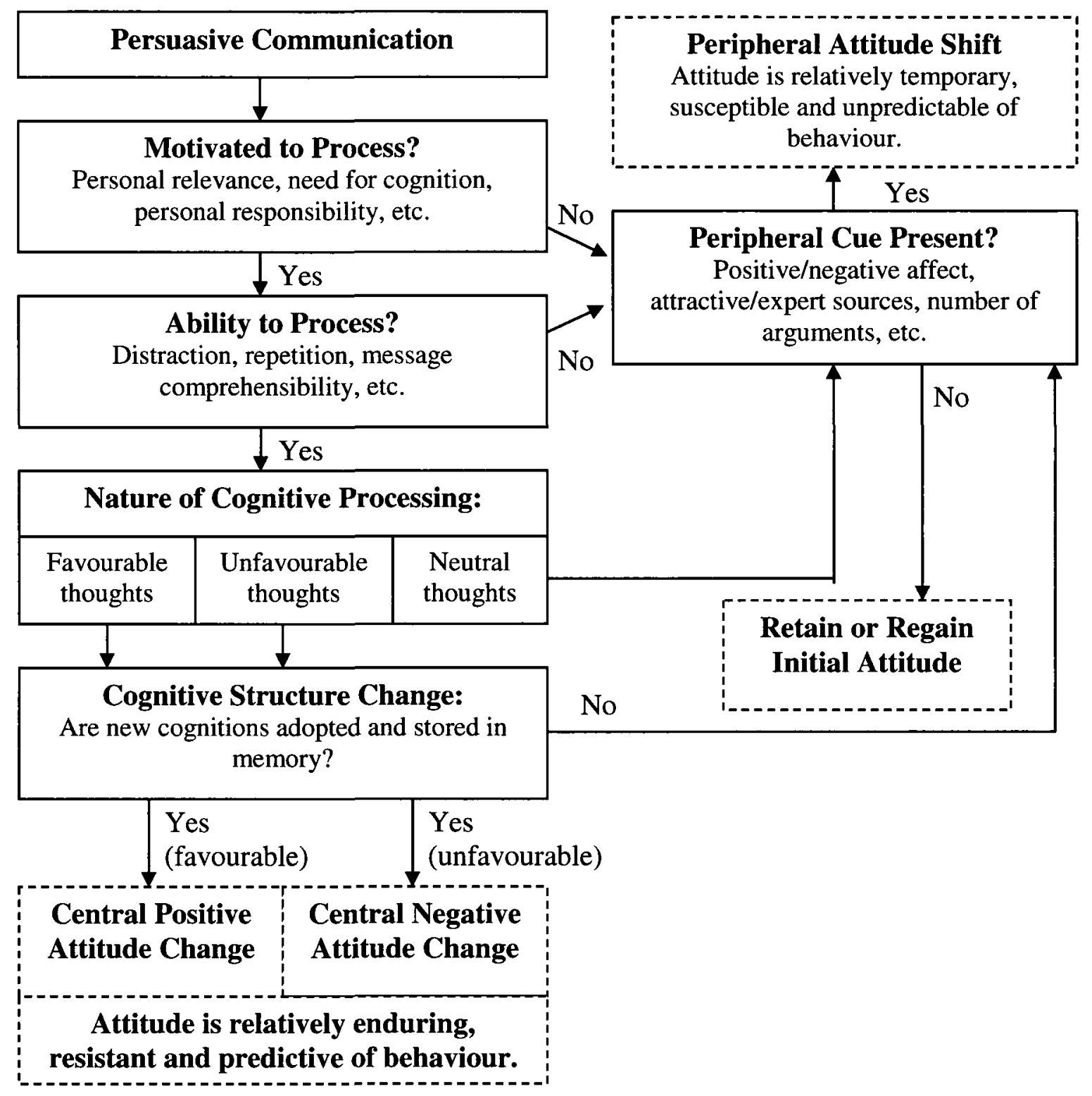

Figure 1. Processes underlying the central and peripheral route to persuasion and their related consequences for attitudes and behaviour. Adopted from Petty and Cacioppo, 1986a.

Central route. As shown in Figure 1, persuasion by the central route requires that the recipient of the persuasive communication has both the motivation and ability to thoroughly evaluate the arguments presented in support of the advocated position (Petty 
\& Cacioppo, 1986a). Under the central route, an individual conducts an effortful assessment of arguments provided in the communication, relates the communication to his or her own circumstances, and generates favourable or unfavourable thoughts in response to the message (Petty, 1995).

Peripheral route. In direct contrast to the central route, the peripheral route is taken by those who do not possess the motivation and/or ability to thoroughly evaluate the merits of arguments presented in support of a particular issue (Petty \& Cacioppo, 1986a). As shown in Figure 1, an individual who lacks the motivation and/or ability to evaluate issue-relevant arguments is more likely to be influenced by surface cues in the persuasive environment (e.g., the perceived credibility of the message source or the length of the message) rather than the merits (i.e., quality) of the arguments set forth (Petty, 1995). These simple cues (e.g., perceived source credibility) in the persuasive context tend to elicit simple inferences (e.g., "experts know best"), which individuals who are lower in elaboration likelihood often rely on to evaluate the message. Whether an individual is motivated and/or able to process message arguments and, thus, whether central or peripheral processes are likely to dominate, can be determined by a host of factors, one of which is described next.

\section{Influencing the Extent of Elaboration}

Prior to discussing specific message and source factors that can have different effects on attitudes formed through the different routes to persuasion, it is important to discuss how one can influence motivation to elaborate, as this partially determines the extent of elaboration and, ultimately, whether central or peripheral processes are 
employed. ${ }^{1}$ Perhaps the most common way of influencing motivation to elaborate in ELM research is to manipulate personal relevance, which has also been referred to as issue involvement (Kiesler, Collins, \& Miller, 1969), personal involvement (Apsler \& Sears, 1968), and task involvement (Sherif \& Hovland, 1961). ${ }^{2}$ Although these various terms exist, the general notion is that for a recipient to be highly involved in an issue, and therefore motivated to carefully consider issue-relevant material, the persuasive message must be seen as intrinsically important, or to hold important consequences for the message recipient's own life (Petty \& Cacioppo, 1986a).

The ELM suggests that as the relevance of an issue increases, an individual will become more motivated to process the arguments contained in the persuasive communication (Petty \& Cacioppo, 1986a; Petty et al., 2003). That is, as the personal consequences of an issue increase, developing an informed opinion becomes increasingly important because the consequences of developing an erroneous opinion are greater (Petty \& Briñol, 2002; Petty \& Wegener, 1999). Thus, those who perceive a high amount of intrinsic importance in a given issue are more likely to expend the cognitive effort that is required to thoroughly assess the arguments presented within a persuasive message (i.e., central route processing). Alternatively, those who perceive a low degree of personal relevance in an issue are less likely to expend the necessary cognitive effort to elaborate upon message arguments (i.e., peripheral route processing; Petty et al., 2003).

\footnotetext{
${ }^{1}$ Although beyond the scope of the current thesis, ability also affects the extent of elaboration. Some factors that have been found to affect the ability to elaborate include distraction (Petty, Wells, \& Brock, 1976), message repetition (Cacioppo \& Petty, 1979), and prior knowledge (Wood, Rhodes, \& Biek, 1995). ${ }^{2}$ There are also other determinants of motivation to elaborate, the two most common being personal responsibility (i.e., those who share responsibility for a task often exert less mental effort than those who feel they are more individually responsible; Petty \& Cacioppo, 1986a) and need for cognition (i.e., those who are predisposed to engage in and enjoy thinking are more likely to elaborate message arguments than those who do not enjoy cognitive activities; Cacioppo, Petty \& Morris, 1983). However, the focus here will be on personal relevance both because it is the most commonly studied determinant and because it can be easily manipulated in a practical setting and thus might have value for police recruitment.
} 
Various studies have demonstrated that personal relevance can be successfully manipulated within the experimental setting and that such manipulations can impact persuasion (Petty et al., 1992; Petty, Wheeler, \& Bizer, 2000; Tomsen, Borgida, \& Lavine, 1995). For example, Petty \& Cacioppo (1979) provided college participants with a message advocating the implementation of a mandatory senior comprehensive exam. Subjects were told that this policy was going to be instituted at their own university (high personal relevance) or at a distant university (low personal relevance). In addition, half the subjects were provided with strong arguments in support of the exam, whereas the other half were provided with weak arguments. Results revealed that, when personal relevance was high, strong and weak arguments increased and decreased favourable attitudes, respectively. When personal relevance was low, however, the quality of the arguments had no effect on post-exposure attitudes. In other words, increasing relevance led to more message scrutiny (i.e., post-message attitudes reflected the strength of message arguments), whereas decreasing relevancy led to less message scrutiny (i.e., post-message attitudes did not differ between strong and weak arguments).

\section{Factors Influencing the Effectiveness of Persuasive Communications}

Perceived personal relevance influences the extent of elaboration that takes place in any given persuasive situation, and thus partially determines the route to persuasion taken by any given individual (Petty et al., 1993). In turn, the route to persuasion determines how a multitude of other factors within the persuasive environment influence attitudes. Although countless message, source, and recipient factors exist, the following section will be restricted to those variables that are relevant to the current thesis. These include: (1) argument quality, (2) source credibility, and (3) argument quantity. Generally, the ELM holds that as the likelihood of elaboration increases, the quality of 
message arguments becomes a more important determinant of message persuasiveness. In contrast, when the likelihood of elaboration decreases, other variables (e.g., source credibility and argument quantity) can act as peripheral cues, and thus become a more important determinant of message persuasiveness (Petty \& Cacioppo, 1986a; Petty \& Wegener, 1999).

Argument quality. As previously alluded to, the quality of the arguments (i.e., whether they are weak or strong) provided in a message is thought to impact the effectiveness of persuasive communications primarily under conditions of high elaboration likelihood. A strong message is "one containing arguments such that when subjects are instructed to think about the message, the thoughts that they generate are predominantly favourable [towards the advocated position]" (Petty \& Cacioppo, 1986a, p. 32). For instance, a potentially strong argument in support of policing as a career may be that it offers individuals countless opportunities to help the community in which they live. Alternatively, a weak message is defined as, "one that is also ostensibly in favor of the advocacy...[but] when subjects are instructed to think about them, the thoughts that they generate are predominantly unfavorable" (Petty \& Cacioppo, 1986a, p. 32). An example of a potentially weak argument in the police recruitment context may be that working different shifts, rather than a job with normal work hours, can create variety in the work environment.

According to most ELM research, when an individual carefully attends to the arguments provided in a persuasive message, as they would under conditions of high elaboration likelihood, attitudes towards the advocated position in the message are determined primarily by an individual's cognitive responses (i.e., thoughts) that result from this careful scrutiny (Rucker, Petty, \& Priester, 2007). If this careful evaluation of 
the message leads to mostly positive thoughts, as would be expected in the case of a strong message, a corresponding more favourable attitude is likely to follow (and vice versa, with negative thoughts leading to less favourable attitudes) (Rucker et al., 2007).

An abundance of evidence exists in support of these postulated effects of argument quality. For example, many studies using the ELM framework have found that messages containing strong arguments induce significantly more favourable thoughts and attitudes towards the position being advocated than do messages containing weak arguments, but only when elaboration likelihood is high (Cacioppo, Petty, Kao, \& Rodrigeuz, 1986; Petty \& Cacioppo, 1979a; Petty \& Cacioppo, 1984b; Petty et al., 1981; Petty, Briñol, \& Tormala, 2002; Wheeler, Petty, \& Bizer, 2005). Moreover, studies have shown that when personal relevance is high, the effect of argument quality on attitudes is stronger than the effect of peripheral cues, such as source credibility, which further indicates that argument quality is a central determinant of post-message attitudes under conditions of high elaboration likelihood (Andrews \& Shimp, 1990; Petty et al., 1981; Petty, Cacioppo, \& Schumann, 1983).

Source credibility. Under conditions of low elaboration likelihood, ELM research has shown that factors such as argument quality have less influence on attitudes than do peripheral variables, such as the perceived credibility of the message source. As a commonly examined source cue, credibility is often defined along one of two dimensions: trustworthiness or expertise (Tormala, Briñol, \& Petty, 2006). Generally speaking, source trustworthiness refers to the extent to which the message source is perceived to be honest and sincere (Priester \& Petty, 2003). On the other hand, source expertise refers to the perceived ability of a source to provide accurate information about the position being advocated (Tormala et al., 2006). As expertise will be examined in the 
current thesis, all subsequent references to source credibility are referring to expertise rather than trustworthiness.

Several studies have demonstrated the effect of source expertise as a simple cue under conditions of low elaboration likelihood (e.g., Andrews \& Shimp, 1990; Bohner, Moskowitz, \& Chaiken, 1995; Chaiken \& Maheswaran, 1994; Johnson \& Scileppi, 1969; Kruglanski \& Thompson, 1999; Petty \& Cacioppo, 1984a; Petty et al., 1981). For example, in a similar study to that described above, Petty and colleagues (1981) presented students with a message advocating that college seniors at their school be required to pass a comprehensive exam prior to graduation either within the next year (high personal relevance) or within the next ten years (low personal relevance). The message contained either strong or weak arguments in support of the exam policy and was provided by either a professor from Princeton University (high expertise source) or a high school student (low expertise source). Results revealed that for students who believed the exam policy would take effect in ten years (i.e., low elaboration likelihood) post-message attitudes were influenced by the expertise of the message source, but not the quality of the arguments. In other words, under conditions of low elaboration, individuals exposed to high expertise sources likely employed an "experts know best" heuristic, resulting in favourable attitudes formed without much deliberate thought. Alternatively, for those who believed the exam policy would take effect in the next year (i.e., high elaboration likelihood), attitudes reflected the quality of the arguments (e.g., more favourable attitudes for strong messages and less favourable attitudes for weak messages), but were not affected by the expertise of the source.

In addition to acting as a peripheral cue under conditions of low elaboration likelihood, other studies have found that source credibility can influence attitudes under 
higher conditions of elaboration likelihood by biasing the favourability of thoughts generated in response to a persuasive message (Chaiken \& Maheswaran, 1994; Tormala, Briñol, \& Petty, 2007), or by influencing the amount of thinking (DeBono \& Harnish, 1988; Petty \& Cacioppo, 1984a; Heesacker, Petty \& Cacioppo 1983). For instance, Heesacker et al. (1983) conducted a study where they examined the effects of source credibility and argument quality on attitudes towards comprehensive exams. In this study, however, they did not directly manipulate the elaboration level of participants. Results indicated that participants, who were neither high nor low in elaboration likelihood, engaged in more message-relevant thinking when they were exposed to a source high in credibility than when they were exposed to a source low in credibility. As a result of this increased message elaboration, central route processes dominated when participants were provided with a high credibility source. That is, attitudes were a function of argument quality (i.e., attitudes were more/less favourable for strong/weak arguments) when participants were exposed to a high credibility source, but not when they were exposed to a low credibility source (i.e., attitudes were similar for strong and weak arguments). Heesacker et al. suggested that such effects of source credibility were likely not found in previous studies (e.g., Petty et al., 1981) due to an elaboration ceiling effect. That is, when a high degree of elaboration is expected (e.g., due to manipulations of high personal relevance), thinking may already be maximal, making any further increases as a result of source credibility unlikely to occur.

Argument quantity. Equally as important as source cues, other peripheral cues reside within the content of the persuasive message itself. In particular, the number of arguments contained within a persuasive message has been shown to be a potentially important message factor that can serve as a peripheral cue under conditions of low 
elaboration likelihood (Aaker \& Maheswaran, 1997, Alba \& Marmorstein, 1987; Insko, Lind, \& LaTour, 1976; Petty \& Cacioppo, 1984b; Wang \& Chen, 2006).

For instance, Petty and Cacioppo (1984b) conducted a conceptual replication of Petty et al.'s (1981) study, but instead of manipulating source credibility they manipulated the number of arguments presented in the persuasive message. Specifically, participants were manipulated to be high or low in personal relevance and were provided with either three or nine arguments in support of the exam policy that also differed in terms of quality (i.e., strong or weak). Results revealed that, for those who were low in personal relevance, increasing the number of arguments from three to nine resulted in more favourable attitudes towards comprehensive exams, regardless of the quality of the arguments presented within the messages. In contrast, when personal relevance was high, attitudes were more favourable when exposed to strong versus weak arguments, regardless of the number of arguments. Clearly, when issue-relevant thinking is low, and thus the quality of the arguments is unimportant, peripheral processes govern the formation and change of attitudes in the persuasive environment. In contrast, when issuerelevant thinking is high, attitudes are more a function of the quality of the arguments set forth. $^{3}$

\section{Implications of the Route to Persuasion}

Although the peripheral or central route processes described above can be equally effective in terms of persuasiveness, the consequences of attitudes formed through each route differ. This is an important postulate of the ELM, as the purpose of many persuasive messages, especially recruitment messages, is not simply to foster favourable

\footnotetext{
${ }^{3}$ Unlike studies involving source credibility (e.g., Heesacker et al., 1983), research showing that the quantity of arguments can affect the favourability of thoughts or the extent of thinking under conditions of higher elaboration likelihood is currently lacking.
} 
thoughts towards the advocated position, but to create enduring positive attitudes that are likely to guide future behaviour (Petty, Baker, \& Gleicher, 1991). Since attitudes resulting from processes underlying the central route are often incorporated into an individual's knowledge structure, these attitudes are more enduring than those formed from peripheral route processing (Chaiken, 1980; Haugtvedt \& Petty, 1989). Such attitudes have also been found to be more resistant to counter-persuasive efforts (Haugtvedt \& Petty, 1992) and more likely to guide future behaviour (see Petty, Haugtvedt, \& Smith, 1995 for a review; Rucker, Petty, \& Priester, 2007). As a multidimensional construct reflecting these different properties of attitudes, attitude strength refers to the extent to which an attitude is both durable and influential on behaviour (Krosnick \& Petty, 1995). Generally, the ELM holds that forming an attitude when engaging in high amounts of thinking leads to stronger attitudes than when they are formed on the basis of little issue-relevant thinking (Petty, Rucker, Bizer, \& Cacioppo, 2004; Rucker et al., 2007).

Attitude certainty. As the most commonly examined index of attitude strength, attitude certainty refers to how confident an individual is that the attitude they hold is correct (Gross, Holtz, \& Miller, 1995; Tormala \& Rucker, 2007). ${ }^{4}$ In other words, it can be seen as an indicator of an individual's perceived validity of their attitude (Tormala \& Petty, 2004a). Attitude certainty is a useful indicator of the different impact of attitudes that are similar in extremity. That is, even though two individuals may hold identical attitudes towards a particular issue, one person may hold their attitude with greater certainty than the other because it was formed through thoughtful (i.e., central) rather

\footnotetext{
${ }^{4}$ Although other dimensions of attitude strength exist (e.g., accessibility, intensity, and importance), the current thesis will focus on attitude certainty as it has been suggested to be a particularly important dimension of attitude strength (e.g., Rucker \& Petty, 2006; Tormala \& Rucker, 2007).
} 
than non-thoughtful (i.e., peripheral) processes (Abelson, 1988; Barden \& Petty, 2008).

Consequently, attitudes that are held with greater certainty are likely to be more enduring and are more likely to guide individuals' attitude-relevant behaviour (Bassili, 1996;

Berger \& Mitchell, 1989; Bizer, Tormala, Rucker, \& Petty, 2006; Fazio \& Zanna, 1978;

Tormala \& Petty 2002).

In addition to whether an individual has engaged in much thought concerning the attitude object or issue, other factors have been found to increase attitude certainty. For instance, since people are more certain of their initial attitudes when they successfully resist a strong rather than a weak message (Tormala \& Petty, 2002), it has been suggested that people may become more certain of their successfully changed attitudes when they perceive that this change was a result of strong rather than weak message arguments (Tormala \& Rucker, 2007). In addition, other research has found that, even though attitudes themselves may remain the same in extremity, participants can be more certain of their attitudes when a message is provided by an expert rather than a non-expert source (Rucker \& Petty, 2007 as cited in Tormala \& Rucker, 2007). Ultimately, whether or not a recruitment message is successful in creating certainty in attitudes towards a career in policing is one factor that may play a role in whether or not these attitudes will persist and guide an individual's future job-seeking behaviour.

Importance of the Elaboration Likelihood Model to the Police Recruitment Crisis

As illustrated, the ELM has the potential to be a valuable theoretical framework for designing and evaluating police recruitment messages. Indeed, researchers have employed the ELM as a framework for developing effective communications in a wide range of practical domains, including drug abuse prevention (Petty, Baker, \& Gleicher, 1991), public service announcements (Rucker \& Petty, 2006), HIV educational programs 
(Petty, Gleicher, \& Jarvis, 1993), and advertising effectiveness (Petty, Unnava, \& Strathman, 1991; Rucker et al., 2007). Thus, it seems likely that the ELM can also be used in the police recruitment setting. That being said, whether or not ELM concepts apply to the unique context of police recruitment messages must be empirically determined (see Petty, Heesacker, \& Hughes, 1997, for a similar argument in the school psychology setting). Indeed, there remain many questions about how, or even if, the ELM can be applied to the police recruitment setting. For instance, how can personal relevance in the context of police recruitment be effectively manipulated? What is considered a strong and weak argument in support of policing as a career? Is the credibility of the source or the number of arguments contained in a police recruitment message an important factor in determining persuasiveness?

The purpose of the current thesis is to provide answers to these questions in order to determine how the ELM can be extended to the domain of police recruitment. Theoretically speaking, the results from this research will shed light on whether or not the ELM can be extended into the police recruitment context, which may help to clarify potential boundary conditions for this framework. In practical terms, not only will this research determine the perceived quality of arguments that can be made in support of policing as a career, which is valuable in its own right, it will also help to determine ways in which the police can persuade potential applicants to think more carefully about their recruitment messages and it will demonstrate the potential importance of factors such as argument quantity and source credibility in recruitment efforts. Ultimately, the hope is that the results emerging from this thesis will offer police departments in Canada new ways to deliver their recruitment messages so that they can effectively expand the currently dwindling applicant pool. 


\section{Overview of the Current Studies}

The proposed research will attempt to replicate (and extend) previous ELM research to determine whether the results found in that research generalize to the police recruitment setting. In order to replicate the results of Petty et al. (1981), Study 1 will examine the effect of argument quality and source credibility on attitudes toward policing as a career option, and will also examine how these factors influence attitude certainty and cognitive responses. To replicate the results of Petty \& Cacioppo (1984b), Study 2 will examine the effect of argument quality and argument quantity within this applied context, and will also examine how these factors influence attitude certainty and cognitive responses. Both studies will manipulate personal relevance in order to investigate the effects of the above variables under varying conditions of elaboration likelihood.

\section{Pilot Study}

Prior to examining the effects of the aforementioned message and source variables, three things must be done. First, the quality of different arguments supporting policing as a career must be established in order to develop strong and weak recruitment messages. As described below, this involves several stages of data collection and analysis. Second, the perceived credibility of two message sources, each of whom will deliver the persuasive message in Study 1, must be determined to ensure that they differ with respect to credibility. Finally, the effectiveness of the personal relevance manipulations to be used in both Study 1 and Study 2 must be assessed prior to the main research. 


\section{Assessing Argument Quality}

The empirical process by which strong and weak messages are derived generally consists of three stages (Petty et al., 1981; Petty \& Cacioppo, 1986a). The first stage is carried out in order to determine the persuasive impact of various arguments (in the current case, arguments in support of policing as a career). The second stage involves the assessment of thoughts induced by a strong and weak message containing persuasive or unpersuasive arguments, respectively, as determined by results of the first stage. The focus in this second stage is on whether the thoughts induced by the message are favourable, unfavourable, or neutral. Finally, the third stage consists of ensuring that the strong and weak messages do not differ in terms of extraneous factors (e.g., complexity) so that, if any differences emerge across conditions in Study 1 and 2, they can be attributed to argument quality instead of other factors. The strong and weak messages that are constructed in this pilot phase will be employed in subsequent studies to vary argument quality.

\section{Stage 1: Assessing Persuasiveness}

\section{Participants}

Undergraduate students from upper-level classes at Carleton University $(N=51)$ were recruited for Stage 1. Data collection took place in the classroom during class time after receiving permission from instructors to do so. The majority of participants were female $(n=38)$. The age of participants ranged from 19 to 48 , with a mean age of 22 ( $S D$ = 5.25). All participants attended Carleton University, with the majority being in their second year of study $(n=28)$ followed by: third $(n=11)$, fourth $(n=8)$, and first year $(n$ $=1)$. In terms of ethnicity, the majority of participants were Caucasian $(n=41)$ followed by: Asian $(n=6)$, Black $(n=1)$ and Hispanic $(n=1)$. Only one participant stated they 
had any experience in the law enforcement field, with experience being in the form of taking a college police foundations program. Similarly, only a small portion $(n=7)$ of the sample had any family members with law enforcement experience. Table 1 displays participants' field of study as well as their career aspirations.

Table 1

Summary of Stage 1 participants' field of study and career aspirations

\begin{tabular}{lclc}
\hline Field of Study & $n$ & Career Aspirations & $n$ \\
\hline Arts and Social Sciences & 33 & Education & 10 \\
Science & 5 & Healthcare & 9 \\
Public Affairs & 9 & Criminal Justice and Security & 7 \\
Engineering and Design & 2 & Undecided & 7 \\
Business & 1 & Research & 6 \\
& & Other & 5 \\
& & Policing & 2 \\
& & Other Public Service & 1 \\
\hline
\end{tabular}

Procedure

Participants were first provided with an informed consent form (see Appendix A). Following this, subjects were given an introductory paragraph indicating that police agencies in Canada are making an effort to modify their recruitment strategies in an attempt to attract more applicants, and that one of the first steps for doing so involves 
assessing the effectiveness of various arguments that can be formed in support of policing as a career. They were then given a list of arguments supporting policing as a career and were asked to indicate, on a 9-point scale, the extent to which they believed that each argument is persuasive (with higher scores indicating higher levels of persuasiveness; see Appendix B). After rating the arguments, participants completed a demographics questionnaire (see Appendix C), and were then debriefed as to the purpose of the study (see Appendix D).

Results

Mean persuasiveness was calculated for each of the arguments rated by the participants. Tables 2 and 3 display the nine arguments rated the highest and lowest on persuasiveness, respectively. A strong and weak recruitment message was then developed based on the average ratings assigned to each argument. Specifically, the strong message contained the nine arguments rated as most persuasive, whereas the weak message contained the nine arguments rated as least persuasive (see Appendix E for messages). A $t$-test comparing the overall mean persuasiveness of the strong and weak message confirmed that the strong message $(M=7.15, S D=0.27)$ as a whole contained arguments that were rated as significantly more persuasive than the arguments contained in the weak message $(M=4.84, S D=0.60), t(11.18)=10.53, p<.001$. Before the constructed messages could be used in the main studies, however, cognitive responses were assessed to ensure that the strong message induced more favourable and less unfavourable thoughts than the weak message, and that the opposite pattern of thoughts occurred for the weak message (Stage 2 below). 
Table 2

Means and associated standard deviations of arguments rated highest in persuasiveness

Argument

$M(S D)$

Not only do many police agencies pay for your training once you are hired, but they offer many opportunities for you to continue your education once employed.

A policing career comes with many other advantages as well - including some of the best medical and dental coverage available to both you and your entire family.

Policing also offers one of the best retirement pensions available to public sector employees.

It is one of the few careers where you will be able to easily retire at a younger age. Not only will you be able to retire younger (e.g., when you're 50 ), but you will be able to do so without any cut in your retirement pension.

By becoming a police officer, you will not just have an ordinary desk job like so many careers out there. Instead you will have a job where the work is exciting and changes everyday.

Policing offers a great deal of employment security. Once you are part of a force, you can rest assured that you have a job that will always be in demand, and do not have to fear being laid off like other jobs out there.

You will have countless opportunities to help victims of crime, including domestic disturbances and sexual assaults.

From traffic, air support, underwater search, and drugs and firearms, you will be exposed to many different career paths as a police officer.

You will also be provided with countless opportunities to travel to many parts of the country. 
Table 3

Means and associated standard deviations of arguments rated lowest in persuasiveness

Argument

$M(S D)$

Becoming a police officer also offers you ways to increase your income,

such as by taking a job for which you can receive isolation pay.

You will become part of a workforce that encourages employee input in policy development such as shift configurations, uniform design, and community policing strategies.

You will be provided with countless opportunities to enforce the law in a variety of situations, including traffic violations, assaults, and drug offences.

Becoming a police officer will win you the respect of your friends and family members. You will be taken seriously if you pursue a career that is highly respected.

By pursuing a career in the policing field, you will be able to fight crime and put the bad guys behind bars.

You will have a job that carries with it much status. This will give you the ability to exercise your power and authority over others who will listen to you.

To be eligible for a career in policing, most agencies only require a high school education. In other words, you do not need to have perfect grades or be highly educated to become a police officer.

You'll also be required to wear a uniform while at work so you won't have to worry about shopping for work attire. The money that you save on work clothes can go towards other things that are more important to you. 


\section{Stage 2 and 3: Assessing Cognitive Responses and the Role of Extraneous Factors}

\section{Participants}

Undergraduate students from upper-level classes at Carleton University $(N=59)$ were recruited for Stage 2 and 3 and were randomly assigned to either a strong $(n=30)$ or weak ( $n=29)$ message condition. Students were informed that they could not participate in this study if they had already done so for Stage 1. Data collection took place in the classroom during class time after receiving permission from instructors to do so. The majority of participants were female $(n=45)$. The age of participants ranged from 18 to 50, with a mean age of $22(S D=4.44)$. All participants attended Carleton University, with the majority being in their second year of study $(n=28)$ followed by: third ( $n=22)$, fourth $(n=3)$, and first year $(n=1)$. In terms of ethnicity, the majority of participants were Caucasian $(n=47)$ followed by: Black $(n=3)$, Asian $(n=2)$, Aboriginal $(n=2)$, and Middle-Eastern $(n=1)$. A small portion of participants $(n=3)$ stated they had experience in the law enforcement field, with experience being in the form of a related college degree. A total of 19 participants stated they had family members with law enforcement experience. Table 4 displays participants' field of study as well as their career aspirations. T-tests (for age) and chi-square tests (for gender, family experience, own experience, program of study, and career goal) did not reveal any between group differences (all $p$ 's $>.05$ ). Ethnicity and level of study could not be reliably analyzed using chi-square analysis because the expected frequency counts for too many of the cells were less than 5 (Norusis, 2006). However, a visual examination of the frequency distributions for these variables (via cross-tabs) did not reveal any noticeable differences across the strong and weak message conditions. 
Table 4

Summary of Stage 2 and 3 participants' field of study and career aspirations

\begin{tabular}{lclc}
\hline Field of Study & $n$ & Career Aspirations & $n$ \\
\hline Arts and Social Sciences & 39 & Education & 15 \\
Public Affairs & 15 & Undecided & 10 \\
& & Criminal Justice and Security & 9 \\
& Other Public Service & 7 \\
& Healthcare & 4 \\
& Research & 3 \\
& Other & 3 \\
& Policing & 2 \\
\hline
\end{tabular}

Procedure

After signing an informed consent form (see Appendix A for template), participants were presented with either the strong or weak message developed in Stage 1 (see Appendix E for messages). All subjects were told to think about their respective message thoroughly (Petty \& Cacioppo, 1986a). Following their examination of the message, each subject was asked to list thoughts that were induced by the recruitment message using a procedure adopted from Greenwald (1968), and used routinely in ELM research (e.g., Petty \& Cacioppo, 1984b; Petty et al., 1981). Specifically, participants were provided with 10 separate boxes on their questionnaire (Cacioppo, Harkins, \& Petty, 1981). They were instructed to write one thought that came to mind while reading the recruitment message in each box, and to spend at least 3 minutes but no longer than 
10 minutes to write as many thoughts as they could recall, without worrying about any spelling or grammatical errors (see Appendix F). After listing their thoughts, participants rated the message in terms of: (1) understandability, (2) complexity, and (3) believability using 9-point scales, with lower scores indicating that the message was less understandable/complex/ believable (see Appendix F). Before being provided with the debriefing form (see Appendix D for a template), participants completed the same demographics questionnaire as used in Stage 1 (see Appendix C).

Thoughts were then coded by the primary researcher in terms of whether they were: (1) favourable, (2) unfavourable, or (3) neutral towards policing as a career. Interrater reliability was assessed by having a second researcher code $25 \%$ of the generated lists. Cohen's Kappa revealed that overall agreement between raters concerning what thoughts were favourable, unfavourable and neutral was high $(\kappa=.86$; Landis \& Koch, 1977). Any disagreements between raters were discussed and resolved so that analyses were based on complete agreement. Analyses were then conducted to ensure that the strong message induced more favourable thoughts than the weak message and less unfavourable thoughts than the weak message (and vice versa for the weak message). In order to do this in a succinct fashion, an index of thought favourability was calculated for each participant by subtracting the number of unfavourable thoughts from the number of favourable thoughts and dividing this difference by the total number of message-relevant thoughts (Blankenship \& Wegener, 2008; Tormala \& Petty, 2007; Tormala et al., 2007). Next, analyses were conducted in order to examine the hypothesized differences in the valence of thoughts generated by subjects receiving the strong or weak message. Finally, analyses were conducted to ensure that no significant differences exist between the strong and weak message in terms of understandability, complexity, and believability. 


\section{Results}

An independent samples $t$-test comparing thought favourability scores across the strong and weak messages indicated that thought favourability was significantly higher (i.e., more favourable thoughts and less unfavourable thoughts were generated) for the strong $(M=-0.12, S D=0.68)$ than the weak message $(M=-0.81, S D=0.38), t(44.23)=$ $4.84, p<.001$. However, as revealed by the negative value of the mean thought favourability index, even in the condition where participants were exposed to the strong message, the majority of thoughts induced by the message were negative. No significant differences existed between the strong and weak message in terms of understandability $(M=8.37, S D=0.74 ; M=8.59, S D=0.78$, respectively $)$, complexity $(M=7.93, S D=$ $1.27 ; M=8.03, S D=1.38$, respectively), or believability $(M=5.93, S D=2.48 ; M=5.10$, $S D=2.08$, respectively); all $t^{\prime} s<1.35$, all $p ' s>.10$.

\section{Manipulation Checks for Source Credibility and Personal Relevance}

Prior to the main studies, manipulation checks for source credibility and personal relevance were conducted in order to ensure that the chosen manipulations did indeed vary these constructs in the expected fashion.

\section{Participants}

Undergraduate students from upper-level classes at Carleton University $(N=160)$ were recruited for the purpose of conducting manipulation checks and were randomly assigned to conditions in a 2 (personal relevance: high versus low) by 2 (argument quality: strong versus weak) by 2 (source credibility: high versus low) between subjects design. Each student was informed that they could not participate in this study if they were involved in any of the previous stages. Data collection took place in the classroom during class time after receiving permission from instructors to do so. The majority of 
participants were female $(n=111)$. The age of participants ranged from 18 to 47 , with a mean age of $22(S D=4.72)$. All participants attended Carleton University, with the majority being in their second year of study $(n=81)$ followed by: third $(n=52)$, fourth ( $n$ $=22$ ), and first year $(n=2)$. In terms of ethnicity, the majority of participants were Caucasian $(n=137)$ followed by: Asian $(n=8)$, those of mixed race $(n=5)$, MiddleEastern $(n=4)$, Aboriginal $(n=2)$, Black $(n=2)$, and Hispanic $(n=1)$. A small portion of participants $(n=8)$ stated they had experience in the law enforcement field, with experience being from: working security, volunteering with various police agencies, and taking police foundations college courses. A total of 32 participants stated they had family members with law enforcement experience. Table 5 displays participants' field of study as well as their career aspirations. Analysis of variance (for age) and chi-square tests (for gender) revealed no significant between group differences (all $p$ 's $>.05$ ). In addition, an examination of cross-tabs (for ethnicity, level of study, family experience, own experience, program of study, and career goal) revealed no noticeable between group differences. 
Table 5

Summary of manipulation check participants' field of study and career aspirations

\begin{tabular}{lclc}
\hline Field of Study & $n$ & Career Aspirations & $n$ \\
\hline Arts and Social Sciences & 92 & Healthcare & 33 \\
Public Affairs & 49 & HR, Media and Entertainment & 27 \\
Science & 6 & Education & 19 \\
Engineering and Design & 2 & Criminal Justice and Security & 15 \\
Business & 2 & Undecided & 15 \\
& & Other Public Service & 8 \\
& Other & 7 \\
& Policing & 5 \\
& & Business & 1 \\
\hline
\end{tabular}

Procedure

After signing an informed consent form (see Appendix A for a template), half of the subjects were provided with the following scenario (high relevance manipulation):

At this time in Canada, there exists an impending police recruitment crisis. Canadian police agencies have estimated that over the next year, the number of new police recruits must double in order to maintain current levels of officer strength. If this recruitment crisis is not resolved in a timely fashion, it will negatively affect you as a Canadian citizen in numerous ways. Fewer officers on the streets will ultimately lead to slower response times to emergency situations and a significantly lower crime detection rate. Clearly, police are a crucial part of our society, and this recruitment crisis will be extremely devastating to you as a Canadian citizen. 
The other half were provided with the following scenario (low relevance manipulation):

At this time in many European countries, there exists a potential police recruitment crisis. Police agencies in these countries have estimated that within 20 years from now, the number of new police recruits must double in order to maintain current levels of officer strength. If this recruitment crisis is not resolved in a timely fashion, it will negatively affect citizens of these countries in numerous ways. Fewer officers on the streets will potentially lead to slower response times to emergency situations and a lower crime detection rate. Clearly, police are a crucial part of society, and this recruitment crisis may be potentially upsetting to citizens of these countries.

After this, participants received either the strong or weak message that was delivered by an assumed high credibility source (i.e., Sergeant Steve Smith, a recruiter who has been working as a police officer for 20 years) or an assumed low credibility source (i.e., Steve Smith, a first year college student who is currently volunteering for his local police department's human resources branch; see Appendix G for the full introduction to the messages). After reading the message, participants responded to questions designed as manipulation checks for relevance and credibility (see Appendix H). Following this, participants completed the demographics questionnaire (see Appendix C) and were then debriefed as to the purpose of the study (see Appendix D for a template).

Results

Independent samples $t$-tests were conducted to ensure that those receiving the high relevance manipulation perceived the message to be more personally relevant than those receiving the low relevance manipulation. Similarly, the average expertise ratings for each source was compared to ensure that those provided with the high credibility 
source perceived their source as having significantly more expertise than those provided with the low credibility source.

Results confirmed that those who received the message portraying the imminent Canadian situation (i.e., high relevance manipulation; $M=5.42, S D=1.80$ ) believed the recruitment crisis would have more of an impact on them than those who received the message portraying the distant European situation (i.e., low relevance manipulation; $M=$ $4.49, S D=2.24), t(149.60)=2.88, p=.005$. Similarly, those who received a message delivered by the assumed to be high credibility source $(M=6.59, S D=1.79)$ rated their source as having more knowledge about policing as a career than those who received a message delivered by the low credibility source $(M=4.99, S D=1.95), t(158)=5.40, p<$ .001. Consequently, the above manipulations were used in the main studies in order to vary conditions of personal relevance (both Study 1 and Study 2) and source credibility (Study 1 only). ${ }^{5}$

Study 1: Personal Relevance, Argument Quality, and Source Credibility

\section{Purpose}

The goal of Study 1 was to determine the effect of argument quality and source credibility on attitudes towards policing as a career under different conditions of elaboration likelihood (i.e., personal relevance). The impact of these factors on attitude certainty and cognitive responses were also examined.

\footnotetext{
${ }^{5}$ Prior to achieving these results, an initial attempt was made to manipulate personal relevance by referring to the United States in the low relevance condition rather than Europe. Similarly, an attempt was made to manipulate credibility using police officers as both the high and low credibility message source, differing only on the number of years of policing experience (i.e., 4 versus 20). These initial attempts, however, did not yield the desired results. As a consequence, the above manipulations were tested and used in the main studies.
} 


\section{Method}

\section{Participants}

Undergraduate students from upper-level classes at Carleton University $(N=251)$ were recruited for Study 1 and randomly assigned to conditions in a 2 (personal relevance: high versus low) by 2 (argument quality: strong versus weak) by 2 (source credibility: high versus low) between subjects design. Each student was informed that they could not participate in this study if they were involved in any of the pilot research. Data collection took place in the classroom during class time after receiving permission from instructors to do so, and those interested were entered into a lottery draw for $\$ 100$ for their participation. The majority of participants were female $(n=146)$. The age of participants ranged from 18 to 50 , with a mean age of $22(S D=4.19)$. All participants attended Carleton University, with most being in their third year of study $(n=95)$ followed by: second ( $n=65)$, fourth $(n=54)$, and first year $(n=32)$. In terms of ethnicity, the majority of participants were Caucasian $(n=161)$ followed by: Middle Eastern $(n=36)$, Asian $(n=30)$, Black $(n=12)$, Aboriginal $(n=4)$, those of mixed race $(n=4)$, and Hispanic $(n=2)$. A small portion of participants $(n=12)$ stated they had experience in the law enforcement field, with experience being from: working security, volunteering or working for various police agencies, and taking police foundations college courses. A total of 54 participants stated they had family members with law enforcement experience. Table 6 displays participants' field of study as well as their career aspirations. Analysis of variance (for age) and chi-square tests (for gender, family experience, program of study, and career goal) revealed no significant between group 
differences (all $p$ 's $>.05$ ). In addition, an examination of cross-tabs (for ethnicity, level of study, and own experience) revealed no noticeable between group differences. ${ }^{6}$

Table 6

Summary of Study 1 participants' field of study and career aspirations

\begin{tabular}{lclc}
\hline Field of Study & $n$ & Career Aspirations & $n$ \\
\hline Public Affairs & 121 & Criminal Justice and Security & 52 \\
Arts and Social Sciences & 83 & Education & 36 \\
Engineering and Design & 14 & Healthcare & 33 \\
Business & 12 & Undecided & 30 \\
Science & 10 & Policing & 21 \\
& & Other Public Service & 17 \\
& & Business & 17 \\
& & Engineering & 13 \\
& & HR, Media and & 10 \\
& & Fntartsinmant & 8 \\
& & Other & 6 \\
\hline
\end{tabular}

\section{Procedure}

After reading and signing the informed consent form (see Appendix I), the participants read the high or low personal relevance manipulation. They were then provided with either the strong or weak recruitment message developed in the pilot study

\footnotetext{
${ }^{6}$ As indicated, the majority of participants were female. This is also true for Study 2 as well as all phases of the pilot research. It is important to note that gender differences may arise in the persuasion setting, particularly in this context where the attitude domain concerns a traditionally male-dominated career (cf. gender differences and persuasion; Eagly \& Carli, 1981). Although there may be differences in males and females within this context, the imbalance of males to females coupled with the small male sample size made it difficult to reliably examine this issue in the current research.
} 
(see Appendix E for messages). Participants in the high and low source credibility conditions were presented with a message delivered by the high and low credibility sources, respectively (see Appendix $G$ for credibility manipulations). After reading their respective recruitment messages, participants responded to a variety of measures, all of which are described in the following section.

\section{Measures}

Attitudes towards policing as a career. Immediately after message exposure, subjects were asked to indicate their attitudes towards policing as a career on two 9-point semantic differential scales adopted from previous ELM research: unfavourablefavourable and undesirable-desirable (Petty et al., 1981; see Appendix J). Since higher scores on both scales are indicative of more positive attitudes, the internal consistency of these scales was calculated and responses were averaged to form a combined index of attitudes towards policing as a career. ${ }^{7}$

Attitude certainty. As an index of the strength of attitudes resulting from the different conditions, attitude certainty was measured following the attitude measure. Specifically, after indicating their post-message attitudes, participants were asked: "How confident are you that your attitude towards policing as a career is correct?" Consistent with other ELM research, answers were provided on a 9-point scale, with 1 indicating that the participant is not confident at all and 9 indicating that they are extremely confident (see Appendix J).

\footnotetext{
${ }^{7}$ Averaging rather than summing across measures is the norm in attitude research (e.g., Barden \& Petty, 2008; Cacioppo, Petty, Kao, \& Rodriguez, 1986; Petty \& Cacioppo, 1979a; Tormala \& Petty, 2004b; Tormala et al., 2006). The internal consistency $(\alpha)$ of semantic differential scales assessing attitudes is often high, typically ranging anywhere from .84 to .96 (Chaiken \& Maheswaran, 1994; Haugtvedt \& Petty, 1992; Priester \& Petty, 2003; Rucker, Petty, \& Briñol, 2008; Tormala \& Petty, 2004a; Tormala et al., 2007).
} 
Cognitive responses to recruitment messages. To provide evidence for differences in message elaboration, cognitive responses to the recruitment messages were also measured after attitude certainty. Using the same procedure as described in the pilot study, participants were instructed to list any thoughts they had while reading the message in the boxes provided (see Appendix F). These thoughts were then coded as favourable, unfavourable, or neutral and inter-rater reliability was again assessed in the same manner as described in the pilot research. Cohen's Kappa revealed that overall agreement between raters concerning what thoughts were favourable, unfavourable and neutral was high ( $\kappa=.81$; Landis $\&$ Koch, 1977). Any disagreements between raters were discussed and resolved so that analyses were based on complete agreement. The total number of message-relevant thoughts (i.e., the total combined number of favourable and unfavourable thoughts) was also calculated for each subject in order to examine differences in the extent of thinking between conditions. Agreement between raters on the total number of message-relevant thought was also high $(r(61)=.96, p<.001)$. Finally, in order to examine differences in the valence of thinking across conditions, an index of thought favourability was also calculated for each participant in the same manner as done for the pilot research (i.e., subtracting the number of unfavourable thoughts from the number of favourable thoughts and dividing this difference by the total number of message-relevant thoughts; Blankenship \& Wegener, 2008; Tormala \& Petty, 2007; Tormala et al., 2007).

Manipulation checks. At the end of the study, participants were asked questions designed to serve as manipulation checks for: (1) personal relevance, (2) the quality of the message arguments, and (3) the credibility of the source (see Appendix K). Manipulation checks for personal relevance and credibility were consistent with those 
conducted during the pilot stage of this research. The argument quality manipulation was assessed by asking subjects: "How would you rate the quality of the arguments used by the recruiter to support policing as a career?" Responses to all manipulation checks were provided on 9-point scales $(1=$ not at all likely/extremely weak/not at all knowledgeable, $9=$ extremely likely/extremely strong/extremely knowledgeable). These measures are consistent with how manipulation checks are typically done in ELM research (e.g., Blankenship \& Wegener, 2008; Petty \& Cacioppo, 1979a; Petty et al., 1981; Petty, Tormala, Hawkins, \& Wegener, 2001; Rucker \& Petty, 2004; Tormala \& Petty, 2004b; Wheeler, Petty, \& Bizer, 2005).

Demographics questionnaire. Prior to receiving the debriefing form (see Appendix L), all participants were asked to complete a demographics questionnaire (see Appendix C).

\section{Hypotheses}

Below are specific hypotheses concerning the effects that were expected in Study 1, assuming that the results of previous ELM research generalize to the police recruitment context (e.g., Petty et al., 1981). Hypotheses are separated into the expected effects for each dependent measure. Each hypothesis was generated from past research that has simultaneously examined the effects of personal relevance, argument quality, and source credibility. For instances where research on the combined effects of these three variables on a given dependent variable is lacking (e.g., attitude certainty), interactions are not hypothesized and exploratory analyses were instead carried out to determine if any effects exist. 


\section{Attitudes Towards Policing as a Career}

Hypothesis 1 . Although higher quality arguments are expected to result in more favourable attitudes, it is expected that this effect will be qualified by an interaction between personal relevance and argument quality. Under conditions of high relevance, participant attitudes towards policing as a career are expected to be more favourable when exposed to strong versus weak arguments. Attitudes for those low in personal relevance are not expected to vary as a function of argument quality (see Figure 2).

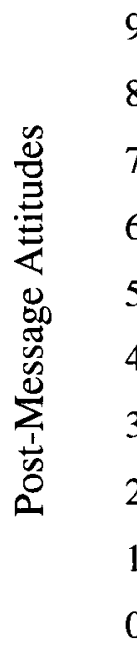

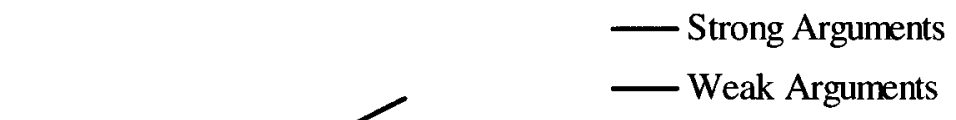

Low Relevance

High Relevance

Figure 2. Expected interaction between personal relevance and argument quality on attitudes towards policing as a career. Adopted from Petty et al. (1981). 
Hypothesis 2. Although the high credibility source is expected to produce more favourable attitudes, it is expected that this effect will be qualified by an interaction between personal relevance and source credibility. Under conditions of low personal relevance, participant attitudes towards policing as a career are expected to be more favourable when exposed to high versus low credibility sources. Attitudes for those high in personal relevance are not expected to vary as a function of source credibility (see Figure 3).

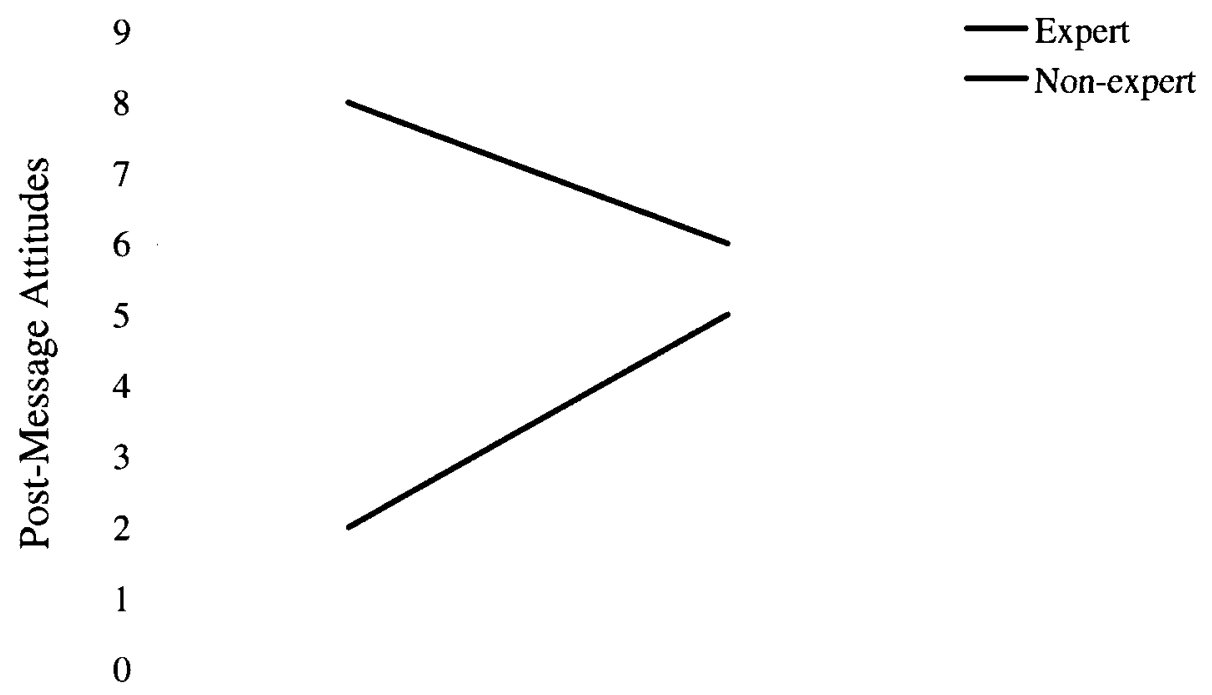

Low Relevance High Relevance

Figure 3. Expected interaction between personal relevance and source credibility on attitudes towards policing as a career. Adopted from Petty et al. (1981). 


\section{Attitude Certainty}

Hypothesis 3. Participants in the high relevance, strong message, and high credibility conditions will be more certain of their attitudes than those in the low relevance, weak message, and low credibility conditions, respectively.

\section{Cognitive Responses to Recruitment Messages}

Hypothesis 4 . High relevance subjects will produce significantly more messagerelevant cognitive responses than will low relevance subjects, serving as an indication of the extent of elaboration.

Hypothesis 5. Although strong arguments are expected to induce higher thought favourability scores, it is expected that this effect will be qualified by an interaction between personal relevance and argument quality. High relevance subjects are expected to have higher thought favourability scores when exposed to strong versus weak messages. Low relevance subjects are not expected to show any significant differences in thought favourability scores for strong versus weak messages (see Figure 4). 


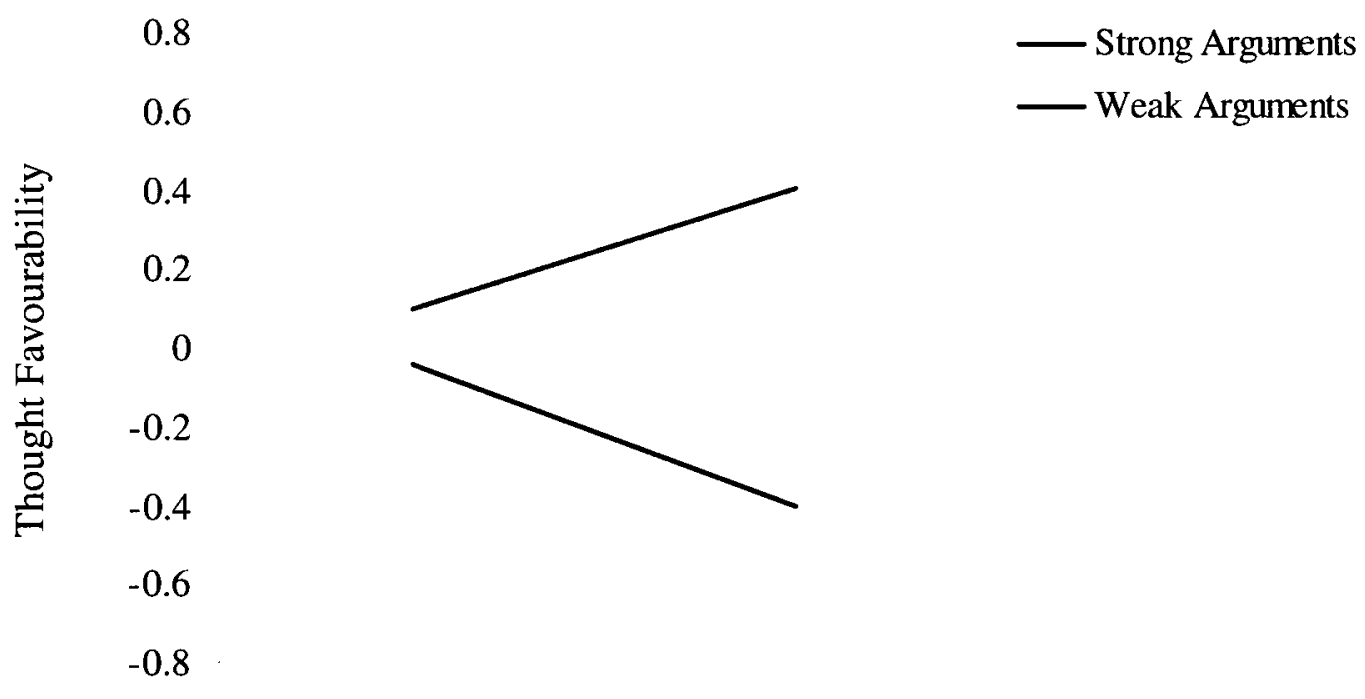

Low Relevance High Relevance

Figure 4. Expected interaction between personal relevance and argument quality on thought favourability scores.

\section{Mediating Role of Cognitive Responses}

Hypothesis 6. In addition to the direct effect of argument quality on attitudes

(Hypothesis 1), it is expected that this effect will be mediated by thought favourability (see Figure 5). However, it is expected that the mediating effect of thought favourability on attitudes will only be evident under conditions of high rather than low personal relevance. 


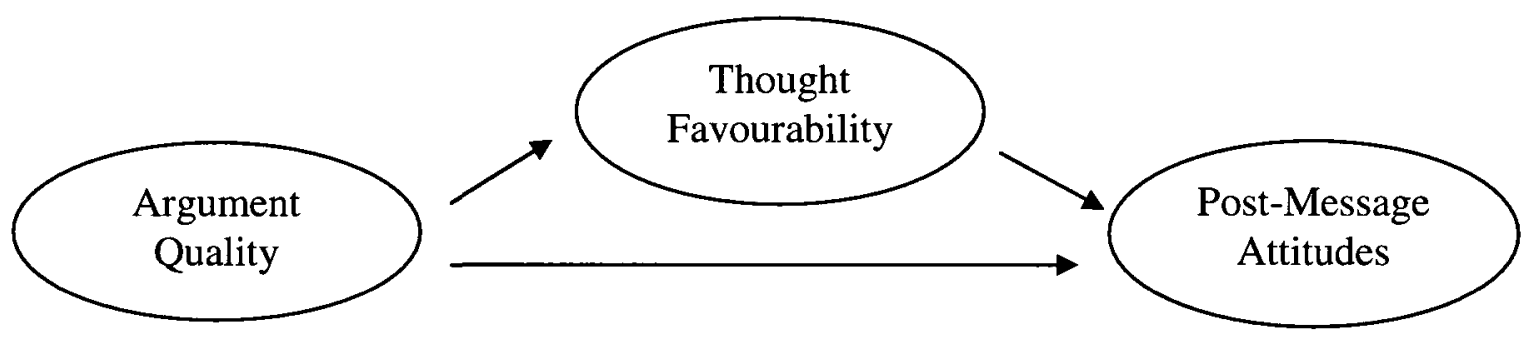

Figure 5. Proposed direct and indirect effects of argument quality on attitudes under conditions of high personal relevance.

\section{Results}

\section{Preliminary Screening and Analyses}

Missing data. Although less than five percent of data points were missing in the current study, a missing values analysis was still conducted in order to ensure that the pattern of missing data points across all dependent measures was random. Little's MCAR test was not significant, indicating that the pattern of missing data points in the current study was random $\left(\chi^{2}(177)=187.87, p=.274\right)$. As such, missing data points for all variables, with the exception of thought favourability and demographics, were estimated by replacing each missing score with the corresponding group mean (Tabachnick \& Fidell, 2007a). Missing thought favourability scores were not estimated due to the fact that a participant may genuinely not have had (or may not have been able to remember) thoughts while reading the message. As a result, those who did not list any thoughts were excluded from the thought favourability analyses $(n=18)$.

Manipulation checks. Prior to the main analyses, a series of independent samples $t$-tests were conducted in order to ensure that all manipulations had their intended effects. Specifically, checks were conducted to ensure that: (1) high relevance subjects felt that the recruitment crisis would have more of an impact on them than those in the low 
relevance condition, (2) subjects exposed to high credibility sources viewed the source as more credible than those in the low credibility condition, and (3) participants exposed to strong message arguments thought the message was of higher quality than those exposed to weak arguments.

Although the means were in the expected direction, those who received the high relevance manipulation $(M=5.74, S D=2.08)$ did not believe the recruitment crisis would have more of an impact on them than those who received the low relevance manipulation $(M=5.42, S D=2.20), t(249)=1.17, p=.245$. Similar to the results of the pilot research, however, those who received the message delivered by the high credibility source $(M=6.38, S D=1.99)$ perceived the source as having significantly more knowledge about policing as a career than those who received the message delivered by the low credibility source $(M=5.46, S D=1.90), t(249)=3.73, p<.001$. Finally, those who received the strong message $(M=6.20, S D=1.67)$ rated the arguments contained in the message as significantly higher in quality than those who received the weak message $(M=4.42, S D=2.16), t(236.85)=7.33, p<.001$.

ANOVA assumptions. Scores on all dependent measures (i.e., attitudes, attitude certainty, total number of message-relevant thoughts, and thought favourability) were examined to ensure that assumptions of absence of outliers, independence, homogeneity of variance, and normality were tenable before the ANOVAs were conducted. ${ }^{8}$ Only two outliers $(z> \pm 3.29, p<.001)$ were found across all dependent measures, and both were present within the attitude certainty factor. In order to ensure these values did not have

\footnotetext{
${ }^{8}$ This was done for both datasets (i.e., with and without missing values estimated) in order to ensure that the inclusion of estimated values did not influence the results of the assumptions testing. When done with the dataset including missing data points, results of assumptions testing did not differ in any meaningful way.
} 
undue influence on results, they were adjusted to a value one unit larger than the next most extreme attitude certainty score (Tabachnick \& Fidell, 2007a). Examination of scatterplots did not show any patterns in errors for all dependent measures, and Levene's test for equality of error variance indicated homogenous variances across groups for all dependent measures (all $p$ 's $>.05$ ). Finally, normality plots suggested non-normal trends for all measures, as confirmed by Shapiro-Wilk significance tests for attitudes $(W(251)=$ $.958, p<.001)$, attitude certainty $(W(251)=.929, p<.001)$, total number of messagerelevant thoughts $(W(251)=.937, p<.001)$, and thought favourability $(W(233)=.835, p$ $<.001)$. However, as ANOVA has been shown to be robust to violations of normality when degrees of freedom for error are greater than 20 , and since transforming variables makes interpretation fraught with difficulty (Tabachnick \& Fidell, 2007b), conducting ANOVAs with untransformed scores was still deemed appropriate for the current study. Main Analyses ${ }^{9}$

To test the hypotheses outlined above, separate univariate ANOVAs were carried out on attitudes, attitude certainty, total number of message-relevant thoughts, and thought favourability. This procedure is consistent with the data analysis methods used in ELM research (e.g., Chaiken \& Maheswaran, 1994; DeBono \& Harnish, 1988; Petty et al., 1981; Petty \& Cacioppo, 1984b; Tormala \& Petty, 2004a; Tormala et al., 2006). ${ }^{10}$ Attitudes towards policing as a career (H1 and H2). An index of participants' overall attitude towards policing as a career was first calculated by averaging across each

\footnotetext{
${ }^{9}$ All main analyses were run with and without missing data estimated in order to ensure that the estimation procedure did not alter the results. Models were compared across dependent measures and no noticeable variations in results were found.

${ }^{10}$ In a personal communication with Richard E. Petty (R.E. Petty, personal communication, November 11, 2008), he indicated that running multiple ANOVAs, rather than a MANOVA, has been the preferred method in ELM studies because the pattern of effects found for the independent variables may differ across each dependent variable.
} 
participants' responses to both attitude measures $(\alpha=.92)$. A 2 (personal relevance: high or low) x 2 (argument quality: strong or weak) x 2 (source credibility: high or low) between-subjects ANOVA was then carried out using attitudes towards policing as a career as the dependent variable with personal relevance, argument quality, and source credibility as the independent variables (see Table 7 for group sizes, means, standard errors, and associated confidence intervals).

\section{Table 7}

Study 1 group sizes, cell means, standard errors, and associated confidence intervals for attitudes towards policing as a career

\begin{tabular}{cccc}
\hline Group & $n$ & $M(S E)$ & CI $_{95}$ \\
\hline $\begin{array}{c}\text { High Relevance } \\
\text { Strong Message }\end{array}$ & & & \\
$\quad$ High Credibility & 30 & $5.63(.40)$ & 4.86 to 6.41 \\
$\quad$ Low Credibility & 31 & $5.13(.40)$ & 4.36 to 5.90 \\
Weak Message & & & \\
$\quad$ High Credibility & 33 & $4.82(.38)$ & 4.08 to 5.56 \\
$\quad$ Low Credibility & 32 & $4.98(.38)$ & 4.23 to 5.74 \\
Low Relevance & & & \\
Strong Message & & $5.87(.39)$ & 5.11 to 6.64 \\
High Credibility & 31 & $5.91(.38)$ & 5.15 to 6.66 \\
Low Credibility & 32 & & 4.87 to 6.38 \\
Weak Message & & $5.63(.38)$ & 4.37 to 5.93 \\
High Credibility & 32 & $5.15(.40)$ & \\
Low Credibility & 30 & &
\end{tabular}


In contrast to what was predicted in hypothesis 1 , the main effect of quality was not significant, indicating that strong arguments $(M=5.64, S E=.19)$ did not result in significantly more favourable attitudes towards policing as a career than weak arguments $(M=5.14, S E=.19), F(1,243)=3.22, p=.074$. Similarly, the Relevance by Quality interaction was not significant, indicating that attitudes were similar across high and low relevance subjects when exposed to the strong $(M=5.38, S E=.28 ; M=5.89, S E=.27$, respectively) and weak $(M=4.90, S E=.27 ; M=5.39, S E=.28$, respectively) messages, $F(1,243)=0.00, p=.969$. In other words, there was no effect of argument quality that could be attributed to the high relevance subjects only.

Unlike what was predicted in hypothesis 2 , the main effect of credibility was not significant, indicating that the high credibility source $(M=5.49, S E=.19)$ did not result in significantly more favourable attitudes towards policing as a career than the low credibility source $(M=5.29, S E=.19), F(1,243)=0.51, p=.477$. Similarly, the Relevance by Credibility interaction did not reach significance, indicating that the pattern of attitudes was similar across high and low relevance subjects when the message was delivered by a high $(M=5.23, S E=.27 ; M=5.75, S E=.28$, respectively $)$ and low $(M=$ $5.06, S E=.27 ; M=5.50, S E=.28$, respectively) credibility source, $F(1,243)=0.01, p=$ 926. Finally, all other main and interaction effects were not significant (all $p$ 's $>.05$ ). Power and effect size estimates for all main and interaction effects are presented in Appendix M (Table M-1).

Attitude certainty (H3). A $2 \times 2 \times 2$ ANOVA was also conducted using attitude certainty as the dependent variables with personal relevance, argument quality, and source credibility as the independent variables (see Table 8 for group sizes, cell means, 
standard errors, and associated confidence intervals). In contrast to what was hypothesized, the main effects of relevance, $F(1,243)=0.01, p=.929$, quality, $F(1,243)$ $=0.66, p=.417$, and credibility, $F(1,243)=0.24, p=.628$, on attitude certainty were not significant. In other words, those in the high relevance $(M=6.75, S E=.15)$, strong message $(M=6.85, S E=.15)$, and high credibility $(M=6.71, S E=.15)$ conditions were not more certain of their attitudes than those in the low relevance $(M=6.77, S E=.15)$, weak message $(M=6.68, S E=.14)$ and low credibility conditions $(M=6.81, S E=.15)$, respectively. Similarly, none of the interaction effects were significant (all $p$ 's $>.05$ ). Observed power and effect size estimates for all main and interaction effects are presented in Appendix M (Table M-2). 
Table 8

Study 1 group sizes, cell means, standard errors and associated confidence intervals for attitude certainty

\begin{tabular}{cccc}
\hline Group & $n$ & $M(S E)$ & CI $_{95}$ \\
\hline $\begin{array}{c}\text { High Relevance } \\
\text { Strong Message }\end{array}$ & & & \\
High Credibility & 30 & $6.63(.30)$ & 6.05 to 7.22 \\
Low Credibility & 31 & $7.03(.29)$ & 6.46 to 7.61 \\
Weak Message & & & 6.38 to 7.50 \\
High Credibility & 33 & $6.94(.28)$ & 5.84 to 6.97 \\
Low Credibility & 32 & $6.41(.29)$ & \\
Low Relevance & & & 6.27 to 7.41 \\
Strong Message & & $6.84(.29)$ & 6.31 to 7.44 \\
High Credibility & 31 & $6.88(.29)$ & \\
Low Credibility & 32 & & 6.87 to 7.00 \\
Weak Message & & $6.44(.29)$ & 6.35 to 7.52 \\
High Credibility & 32 & $6.93(.30)$ & \\
Low Credibility & 30 & & \\
\hline CI $95=95 \%$ confidence intervals. & & & \\
\hline
\end{tabular}

Cognitive responses ( $H 4$ and $H 5$ ). A $2 \times 2 \times 2$ ANOVA was also conducted using the total number of thoughts as the dependent variable with personal relevance, argument quality, and source credibility as the independent variables (see Table 9 for group sizes, cell means, standard errors and associated confidence intervals). In contrast to the expected results outlined in hypothesis 4 , the main effect of relevance was not significant, indicating that those in the high relevance condition $(M=3.58, S E=.21)$ did not elaborate upon the message more than those in the low relevance condition $(M=3.26, S E$ 
$=.21), F(1,243)=1.10, p=.296$. None of the other main or interaction effects were significant (all $p$ 's $>.05$ ). Power estimates and effect sizes for all main and interaction effects are presented in Appendix M (Table M-3).

Table 9

Study 1 group sizes, cell means, standard errors and associated confidence intervals for total number of relevant thoughts

\begin{tabular}{|c|c|c|c|}
\hline Group & $n$ & $M(S E)$ & $\mathrm{CI}_{95}$ \\
\hline \multicolumn{4}{|l|}{ High Relevance } \\
\hline \multicolumn{4}{|l|}{ Strong Message } \\
\hline High Credibility & 30 & $3.23(.43)$ & 2.39 to 4.08 \\
\hline Low Credibility & 31 & $3.19(.42)$ & 2.37 to 4.02 \\
\hline \multicolumn{4}{|l|}{ Weak Message } \\
\hline High Credibility & 33 & $4.03(.41)$ & 3.23 to 4.83 \\
\hline Low Credibility & 32 & $3.84(.41)$ & 3.03 to 4.66 \\
\hline \multicolumn{4}{|l|}{ Low Relevance } \\
\hline \multicolumn{4}{|l|}{ Strong Message } \\
\hline High Credibility & 31 & $2.94(.42)$ & 2.11 to 3.76 \\
\hline Low Credibility & 32 & $3.59(.41)$ & 2.78 to 4.41 \\
\hline \multicolumn{4}{|l|}{ Weak Message } \\
\hline High Credibility & 32 & $3.50(.41)$ & 2.69 to 4.32 \\
\hline Low Credibility & 30 & $3.03(.43)$ & 2.19 to 3.88 \\
\hline
\end{tabular}

$\mathrm{CI}_{95}=95 \%$ confidence intervals.

Finally, a $2 \times 2 \times 2$ ANOVA was conducted using thought favourability as the dependent variable with personal relevance, argument quality, and source credibility as the independent variables (see Table 10 for group sizes, cell means, standard errors and 
confidence intervals). As expected (hypothesis 5), the main effect of quality was significant, with those who received the strong message having significantly higher thought favourability scores $\left(M=-.07, S E=.06 . \mathrm{CI}_{95}=-.19\right.$ to .06$)$ than those receiving the weak message, $\left(M=-.52, S E=.06, \mathrm{CI}_{95}=-.64\right.$ to -.40$), F(1,225)=26.32, p<.001$, partial $\eta^{2}=.11$. However, in contrast to what was predicted in hypothesis 5 , the Relevance by Quality interaction was not significant, indicating that the pattern of thought favourability scores was similar across high and low relevance subjects when exposed to the strong $(M=-.19, S E=.09 ; M=.05, S E=.09$, respectively) and weak ( $M$ $=-.54, S E=.09 ; M=-.50, S E=.09$, respectively) messages, $F(1,225)=1.33, p=.248$. All other main and interaction effects were not significant (all $p$ 's $>.05$ ). Power estimates and effect sizes for all main and interaction effects are presented in Appendix M (Table M-4). 
Table 10

Study 1 group sizes, cell means, standard errors and associated confidence intervals for thought favourability

\begin{tabular}{cccc}
\hline Group & $n$ & $M(S E)$ & CI $_{95}$ \\
\hline $\begin{array}{c}\text { High Relevance } \\
\text { Strong Message }\end{array}$ & & & \\
High Credibility & 27 & $-.18(.13)$ & -.43 to .08 \\
Low Credibility & 29 & $-.21(.13)$ & -.46 to .04 \\
Weak Message & & & -.81 to -.34 \\
High Credibility & 32 & $-.57(.12)$ & -.76 to -.27 \\
Low Credibility & 30 & $-.52(.12)$ & \\
Low Relevance & & & -.08 to .42 \\
Strong Message & & & -.31 to .19 \\
High Credibility & 28 & $-.06(.13)$ & \\
Low Credibility & 29 & & -.72 to -.24 \\
Weak Message & & $-.48(.12)$ & -.78 to -.27 \\
High Credibility & 31 & $-.52(.13)$ & \\
Low Credibility & 27 & & \\
\hline CI & & & \\
\hline
\end{tabular}

$\mathrm{CI}_{95}=95 \%$ confidence intervals.

Mediating role of cognitive responses (H6). Recall that the current study found no support for the effect of argument quality on attitudes (i.e., hypothesis 1). Although some researchers argue that meditational effects should still be examined in the absence of a relationship between the predictor (e.g., argument quality) and dependent variable (i.e., attitudes), this reasoning largely applies to instances where: (1) suppression of the overall effect is expected due to competing mediators that have opposite effects causing the total effect to disappear, or (2) the effect is temporally distal (e.g., longitudinal research) rather 
than proximal (e.g., the current research where an attempt was made to experimentally produce the effect; MacKinnon, Krull, \& Lockwood, 2000; Shrout \& Bolger, 2002). As stated by Shrout and Bolger (2002), "experimentalists who wish to elaborate the mechanisms of an experimental effect need to first establish that an effect exists" (p. 430). Since this direct effect was not confirmed, meditational analyses were not conducted.

\section{Discussion}

Study 1 attempted a conceptual replication of Petty et al.'s (1981) experiment, which examined the effects of argument quality and source credibility on student attitudes towards comprehensive exams under conditions of high and low personal relevance. Although it was expected that similar results (as outlined in the hypotheses above) would be found in the police recruitment domain, this study was unable to replicate the differential effect (across levels of personal relevance) of argument quality and source credibility on attitudes towards policing as a career. Similarly, no effect of any of the manipulated independent variables was found for attitude certainty or the number of cognitive responses (i.e., thoughts) generated in response to the message. The only predicted effect that was supported was that participants provided with the strong message had higher thought favourability scores than participants provided with the weak message (essentially confirming that the argument quality manipulation was successful).

Potentially contributing to these unexpected findings is the fact that, although successful during the pilot research, the personal relevance manipulation was not found to be effective in Study 1. Even though the mean relevancy ratings were in the expected direction, the difference between the high (Canada) and low (Europe) relevance groups, in terms of their perceived personal impact of the police staffing crisis, was relatively 
small. This may explain, in part, why the impact of argument quality and source credibility on post-message attitudes did not differ according to personal relevance, and also why the high and low relevance groups did not differ in terms of the extent to which they elaborated upon the message (i.e., their total number of thoughts).

Furthermore, it is possible that other factors, beyond the relevancy manipulation, may have affected the participants' motivation to elaborate. One distinct possibility relates to the extent to which participants in Study 1 were open (at the outset of the study) to even considering a career in policing. Similar to other individual difference factors commonly employed in ELM research (e.g., need for cognition; Cacioppo et al., 1983), openness to policing as a career may essentially cancel out any type of relevancy manipulation, making the manipulation ineffective. For example, it seems unlikely that an individual who has no interest in policing as a career will feel compelled to carefully scrutinize a police recruitment message even if they are informed of the dire consequences facing Canadians if the police staffing crisis is not quickly resolved (i.e., the high relevance manipulation). The same argument applies to the individual who is placed in the low relevance condition, but is extremely interested in a policing career.

Thus, it seems plausible that between-subject differences in "openness to policing as a career" could potentially be masking the expected effects of argument quality and source credibility on post-message attitudes under the different conditions of personal relevance (i.e., motivation to elaborate). Given this possibility, the issue was further explored in Study 2. In addition, a number of other variations to the procedure used in Study 1 will be introduced in Study 2. These are all described in detail below. 
Study 2: Personal Relevance, Argument Quality, and Argument Quantity

\section{Purpose}

Study 2 attempted a conceptual replication of Petty and Cacioppo's (1984b) study, which examined the effects of argument quality and argument quantity under different conditions of personal relevance. Similar to Study 1, the impact of these factors on several dependent variables were examined, including attitudes towards policing as a career, how certain participants are of their attitudes, and the cognitive responses of participants to the recruitment message. Beyond the fact that a different peripheral cue was examined in Study 2 (i.e., argument quantity versus source credibility) there were three other important differences between Study 1 and Study 2.

First, in an attempt to explain why the expected ELM effects were not found in Study 1, each participant's openness to policing as a career was measured prior to any experimental manipulations. This was done in order to determine if the expected differences between high and low relevance subjects on the dependent measures could be found after controlling for this potentially influential factor (i.e., openness will be used as a covariate in the analysis). Second, a variety of behavioural intention questions were included as additional dependent variables so that, if the expected effects on postmessage attitudes were found, it could be determined (to some extent) whether or not attitudes were predictive of future behaviour (see below for more details). Third, Study 2 was conducted on-line. Not only did an on-line study allow for the collection of a larger, more representative sample than would have been possible otherwise, it increased the likelihood that the sample would exhibit a range of interests (openness) in policing as a career (e.g., by sampling from colleges with police foundation courses). Furthermore, conducting the study on-line was thought to be important because police agencies are 
increasingly turning to the Internet to attract potential job applicants (Hay Group, 2007). In support of the decision to use an online format for Study 2, it is important to note that responses obtained online tend to be just as reliable as those obtained from traditional paper-pencil experiments (Gosling, Vazire, Srivastava, \& John, 2004). Moreover, studies directly comparing online versus paper-pencil methodologies have shown that both produce comparable results (Allen, 1999 as cited in Krantz \& Dalal, 2000; Birnbaum, 1999; Fouladi, McCarthy, \& Moller, 2002; Senior, Phillips, Barnes, \& David, 1999).

\section{Method}

\section{Participants}

Students from various post-secondary institutions across Canada were recruited for participation in Study $2(N=257)$ and randomly assigned to conditions in a 2 (personal relevance: high versus low) by 2 (argument quality: strong versus weak) by 2 (argument quantity: nine versus three) between subjects design. All participants were entered into a lottery draw for $\$ 100$ for their participation in the current study. Participants were recruited by: (1) contacting colleges from across Canada who then sent out a participation request notification via email to the student population, and (2) visiting classes at Carleton University to announce the research to interested students. The majority of participants were female $(n=174)$. The age of participants ranged from 18 to 45 , with a mean age of $22(S D=3.58)$. Most of the participants attended Mount Royal College $(n=126)$, followed by: Carleton University $(n=72)$, Niagara College $(n=39)$, Seneca College $(n=15)$, Athabasca University $(n=2)$, Humber College $(n=1)$ and the University of Victoria $(n=1)$. Most were in their first year of study $(n=71)$ followed by: second $(n=66)$, third $(n=60)$, fourth year $(n=48)$ and fifth year $(n=10)$. In terms of ethnicity, the majority of participants were Caucasian $(n=196)$ followed by: Asian $(n$ 
$=24)$, Middle Eastern $(n=9)$, Hispanic $(n=8)$, Black $(n=6)$, those of mixed race $(n=$ 6 ), and Aboriginal $(n=3)$. A small portion of participants $(n=5)$ stated they had experience in the law enforcement field, with experience being from: volunteering or working for various police agencies or within a security position (e.g., at Carleton University). A total of 39 participants stated they had family members with law enforcement experience. Table 11 displays participants' field of study as well as their career aspirations. Analysis of variance (for age) and chi-square tests (for gender, family experience, program of study, and career goal) revealed no significant between group differences (all p's >.05). In addition, an examination of cross-tabs (for ethnicity, level of study, and own experience) revealed no noticeable between group differences. 
Table 11

Summary of Study 2 participants' field of study and career aspirations

\begin{tabular}{llll}
\hline Field of Study & $n$ & Career Aspirations & $n$ \\
\hline General Arts and Sciences & 62 & Healthcare & 46 \\
Criminal Justice and Security & 58 & Criminal Justice and Security & 33 \\
Business & 30 & Education & 29 \\
Health Services & 22 & Business & 27 \\
Other & 21 & Other & 27 \\
Public Relations and Marketing & 15 & Policing & 25 \\
Social and Child Services & 12 & Other Public Service & 24 \\
Environmental Studies & 9 & HR, Media and Entertainment & 18 \\
Engineering & 8 & Undecided & 8 \\
Education & 7 & Engineering & 6 \\
Policing & 6 & Research & 5 \\
\hline
\end{tabular}

Procedure

After reading and agreeing to the informed consent form (see Appendix I for a template), participants were provided with the same relevance manipulations used in Study 1 . Following this, participants read a recruitment message containing either: 9 strong arguments, 9 weak arguments, 3 strong arguments, or 3 weak arguments supporting policing as a career. To construct the sets of three arguments, each of the 9 arguments were randomly divided into three mutually exclusive sets of 3 arguments. To ensure that the results from participants who received 3 arguments were not biased by using one specific set of arguments, each of the three mutually exclusive sets of 
arguments were randomly distributed to participants within those conditions (see Appendix $\mathrm{N}$ for the three sets of strong and three sets of weak arguments randomly selected). Participants then responded to a variety of measures (see below). At the end of the experimental session, all participants were provided with a debriefing form (see Appendix L for a template).

\section{Measures}

After reading their respective recruitment messages, participants responded to the same dependent measures as assessed in Study 1. As indicated above, the only differences that existed between the measures used in Study 1 and 2 concerned the addition of questions concerning openness to various career fields and behavioural intentions. In addition, the source credibility manipulation check used in Study 1 was obviously replaced by a manipulation check for argument quantity.

Openness to policing as a career. Prior to the experimental manipulations, openness to policing as a career was assessed by asking participants to indicate on a 9point scale how open they were to a career in a variety of fields, including policing $(1=$ not at all open, $9=$ extremely open). To conceal the purpose of this question, and to prevent this question from impacting responses on the experimental task, it was incorporated into a list of other questions pertaining to different career options (e.g., education; see Appendix O).

Attitudes towards policing as a career. Immediately after message exposure, subjects were asked to indicate their attitudes towards policing as a career on the same 9point semantic differential scales used in Study 1: unfavourable-favourable and undesirable-desirable (see Appendix J). As in Study 1, the internal consistency of these 
scales was calculated and responses were averaged to form a combined index of attitudes towards policing as a career.

Attitude certainty. As an index of attitude strength, attitude certainty was measured following the attitude measure. Specifically, after indicating their post-message attitudes, participants were asked: "How confident are you that your attitude towards policing as a career is correct?" Answers were provided on a 9-point scale, with 1 indicating that the participant is not confident at all and 9 indicating that they are extremely confident (see Appendix J).

Cognitive responses to recruitment messages. To provide evidence for differences in message elaboration, cognitive responses to the recruitment messages were also measured after attitude certainty. Using the same procedure as described in the pilot study and Study 1, participants were instructed to list any thoughts they had while reading the message in the boxes provided (see Appendix F). Similar to Study 1, these thoughts were then coded by the primary researcher as favourable, unfavourable, or neutral towards policing as a career. A second researcher coded $25 \%$ of the generated lists, and Cohen's Kappa revealed that the overall agreement between raters concerning what thoughts were favourable, unfavourable and neutral was high ( $\kappa=.85$; Landis $\&$ Koch, 1977). Any disagreements between raters were discussed and resolved so that analyses were based on complete agreement. The total number of relevant thoughts (i.e., the total combined number of favourable and unfavourable thoughts) was also calculated for each subject in order to examine differences in the extent of thinking between conditions. Agreement between raters on the total number of message-relevant thought was also high $(r(61)=$ $.96, p<.001)$. Finally, in order to examine differences in the valence of thinking across conditions, the same thought favourability index used in Study 1 was calculated. 
Manipulation checks. At the end of the study, participants were asked questions designed to serve as manipulation checks for: (1) personal relevance, (2) the quality of the message arguments, and (3) the number of arguments contained in the message. The same questions used in Study 1 were asked for personal relevance and argument quality (see Appendix K). To check argument quantity, participants were asked, "About how many arguments did the recruiter provide in support of policing as a career?". Responses to this question were provided in an open-ended format, which is consistent with how this manipulation is assessed in other ELM research (e.g., Petty \& Cacioppo, 1984b).

Behavioural intentions. Once participants had responded to all manipulation checks, they were provided with the behavioural intention questions (see Appendix P). Specifically, participants were asked how likely it was that they would engage in a range of behaviours reflecting various degrees of interest in pursuing a career in policing (e.g., ranging from seeking out more information about policing as a career on websites to actually applying for a career in policing). Each response was provided on a 9-point scale, with higher scores indicating a higher likelihood that they would engage in the target behaviour.

Demographics questionnaire. Prior to receiving the debriefing form (see Appendix L for a template), all participants were asked to complete the demographics questionnaire (see Appendix C).

\section{Hypotheses}

Below are the specific hypotheses concerning the effects that are expected in Study 2, assuming that the results of previous ELM research will extend to the current domain (e.g., Petty \& Cacioppo, 1984b). Hypotheses are separated into the expected effects for each dependent measure. Similar to Study 1, each hypothesis was generated 
from past research that has simultaneously examined the effects of personal relevance, argument quality, and argument quantity. For instances where research on the combined effects of these three variables on a given dependent variable is lacking (e.g., attitude certainty), interactions were hypothesized and exploratory analyses were carried out to determine if such effects exist.

Attitudes Towards Policing as a Career

Hypothesis 1. Although higher quality arguments are expected to result in more favourable attitudes, it is expected that this effect will be qualified by an interaction between personal relevance and argument quality. Under conditions of high relevance, participant attitudes are expected to be more favourable when exposed to strong versus weak arguments. Attitudes for those low in personal relevance are not expected to vary as a function of argument quality (see Figure $6)$. 


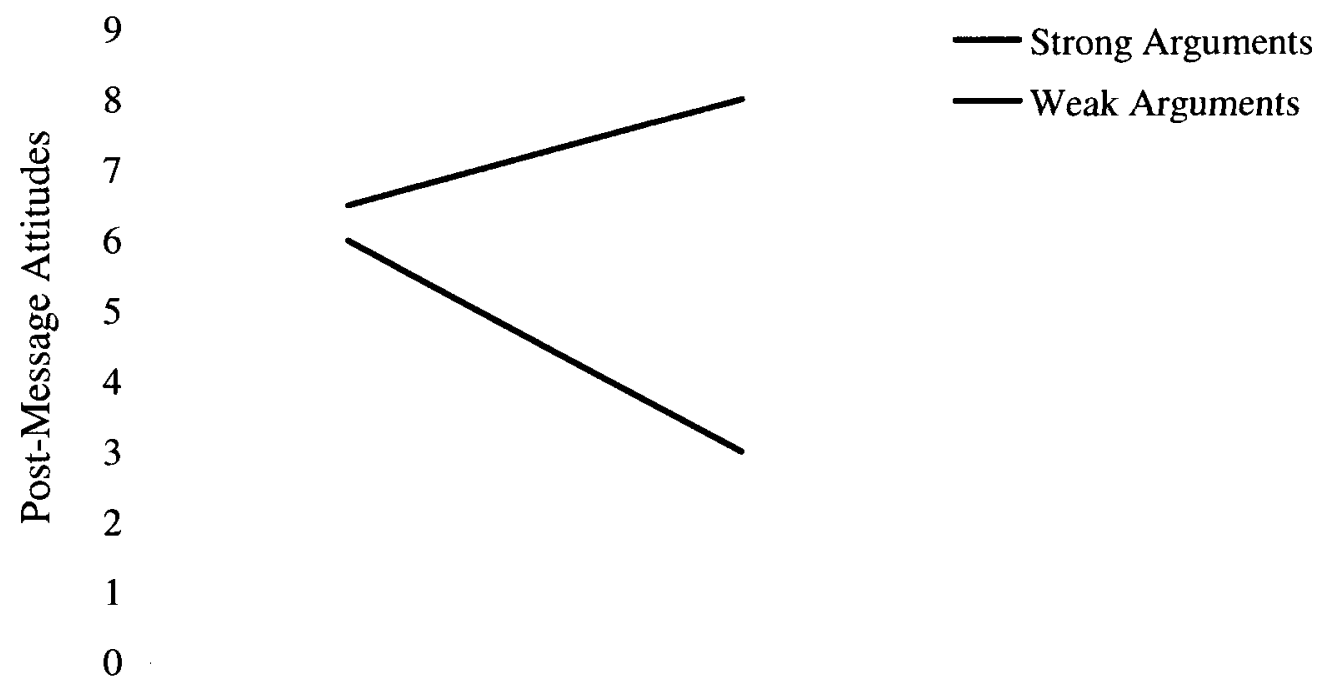

Low Relevance High Relevance

Figure 6. Expected interaction between personal relevance and argument quality on attitudes towards policing as a career .Adopted from Petty \& Cacioppo (1984b).

Hypothesis 2. Although 9 arguments are expected to result in more favourable attitudes, it is expected that this effect will be qualified by an interaction between personal relevance and argument quantity. Under conditions of low personal relevance, participant attitudes towards policing as a career will be more favourable when exposed to 9 versus 3 arguments. Attitudes for those high in personal relevance are not expected to vary as a function of argument quantity (see Figure 7). 


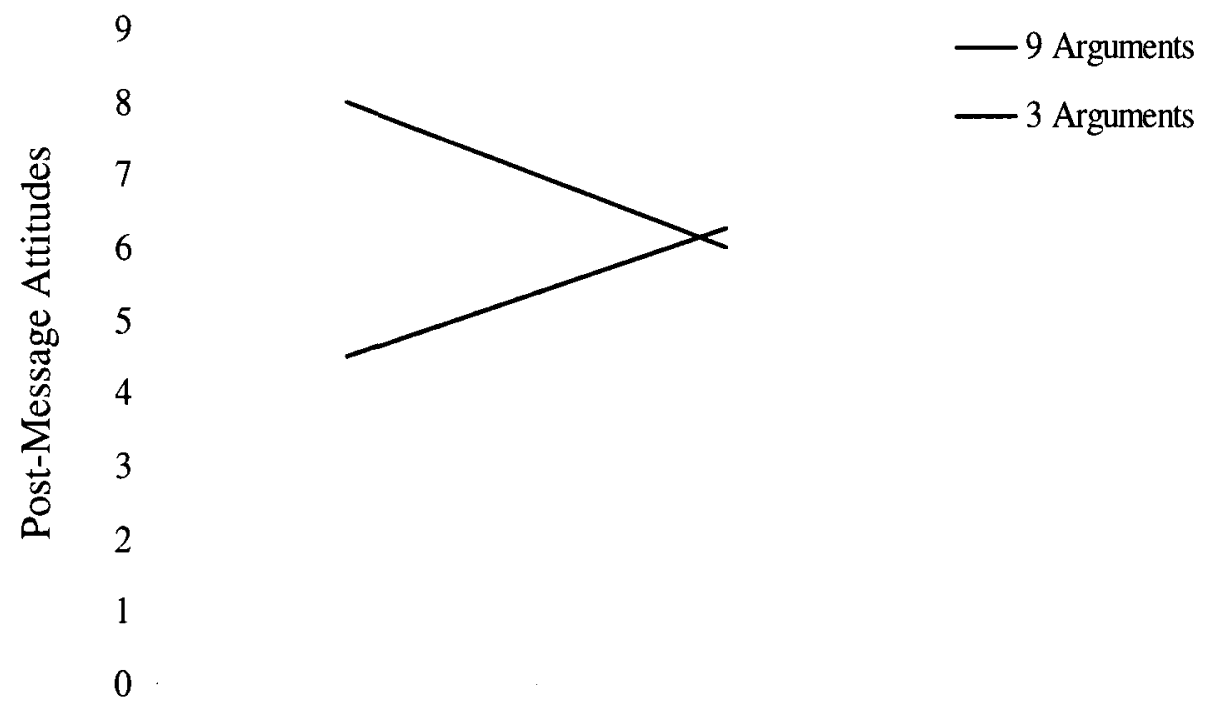

Low Relevance High Relevance

Figure 7. Expected interaction between personal relevance and argument quantity on attitudes towards policing as a career. Adopted from Petty \& Cacioppo (1984b).

\section{Attitude Certainty}

Hypothesis 3. Participants in the high relevance, strong argument, and 9 argument conditions will be more certain of their attitudes than those in the low relevance, weak argument, and 3 argument conditions, respectively.

\section{Cognitive Responses to Recruitment Messages}

Hypothesis 4 . High relevance subjects will produce significantly more messagerelevant cognitive responses than will low relevance subjects, serving as an indication of the extent of elaboration.

Hypothesis 5. Although strong arguments are expected to induce higher thought favourability scores, it is expected that this effect will be qualified by an interaction between personal relevance and argument quality. Under conditions of 
high relevance, it is expected that subjects will have higher thought favourability scores when exposed to strong versus weak messages. Low relevance subjects are not expected to show any significant differences in thought favourability scores for strong versus weak messages (see Figure 8).

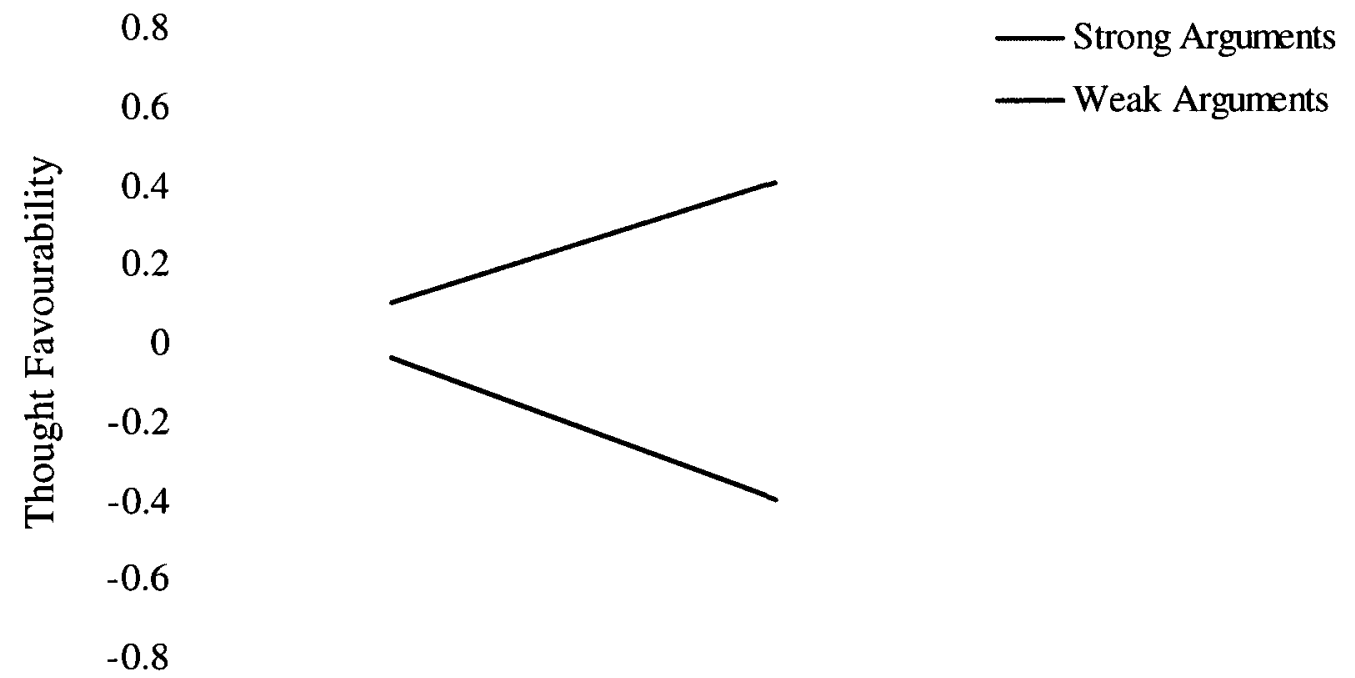

Low Relevance High Relevance

Figure 8. Expected interaction between personal relevance and argument quality on thought favourability scores.

\section{Mediating Role of Cognitive Responses}

Hypothesis 6. In addition to the direct effect of argument quality on attitudes (Hypothesis 1), it is expected that this effect will be mediated by thought favourability in the same way as described in Study 1. However, it is expected that the mediating effect of thought favourability on attitudes will only be evident under conditions of high rather than low personal relevance. 


\section{Behavioural Intentions}

Hypothesis 7. It is expected that attitudes will be more predictive of behavioural intentions under high elaboration conditions than attitudes formed under low elaboration conditions.

\section{Results}

\section{Preliminary Screening and Analyses}

Missing data. Similar to Study 1, although less than five percent of data points were missing in the current study, a missing values analysis was still conducted in order to ensure that the pattern of missing data points across all dependent measures was random. Little's MCAR test was not significant, indicating that the pattern of missing data points in the current study was random $\left(\chi^{2}(363)=370.60, p=.380\right)$. As such, missing data points for all variables, with the exception of thought favourability and demographics, were estimated by replacing each missing score with the corresponding group mean (Tabachnick \& Fidell, 2007a). Similar to the reasoning in Study 1, missing thought favourability scores were not estimated due to the fact that a participant may genuinely not have had (or may not have been able to remember) thoughts while reading the message. As a result, those who did not list any thoughts were excluded from the thought favourability analyses $(n=13)$.

Manipulation checks. Prior to the main analyses, a series of independent samples $t$-tests were conducted in order to ensure that all manipulations had their intended effects. Specifically, checks were conducted to ensure that: (1) high relevance subjects felt that the recruitment crisis would have more of an impact on them than those in the low relevance condition, (2) participants exposed to strong message arguments thought the message was of higher quality than those exposed to weak arguments, and (3) subjects 
exposed to 9 arguments believed there were more arguments in the message than those exposed to 3 arguments.

Although the means were in the expected direction, those who received the high relevance manipulation $(M=5.91, S D=2.42)$ did not believe the recruitment crisis would have significantly more of an impact on them than those who received the low relevance manipulation $(M=5.66, S D=2.13), t(255)=0.88, p=.250$. Similar to the results of Study 1, however, those who received the strong message $(M=5.97, S D=$ 1.91) rated the arguments contained in the message as significantly higher in quality than those who received the weak message $(M=4.52, S D=2.39), t(245.37)=5.39, p<.001$. Finally, participants receiving 9 arguments $(M=7.16, S D=3.25)$ believed the message they read contained significantly more arguments in support of policing as a career than those who received 3 arguments $(M=4.22, S D=1.89), t(197.32)=8.81, p<.001$.

ANCOVA assumptions. In order to conduct an ANCOVA, the covariate must be related to the dependent measure (Tabachnick \& Fidell, 2007b). As a result, correlations were examined before running ANCOVAs to ensure that attitudes, attitude certainty, number of relevant thoughts, and thought favourability were related to openness to policing as a career. As shown in Table 12, openness to policing as a career was significantly correlated with all of the ANCOVA-relevant dependent measures except the total number of relevant thoughts (as a result, an ANOVA, rather than an ANCOVA, was conducted to examine the effects of the independent variables on total number of relevant thoughts). 
Table 12

Correlations between each dependent variable and openness to policing as a career

\begin{tabular}{lc}
\hline Dependent Variable & $r$ \\
\hline Attitudes & $.73^{*}$ \\
Attitude Certainty & $.39^{*}$ \\
Relevant Thoughts & -.02 \\
Thought Favourability & $.35^{*}$ \\
\hline${ }^{*} p<.001$ &
\end{tabular}

Responses on all relevant dependent measures (i.e., attitudes, attitude certainty, number of relevant thoughts, and thought favourability) and the covariate (i.e., openness to policing as a career) were then examined to ensure that assumptions of absence of outliers, independence, homogeneity of variance, homogeneity of regression, and normality were tenable before the analyses were conducted. ${ }^{11}$ No outliers $(\mathrm{z}> \pm 3.29, p<$ .001 ) were found for any of the dependent measures and the covariate. Examination of a series of scatterplots displayed a linear relationship between each of the ANCOVArelevant dependent variables and the covariate, and did not display any indications of non-independence of errors for any of the measures. The homogeneity of regression assumption was also supported, with no interactions between independent variables and the covariate reaching significance for any of the ANCOVA-relevant dependent measures (all $p$ 's $>.05$ ). Levene's test for equality of error variance indicated homogenous variances across groups for all of the relevant dependent measures (all $p$ 's $>.05$ ). Finally,

\footnotetext{
${ }^{11}$ This was done for both datasets (i.e., with and without missing values estimated) in order to ensure that the inclusion of estimated values did not influence the results of the assumptions testing. When done with the dataset including missing data points, results of assumptions testing did not differ in any meaningful way.
} 
normality plots suggested that the distributions were skewed for all measures, as

confirmed by Shapiro-Wilk significance tests for attitudes $(W(257)=.958, p<.001)$, attitude certainty $(W(257)=.909, p<.001)$, total number of message-relevant thoughts $(W(257)=.960, p<.001)$, and thought favourability $(W(244)=.890, p<.001)$. However, as ANCOVA has been shown to be robust to violations of assumptions (e.g., normality) when degrees of freedom for error are greater than 20 , and since transforming variables makes interpreting the results more difficult (Tabachnick \& Fidell, 2007b), conducting the analyses with untransformed scores was still deemed appropriate for the current study.

Main Analyses ${ }^{12}$

Similar to Study 1, separate univariate analyses were carried out on attitudes, attitude certainty, total number of relevant thoughts, and thought favourability. The only difference between Study 1 and Study 2 analyses was the addition of openness to policing as a career $(M=4.66, S D=2.75)$ as a covariate for the analyses run on all of the abovementioned dependent measures apart from total relevant thoughts (see Table 13 for group sizes, cell means, standard errors and associated confidence intervals for the covariate). As stated above, since total number of relevant thoughts was not related to openness to policing as a career, an ANOVA, rather than an ANCOVA, was conducted to examine hypotheses related to this variable.

\footnotetext{
${ }^{12}$ All main analyses were run with and without missing data estimated in order to ensure that the estimation procedure did not alter the results. Models were compared across dependent measures and no noticeable variations in results were found.
} 
Table 13

Group sizes, cell means, standard errors, and associated confidence intervals for the covariate, openness to policing as a career

\begin{tabular}{cccc}
\hline Group & $n$ & $M(S E)$ & CI $_{95}$ \\
\hline $\begin{array}{c}\text { High Relevance } \\
\text { Strong Message }\end{array}$ & & & \\
9 Arguments & 31 & $4.48(.49)$ & 3.52 to 5.45 \\
3 Arguments & 33 & $4.36(.48)$ & 3.42 to 5.30 \\
Weak Message & & & 4.18 to 6.06 \\
9 Arguments & 33 & $5.12(.48)$ & 3.69 to 5.57 \\
3 Arguments & 33 & $4.63(.48)$ & \\
Low Relevance & & & 4.65 to 6.62 \\
Strong Message & 30 & $5.63(.50)$ & 3.63 to 5.51 \\
9 Arguments & 33 & $4.57(.48)$ & \\
3 Arguments & & & 3.85 to 5.73 \\
Weak Message & 31 & $4.79(.47)$ & \\
9 Arguments & 33 & & \\
3 Arguments & & & \\
\hline
\end{tabular}

$\mathrm{CI}_{95}=95 \%$ confidence intervals.

Attitudes towards policing as a career (H1 and H2). Similar to Study 1, an index of participants' overall attitude towards policing as a career was first calculated for each participant by averaging across responses to both attitude measures $(\alpha=.90)$. A 2 (personal relevance: high or low) x 2 (argument quality: strong or weak) x 2 (argument quantity: 9 or 3) ANCOVA was then conducted on the attitude index as the dependent variable with personal relevance, argument quality, and argument quantity as the 
independent variables and openness to policing as a career as the covariate (see Table 14 for group sizes, cell means, standard errors and associated confidence intervals).

In contrast to the expected effect outlined in hypothesis 1 , the main effect of quality was not significant, indicating that strong arguments $(M=5.40, S E=.14)$ did not result in more favourable attitudes towards policing as a career than weak arguments $(M$ $=5.41, S E=.14)$, while controlling for openness to policing as a career, $F(1,248)=0.00$, $p=.958$. Similarly, the Relevance by Quality interaction was not significant, indicating that the pattern of attitudes was similar across high and low relevance subjects when exposed to the strong $(M=5.34, S E=.20 ; M=5.47, S E=.20$, respectively) and weak ( $M$ $=5.28, S E=.20 ; M=5.55, S E=.20$, respectively) message, $F(1,248)=0.10, p=.748$.

Further, unlike what was predicted in hypothesis 2 , the main effect of argument quantity was not significant, indicating that 9 arguments $(M=5.48, S E=.14)$ did not result in more favourable attitudes towards policing as a career than 3 arguments $(M=$ $5.34, S E=.14)$, after removing the effect of openness to policing as a career, $F(1,248)=$ $0.10, p=.748$. Likewise, the Relevance by Quantity interaction failed to reach significance, indicating that the pattern of attitudes across high and low relevance subjects was similar when $9(M=5.39, S E=.20 ; M=5.56, S E=.20$, respectively $)$ and 3 $(M=5.22, S E=.20 ; M=5.46, S E=.20$, respectively $)$ arguments were presented, $F(1$, $248)=0.04, p=.851$. Finally, all other main and interaction effects were not significant (all $p$ 's $>.05$ ). Power estimates and effect sizes for all main and interaction effects are presented in Appendix Q (see Table Q-1). 
Table 14

Group sizes, cell means, standard errors, and associated confidence intervals for attitudes after adjusting for openness to policing as a career

\begin{tabular}{|c|c|c|c|}
\hline Group & $n$ & $M(S E)$ & $\mathrm{CI}_{95}$ \\
\hline \multicolumn{4}{|l|}{ High Relevance } \\
\hline \multicolumn{4}{|l|}{ Strong Message } \\
\hline 9 Arguments & 31 & $5.38(.29)$ & 4.82 to 5.94 \\
\hline 3 Arguments & 33 & $5.29(.28)$ & 4.74 to 5.83 \\
\hline \multicolumn{4}{|l|}{ Weak Message } \\
\hline 9 Arguments & 33 & $5.40(.28)$ & 4.86 to 5.95 \\
\hline 3Arguments & 33 & $5.16(.28)$ & 4.61 to 5.70 \\
\hline \multicolumn{4}{|l|}{ Low Relevance } \\
\hline \multicolumn{4}{|l|}{ Strong Message } \\
\hline 9 Arguments & 30 & $5.58(.29)$ & 5.00 to 6.15 \\
\hline 3 Arguments & 33 & $5.56(.27)$ & 5.01 to 6.10 \\
\hline \multicolumn{4}{|l|}{ Weak Message } \\
\hline 9 Arguments & 31 & $5.54(.29)$ & 4.97 to 6.10 \\
\hline 3 Arguments & 33 & $5.56(.28)$ & 5.01 to 6.10 \\
\hline
\end{tabular}

$\mathrm{CI}_{95}=95 \%$ confidence intervals.

Attitude certainty (H3). A $2 \times 2 \times 2$ ANCOVA was also conducted on attitude certainty with personal relevance, argument quality, and argument quantity as the independent variables and openness to policing as a career as the covariate (see Table 15 for descriptive statistics). In contrast to what was expected in hypothesis 3 , the main effects of relevance, $F(1,248)=0.51, p=.474$; quality, $F(1,248)=1.67, p=.197 ;$ and quantity, $F(1,248)=0.53, p=.469$, on attitude certainty remained non-significant when controlling for openness to a career in policing. In other words, those in the high 
relevance $(M=6.62, S E=.16)$, strong message $(M=6.69, S E=.17)$, and 9 argument $(M$ $=6.62, S E=.17)$ conditions were not more certain of their attitudes than those in the low relevance $(M=6.45, S E=.17)$, weak message $(M=6.39, S E=.16)$ and 3 argument conditions $(M=6.45, S E=.16)$, respectively. Similarly, none of the interaction effects were significant (all $p$ 's $>.05$ ). Power estimates and effect sizes for all main and interaction effects are presented in Appendix Q (see Table Q-2).

Table 15

Group sizes, cell means, standard errors, and associated confidence intervals for attitude certainty after adjusting for openness to policing as a career

\begin{tabular}{cccc}
\hline Group & $n$ & $M(S E)$ & $\mathrm{CI}_{95}$ \\
\hline
\end{tabular}

High Relevance

Strong Message

9 Arguments

31

$6.82(.34)$

6.16 to 7.49

3 Arguments

33

$6.84(.33)$

6.20 to 7.48

Weak Message

9 Arguments

33

$6.81(.33)$

6.17 to 7.45

3 Arguments

33

$6.01(.33)$

5.37 to 6.65

Low Relevance

Strong Message

9 Arguments

30

$6.42(.34)$

5.75 to 7.10

3 Arguments

33

$6.66(.33)$

6.02 to 7.30

Weak Message

9 Arguments

31

$6.43(.34)$

5.77 to 7.10

3 Arguments

33

$6.30(.33)$

5.66 to 6.94

$\mathrm{CI}_{95}=95 \%$ confidence intervals. 
Cognitive responses ( $H 4$ and H5). A $2 \times 2 \times 2$ ANOVA was conducted on the total number of relevant thoughts with personal relevance, argument quality, and argument quantity as the independent variables (see Table 16 for descriptive statistics). In contrast to what was expected, the main effect of relevance was not significant, indicating that high $(M=4.95, S E=.28)$ and low $(M=5.25, S E=.29)$ relevance subjects generated a comparable number of thoughts about policing as a career, $F(1,248)=0.57, p=.452$. All other effects were not significant (all $p$ 's $>.05$ ). Power and effect size estimates are presented in Appendix Q (see Table Q-3). 
Table 16

Study 2 group sizes, cell means, standard errors, and associated confidence intervals for total relevant thoughts

\begin{tabular}{cccc}
\hline Group & $n$ & $M(S E)$ & $\mathrm{Cl}_{95}$ \\
\hline $\begin{array}{c}\text { High Relevance } \\
\text { Strong Message }\end{array}$ & & & \\
9 Arguments & 31 & $5.00(.58)$ & 3.86 to 6.15 \\
3 Arguments & 33 & $5.12(.56)$ & 4.01 to 6.23 \\
Weak Message & & & \\
9 Arguments & 33 & $4.81(.56)$ & 3.07 to 5.29 \\
3 Arguments & 33 & $5.49(.56)$ & 4.38 to 6.59 \\
Low Relevance & & & 4.47 to 6.80 \\
Strong Message & & & 4.29 to 6.50 \\
9 Arguments & 30 & $5.63(.59)$ & \\
3 Arguments & 33 & $5.39(.56)$ & 3.98 to 6.27 \\
Weak Message & & & 3.74 to 5.96 \\
9 Arguments & 31 & $5.13(.58)$ & \\
3 Arguments & 33 & $4.85(.56)$ &
\end{tabular}

$\mathrm{CI}_{95}=95 \%$ confidence intervals.

Finally, a $2 \times 2 \times 2$ ANCOVA was conducted on thought favourability with the same independent variables (see Table 17 for descriptive statistics). As expected (hypothesis 5), the main effect of quality was significant, with those who received the strong message $\left(M=.05, S E=.06 . \mathrm{CI}_{95}=-.07\right.$ to .17$)$ having significantly higher thought favourability scores than those receiving the weak message, after controlling for openness to policing as a career $\left(M=-.26, S E=.06, \mathrm{CI}_{95}=-.38\right.$ to -.14$), F(1,235)=13.55, p<$ .001 , partial $\eta^{2}=.06$. However, the expected Relevance by Quality interaction was not 
significant, indicating that the pattern of thought favourability scores was comparable across high and low relevance subjects when exposed to the strong $(M=.02, S E=.09 ; M$ $=.09, S E=.09$, respectively $)$ and weak $(M=-.31, S E=.09 ; M=-.21, S E=.08$, respectively) message, $F(1,235)=0.04, p=.845$. All other main and interaction effects were not significant (all $p$ 's $>.05$ ). Power estimates and effect sizes for all main and interaction effects are presented in Appendix Q (see Table Q-4).

Table 17

Group sizes, cell means, standard errors, and associated confidence intervals for thought favourability after adjusting for openness to policing as a career

\begin{tabular}{cccc}
\hline Group & $n$ & $M(S E)$ & $\mathrm{CI}_{95}$ \\
\hline High Relevance & & & \\
Strong Message & & $.11(.12)$ & -.13 to .35 \\
9 Arguments & 31 & $-.07(.12)$ & -.30 to .17 \\
3 Arguments & 33 & & \\
Weak Message & & $-.30(.12)$ & -.54 to -.06 \\
9 Arguments & 33 & $-.32(.12)$ & -.56 to -.09 \\
3 Arguments & 33 & & \\
Low Relevance & & $.24(.12)$ & .00 to .49 \\
Strong Message & & $-.07(.12)$ & -.30 to .16 \\
9 Arguments & 30 & & -.41 to .07 \\
3 Arguments & 33 & $-.17(.12)$ & -.48 to -.02 \\
Weak Message & & $-.25(.12)$ & \\
9 Arguments & 31 & 33 &
\end{tabular}

$\mathrm{CI}_{95}=95 \%$ confidence intervals. 
Mediating role of cognitive responses (H6). In line with Study 1 , the meditational effect of thought favourability on attitudes for high and low relevance subjects was not investigated due to the fact that the experimental effect of argument quality on attitudes was not supported (hypothesis 1 ).

Behavioural intentions (H7). Table 18 displays the correlations between each of the behavioural intention questions and attitudes separately for high and low relevance conditions. As expected, attitudes were positively related to behavioural intentions under high elaboration (i.e., high relevance) conditions. In direct contrast to what was hypothesized, however, attitudes were also predictive of behavioural intentions under low elaboration conditions (i.e., low relevance). Z-contrasts examining the differences between these correlations revealed that none of the high and low relevance correlations were significantly different from one another (all $p$ 's $>.05$ ).

Table 18

Correlations between attitudes and behavioural intentions for high and low relevance conditions

\begin{tabular}{lcc}
\hline \multicolumn{1}{c}{ Behavioural Intention } & High Relevance $r$ & Low Relevance $r$ \\
\hline More Information & $.76^{*}$ & $.70^{*}$ \\
Websites & $.67^{*}$ & $.65^{*}$ \\
Contact Agency & $.62^{*}$ & $.63^{*}$ \\
Apply in Future & $.67^{*}$ & $.68^{*}$ \\
\hline$* p<.001$ & &
\end{tabular}

$$
{ }^{*} p<.001
$$


Additional analyses. Given the importance attached to openness to policing as a career in the current study, additional analyses were also conducted using openness (high versus low based on a median split) as the elaboration likelihood determinant instead of personal relevance (based on the assumption that those who are more open to policing as a career may pay more attention to recruitment messages than those who are not). To examine this possibility, 2 (openness; high or low) x 2 (argument quality: strong or weak) x 2 (argument quantity: 9 or 3) ANOVAs were run for all main dependent measures separately using only participants in the high (and then low) personal relevance conditions. In contrast to what was expected, openness to policing as a career did not operate as an elaboration likelihood determinant. In other words, the results of the analyses were very similar to the Study 2 results reported above.

\section{Discussion}

The primary goal of Study 2 was to replicate Petty and Cacioppo's (1984b) study, which examined the effect of argument quality and argument quantity on attitudes towards comprehensive exams under high and low relevance conditions. A secondary goal was to determine why the expected effects of argument quality and source credibility (under different conditions of personal relevance) were not obtained in Study 1. This was done by measuring participants' openness to policing as a career in an attempt to control for potential differences on this variable across the relevance conditions (which might, in turn, reveal the expected effects of argument quality and argument quantity). In contrast to what was expected, however, the hypotheses tested in Study 2 were generally not supported. Similar to Study 1, the only hypothesis that was supported was that argument quality had the expected effect on thought favourability, again confirming the relative effectiveness of the argument quality manipulation. 
As in Study 1, the most obvious explanation for why many of the hypotheses were not supported is that the personal relevance manipulation used in Study 2 was not effective. This was confirmed by the manipulation check conducted in Study 2 , and by other findings. Specifically, the number of thoughts generated in response to the message were comparable across both high $(M=4.95)$ and low $(M=5.25)$ relevance conditions. In addition, while the scores for the behavioural intention items used in the current study were related to attitudes as expected (i.e., the more positive the attitudes, the greater the intentions), this relationship was not more prominent for high relevance subjects. Indeed, attitudes seemed to predict behavioural intentions to a similar extent in both relevance conditions.

Given these results, it can now be more confidently stated that the relevance manipulation employed in the current research is not as effective as first believed (i.e., during the pilot study). As a result, future research must be conducted to determine how best to induce different conditions of elaboration likelihood in the police recruitment context in order to examine the potential value of ELM for influencing attitudes towards policing as a potential career. This, as well as other issues relevant to the current research, are discussed in more detail below.

\section{General Discussion}

Within the next few years, police agencies across Canada are expected to experience a serious staffing crisis (PSC, 2006). As argued in the introduction to this thesis, one way to help alleviate this crisis is to encourage more young people to consider policing as a profession, especially since recent research has indicated that youth are generally uninterested in a law enforcement career (Hay Group, 2007). The primary goal of this thesis was to explore the possibility of using the ELM to guide the development 
and evaluation of police recruitment messages. In contrast to what was predicted, however, the current research failed to find any of the expected effects of argument quality, source credibility, or argument quantity on attitudes towards policing as a career under different conditions of message processing (i.e., personal relevance). While these results suggest that the ELM might not generalize to the domain of police recruitment, it is still too early to abandon the possibility that this model of persuasion has value in this context.

Indeed, there are a variety of potential explanations for why the current thesis failed to find the predicted effects of argument quality and peripheral cues (i.e., source credibility and argument quantity) on attitudes towards policing as a career under conditions of high and low personal relevance. Many of these reasons stem from potentially important discrepancies between the current research and the original research conducted by Petty and his colleagues, which found strong effects for these factors (i.e., Petty et al., 1981; Petty \& Cacioppo, 1984b). These differences relate to: (1) the extent of elaboration exhibited by the participants, (2) the initial attitudes towards, and prior knowledge or experience with, the attitude domain, (3) the degree of forewarning inherent in the experiment and its potential effect on resistance to persuasion, (4) the significance of the attitude targeted for change, and (5) the experimental environment. Each of these issues, and their potential contribution to the current findings, are discussed below.

\section{Extent of Elaboration}

Perhaps the most significant discrepancy between the current research and the studies conducted by Petty and his colleagues was that the personal relevance manipulation in the current research failed to motivate the high and low relevance groups 
to process the recruitment message to different degrees. Indeed, in both Study 1 and Study 2 , the high and low relevance groups tended to process the message in a similar way, with each group exhibiting relatively high levels of elaboration in comparison to that observed in previous research. For example, the number of thoughts generated by high relevance subjects in Study 2 was noticeably higher than the number of thoughts generated by Petty and Cacioppo's (1984b) high relevance participants (e.g., $M=4.95$; $M=3.46$, respectively). Similarly, the number of thoughts generated by low relevance subjects in Study 2 was substantially higher than the number of thoughts generated by Petty and Cacioppo's low relevance subjects (e.g., $M=5.25 ; M=2.99$, respectively).

Clearly, the lack of significant differences between high and low relevance subjects with respect to their extent of elaboration provides one potential explanation for why the expected effects were not found. For instance, since the effect of a peripheral cue (e.g., number of arguments) on attitudes is most likely to arise when message recipients are low on the elaboration likelihood continuum (i.e., more favourable attitudes for 9 rather than 3 arguments, regardless of the quality of the message), the fact that both relevance groups tended to be relatively high on the continuum might explain why low relevance participants in Study 2 did not exhibit this pattern of responses.

Why was a relatively high degree of elaboration (i.e., number of thoughts) observed across both high and low relevance subjects in the current studies? There are several possibilities, but one likely explanation relates to the highly counter-attitudinal nature of the recruitment message used in the current study (i.e., youth are generally not interested in a policing career; Hay Group, 2007). Research has shown that counterattitudinal messages naturally induce more thinking compared to pro-attitudinal messages (i.e., messages that are consistent with one's initial attitude; e.g., anti acid rain messages) 
because such communications threaten the message recipient's sense of self (Clark, Wegener, \& Fabrigar, 2008; Ditto \& Lopez, 1992).

In addition to this possible explanation, there are a number of other potential reasons for why high and low relevance subjects in the current research elaborated upon the message to a similar extent. As discussed in more detail below, these include the fact that, compared to past research, participants in the current study may have: (1) relied more on their prior experiences with, and beliefs about, the attitude object (i.e., a policing career), and (2) had more forewarning of the message content that in turn may have influenced motivation to attend to the message and thus, the extent of elaboration. These two issues will be discussed next.

Attitude-Relevant Knowledge, Initial Attitudes, and Biased Processing

Even if inaccurate, the attitude-related beliefs and experiences (i.e., attituderelevant knowledge) that surface when an individual encounters an attitude object can bias information processing by influencing the thoughts generated in response to a persuasive communication (Fabrigar, Petty, Smith \& Crites, 2006; Wood, 1982; Wood, Rhodes, \& Biek, 1995). Indeed, attitude-relevant knowledge can sometimes be a more important determinant of the manner in which a persuasive message is elaborated upon than other factors, such as induced personal relevance (Petty \& Cacioppo, 1986a). In such instances, the effect of argument quality on attitudes may be less noticeable or almost entirely diminish (Petty, Briñol, \& Priester, 2009). It is possible that participants in the current research relied more on their prior knowledge (beliefs/experiences) than participants in previous research, potentially contributing to the lack of any of the expected effects. 
Results of the current research do suggest that prior experiences with, and attitudes towards, policing were potentially more important than the relevance manipulation in determining message processing levels (and thus, attitudes). For instance, the process of coding participant thoughts revealed that, in some instances, favourable attitudes and thoughts were obtained in the presence of weak arguments towards policing as a career, providing support for the explanation that biased, rather than objective, processing of the recruitment message may have occurred for these participants. Similarly, the thought lists generated across both studies indicated that participants were often drawing on their negative experiences (direct and indirect) with policing when listing their thoughts rather than the actual recruitment message they were exposed to (e.g., "I was thinking that retiring at 50 would be pretty sweet, and that they probably give fairly good pensions. But then I was thinking about my uncle who is a retired cop, and how they are always broke, so maybe not."; "I was thinking about how on TV, police are depicted as being loners, and unable to handle family life, whether it be children or marriage."). These types of examples clearly suggest that many participants were potentially relying on their prior knowledge (beliefs/experiences) about policing more than they were relying on the cogency of the arguments presented in the message or the credibility of the source when indicating their attitudes towards policing as a career.

Why might participants in the current research have relied more on their prior attitude-relevant knowledge than participants in studies involving attitude objects such as comprehensive exams (i.e., the standard attitude assessed in Petty's studies)? Presumably, participants in Petty's studies (typically college students) also have prior attitude-relevant knowledge given the frequency with which students take exams. While this is likely true, one could argue that what differs between participants in those studies and the current 
ones is not necessarily the amount of prior knowledge that is accessible to the message recipients, but rather the intensity associated with their prior attitudes and beliefs.

Attitude intensity, a dimension of attitude strength, refers to "the strength of the emotional reaction provoked by the attitude object in an individual" (Visser, Bizer, \& Krosnick, 2006, p.4). Attitudes based on intense feelings are more resistant to persuasion than those that are not (Krosnick \& Schuman, 1988). Likewise, the stronger the initial attitude, the more likely the recipient will be to direct their thinking (i.e., processing of the message) in accordance with this attitude, resulting in more counter-arguments and less persuasion in response to counter-attitudinal messages (Tormala \& Petty, 2002). If students in the current study feel more passionately about their prior attitudes towards policing than do students in previous studies about their attitudes towards exams, this may have resulted in a greater tendency for the current participants to process the recruitment message in accordance with their prior beliefs and experiences rather than the information contained in the message. As a consequence, this may have contributed to the lack of expected effects (e.g., with respect to argument quality) on post-message attitudes in the current research.

Although Study 2 attempted to account (to some extent) for the effect that initial attitudes and knowledge may have on post-message attitudes, by controlling for openness to policing as a career, some research suggests that doing so may have had detrimental consequences on the experimental manipulations (Petty \& Cacioppo, 1977). Specifically, making participants aware of their initial attitudes towards policing prior to encountering a persuasive message (i.e., by asking participants to assess their openness to a career in policing) may make prior attitude-relevant knowledge (beliefs/experiences) more accessible. As a consequence, this can promote resistance to persuasion, particularly 
when the persuasive message is counter-attitudinal (Petty \& Cacioppo, 1986b). This issue is explained in more detail next.

\section{Forewarning and Resistance to Persuasion}

Forewarning often refers to the activity of specifically informing participants in advance that they will encounter a persuasive attack, or more generally revealing the content of the persuasive message before it is received (Johnson, Maio, \& SmithMcLallen, 2005). Research has shown that forewarning can have the damaging effect of increasing resistance to persuasion, especially under conditions of high elaboration likelihood (Neimeyer, MacNair, Metzler, \& Courchaine, 1991; Petty \& Cacioppo, 1977, 1979b). These negative effects are partially due to the fact that forewarning of message content enables the recipient to begin considering information that supports their initial position even before any message is encountered (i.e., forewarning leads to biased processing; Petty \& Cacioppo, 1986b).

In terms of the current research, participants in Study 2 may have been primed to counter-argue the recruitment message in part because they were initially asked to indicate their openness to considering a career in the policing field. In order for them to provide an honest answer to this question, they would have needed to draw on their current beliefs and opinions towards policing as a career. In turn, asking participants to do this may have made their prior beliefs and experiences with policing more salient to them than if this question was not included.

In addition, more subtle differences with respect to forewarning between the current studies and the studies conducted by Petty and his colleagues may also have contributed to the resistance observed towards the recruitment messages. Specifically, both Petty et al. (1981) and Petty and Cacioppo (1984b) used some variation of a cover 
story in order to disguise the overall objective of their research. For instance, Petty et al. (1981) told their subjects that they would be asked to evaluate the broadcast quality of an audiotape advocating for the institution of comprehensive exams. In the current studies, however, no such cover study was employed - participants were simply informed that they would be asked to indicate their impressions towards a message concerning policing. Thus, although the methods employed in the current research may not constitute explicit forewarning as it is often described in other research (e.g., explicitly telling participants in advance that they will be provided with a message that is going to attempt to persuade them; Petty \& Cacioppo, 1979b), it is possible that not employing deception in some manner may have enhanced the participant's resistance to persuasion and, in turn, contributed to the lack of support for hypothesized effects in the current research. Significance of the Attitude Targeted for Change

Another difference between the current research and the research undertaken by Petty and his colleagues concerns the significance of the attitude that is being targeted for change. Attempting to influence attitudes concerning a relatively trivial issue, such as whether a comprehensive exam should be instituted at a student's school, is arguably not equivalent to an attempt to influence attitudes concerning a significant life decision, such as a career choice. Certainly, the recipient of a counter-attitudinal message would be less likely to change the targeted attitude when it is seen as more central to their self-concept (i.e., as would be the case, for example, if a career is viewed as something that helps define who we are) than when the targeted attitude pertains to objects and issues that are relatively insignificant (as in the case of the comprehensive exam) (Blankenship \& Wegener, 2008). Furthermore, the vast majority of ELM studies where strong effects of message quality and peripheral cues have been found deal with these relatively trivial 
objects and issues (e.g., comprehensive exams, but also consumer views towards products such as razors, detergent, and toothpaste brands; Heesacker et al., 1983; Wheeler et al., 2005; Petty et al., 1983; Tormala et al., 2007). Thus, it is possible that the ELM may not generalize to a domain where the targeted attitude is more central to an individual's life. With that said, however, a number of studies have dealt with more consequential attitudes, including attitudes towards health-related behaviours (e.g., Jones et al., 2003; Kirby, Ureda, Rose, \& Hussey, 1998; Neimeyer, Guy, \& Metzler, 1989; Updegraff, Sherman, Luyster, \& Mann, 2007). This leaves open the possibility that the ELM can be used to influence attitudes related to important life choices.

\section{Experimental Environment}

Another difference between the current research and that conducted by Petty and his colleagues relates to the data collection method. Whereas Petty and his colleagues typically rely on traditional laboratory-based data collection methods with small groups of subjects, the current research relied on in-class testing with large groups of subjects as well as on-line data collection. As previously mentioned, elaboration likelihood is not only affected by motivational factors; it is also affected by ability factors, such as whether or not distractions are present within the experimental environment (Petty \& Cacioppo, 1986a). Given the data collection methods used in the present research, it seems likely that these types of factors played a larger role here than they did in Petty's previous studies (e.g., participants in Study 2 may have completed the on-line survey with the radio or a TV playing in the background).

As but one example of how this issue might have affected the results of the current studies, consider the role that distraction plays on levels of persuasion when presented with strong versus weak arguments. According to Petty et al. (1976), when a 
message contains strong arguments and an individual is distracted, persuasion is reduced. In contrast, when a message contains weak arguments and an individual is distracted, persuasion is enhanced. This is because distraction interrupts the thought patterns that are expected to arise in response to strong and weak arguments (i.e., favourable and unfavourable thoughts, respectively). This may help explain the lack of argument quality effects in the current research if participants across all conditions were distracted. That being said, one would expect that if participants were distracted, the effect of the peripheral cues on attitudes in the current studies would have been more evident (while distraction should decrease the effect of argument quality, it has been found to increase the effect of peripheral cues; Petty et al., 2003; Petty, Cacioppo, Strathman, \& Priester, 2005). In any case, it may be necessary in the future to conduct this research within the laboratory setting in order for strong effects to be found.

\section{Future Research Directions}

Given the preliminary nature of this investigation, there are some important avenues of research that should be pursued in the future in an attempt to come to a more definitive conclusion concerning the generalizability of the ELM to the police recruitment context. In addition to conducting future research within a laboratory-based environment, some other important avenues for future research include: (1) assessing prior views towards policing, (2) finding an optimal yet still practically useful personal relevance manipulation, and (3) refining the strong and weak message in an attempt to overcome biased processing.

\section{Assessing Prior Views Towards Policing}

Not surprisingly, the results of Study 2 indicated that initial openness to policing as a potential career option accounted for a substantial proportion of the variance in 
attitudes towards policing as a career (partial $\eta^{2}=.52$ ). Nonetheless, the hypothesized effects of argument quality and quantity were still not found when controlling for this factor, suggesting that other covariates may exist that are potentially more important for understanding attitude change in this context. In an attempt to guide the selection of a more appropriate covariate, future research should assess prior views towards policing more directly by having students complete a broad-based questionnaire measuring the nature of their beliefs about, and experience with, policing. Although general views on policing have been assessed in the past (cf. Brandl, Frank, Wooldredge, \& Watkins,1997; Brown \& Benedict, 2002; Hinds \& Murphy, 2007; Skogan, 1996; Worrall, 1999), asking participants to more explicitly list their beliefs and experiences about/with police officers and organizations may prove beneficial for developing future research plans within this context.

For instance, the results of such an assessment may indicate that it would be useful to employ a measure of the number of positive and/or negative interactions that an individual has had with police officers/agencies as a covariate in future research. Indeed, this factor may predict both the number and valence of thoughts that participants have towards police recruitment messages, and/or their attitudes towards a policing career (e.g., more positive/negative interactions would likely be related to more favourable/unfavourable thoughts and/or attitudes). Not only may the number of positive/negative interactions be a useful covariate in future research, it may prove to be a valuable screening tool for future studies, as it may only be possible to increase the attractiveness of a career in policing for those who have had mostly positive (or neutral) experiences with policing in the past. 


\section{Personal Relevance Manipulation}

Second, while the method used in the current studies to manipulate personal relevance (i.e., a Canadian vs. European scenario) was clearly ineffective, it is still possible that different ways of operationalizing personal relevance may lead to at least some effects that are predicted by the ELM. For example, using openness to policing as a career may still be a viable way of examining the impact of relevance/elaboration and future research should test this possibility with a larger sample size. ${ }^{13}$ In addition, there are a range of alternative procedures that could be tested. For instance, one potentially useful way to increase elaboration within the context of police recruitment might be to have the individual arguments in the recruitment message presented by multiple recruiters (Harkins \& Petty, 1981; Moore \& Reardon, 1987). Research has demonstrated that thinking about a message increases when it is presented by many sources rather than just one, leading to the expected argument quality effect when multiple sources are used (i.e., more persuasion for strong arguments and less persuasion for weak arguments; Harkins \& Petty, 1981). Similarly, the degree of elaboration might be manipulated by varying the personal responsibility felt by individuals (e.g., by informing some of them that they will be discussing the issue with a third party upon completion of the experiment; Petty \& Cacioppo, 1986a). Although the latter manipulation may not be as practically useful within the recruitment setting, it may be necessary to revert to such laboratory-based methods of manipulating elaboration likelihood in order to initially reveal the expected ELM effects in this attitude domain.

\footnotetext{
${ }^{13}$ Since the Study 2 analyses using openness to policing as a career as an independent variable were conducted separately for high and low relevance groups to control for this factor, sample sizes for each of the conditions were substantially smaller compared with the main analyses.
} 


\section{Refining Strong and Weak Messages}

Future research must also attempt to overcome the biased processing evident in the current research that was possibly a result of prior attitude-relevant beliefs and experiences. Although some degree of biased processing is likely inevitable in the police recruitment context, it must be possible to overcome, or at the very least minimize the impact of such biases, if the hypothesized effects are to be found. In addition to ensuring that forewarning of the message content is controlled for, another possible way to overcome such biased processing is to make the arguments contained in the strong message more persuasive than they were in the current study.

As briefly alluded to above, the argument quality manipulation used in the current research was not particularly effective when compared to past research. In other words, the cognitive response profiles of participants in the current research (across quality conditions) were somewhat different from that obtained by Petty and his colleagues. Specifically, although thoughts were more positive for strong than weak messages, they were still, on average, slightly negative in valence. This is typically not the case in other research studies (e.g., Petty \& Cacioppo, 1984b). Although an attempt was made in the pilot research to increase the positive valence of thoughts associated with the strong message (e.g., by addressing some of the common, negatively valenced thoughts about policing and attempting to refute them in the recruitment message), this was still not enough to attain the number of favourable thoughts needed to match previous ELM research. Clearly, future research needs to focus on ways to increase thought favourability scores for the strong message in order to more precisely reflect the argument quality manipulations used in past research and overcome biased processing. 
One potential way to do this is to increase the length (and detail) of the arguments themselves, as longer messages tend to be more persuasive than shorter messages (Friedrich, Fetherstonhaugh, Casey, \& Gallagher, 1996; Johnson et al., 2005; Johnson \& Eagly, 1989). Indeed, the arguments employed in the current research were substantially shorter (and less detailed) than those typically employed by Petty and his colleagues (e.g., Cacioppo et al., 1983; Petty et al., 1976; Petty et al., 1981; Petty \& Cacioppo, 1984b). For example, consider one of the strong arguments that Petty and Cacioppo (1984b) used to support the implementation of comprehensive exams:

A study by the U.S. Department of Education revealed that universities with the comprehensive exam requirement average about $32 \%$ more financial aid available to students than comparable universities without the exams. Richard Collings, Director of Financial Aid at the University of Southern California (USC) has written that since the comprehensive exam was instituted at USC five years ago, more individuals and corporations have been willing to donate money for student scholarships.

Not only are these types of arguments longer than those used in the present research, they also employ more detailed, evidence-based arguments supporting comprehensive exams - although the evidence presented in the arguments is typically fabricated. In contrast, the goal of the current research was to construct arguments that provided truthful information that could be applicable across a wide range of police organizations, and that most closely reflected how recruitment messages would be delivered in practice (e.g., shorter, to reflect the time constraints for radio and television broadcasting). While using such arguments is clearly beneficial (e.g., more practical), the approach taken in the current research made it difficult, for example, to include potentially important details, such as those included in arguments presented by Petty (e.g., salary comparisons between policing and other jobs). To achieve the desired results, 
it may be necessary for future research to use longer, more detailed arguments in order to make the recruitment message more persuasive.

Alternatively, it is possible that the police recruitment domain is so highly counter-attitudinal that it may be too difficult to increase thought favourability to the extent needed to find an effect of argument quality on attitudes. If this is the case, it may be necessary to take a different approach to influencing attitudes towards policing as a career. For example, instead of targeting attitudes per se, attitude certainty could be targeted. Indeed, research has shown that, even if attitudes do not differ in extremity across argument quality conditions, one of the effects of increasing the strength of a strong message that advocates a counter-attitudinal position is that it typically reduces the certainty with which the initial attitude is held (Rucker \& Petty, 2004; Tormala, Clarkson, \& Petty, 2006). This is because individuals often perceive their resistance (i.e., counterarguing) as being less effective when a message is strong rather than weak. Moreover, decreasing the strength of initial attitudes makes the recipient more susceptible to future persuasive attacks (Tormala et al., 2006). Decreasing the strength of participants' negative attitudes towards policing as a career may prove to be an interesting avenue of research within this domain. Overall, this may be a useful first step towards future attempts to change attitudes towards policing as a career.

\section{Conclusion}

Although the results of the current thesis did not support the extension of the ELM into the police recruitment domain, some of the differences between the current and previous research may account for these null findings. Even though some of these issues may be difficult to overcome (e.g., the reliance on prior beliefs and experiences), research showing that the ELM does successfully generalize to a vast range of contexts suggests 
that further refinement of the experimental materials and manipulations may prove to be beneficial (e.g., Andrews \& Shimp, 1990; Heesacker, 1986; Kirby et al., 1998; Neimeyer et al., 1989). Since this thesis represents the first attempt to apply the ELM within the police recruitment domain, future research is needed to address the abovementioned concerns before more definitive conclusions can be made as to the appropriateness of the ELM within this context. 


\section{References}

Aaker, J.L., \& Maheswaran, D. (1997). The effect of cultural orientation on persuasion. Journal of Consumer Research, 24, 315-328.

Abelson, R.P. (1988). Conviction. American Psychologist, 43, 267-275.

Alba, J.W., \& Marmorstein, H. (1987). The effects of frequency knowledge on consumer decision making. Journal of Consumer Research, 13, 411- 454.

Andrews, J.C., \& Shimp, T.A. (1990). Effects of involvement, argument strength, and source characteristics on central and peripheral processing of advertising. Psychology \& Marketing, 7, 195-214.

Apsler, R., \& Sears, D.O. (1968). Warning, personal involvement, and attitude change. Journal of Personality and Social Psychology, 9, 162-166.

Barber, A.E. (1998). Recruiting employees: Individual and organizational perspectives. Thousand Oaks, CA: Sage Publications.

Barden, J., \& Petty, R.E. (2008). The mere perception of elaboration creates attitude certainty: Exploring the thoughtfulness heuristic. Journal of Personality and Social Psychology, 95, 489-509.

Bassili, J.N. (1996). Meta-judgmental versus operative indexes of psychological attributes: The case of measures of attitude strength. Journal of Personality and Social Psychology, 71, 637-653.

Berger, I.E., \& Mitchell, A.A. (1989). The effect of advertising on attitude accessibility, attitude confidence, and the attitude-behavior relationship. Journal of Consumer Research, 16, 269-279.

Birnbaum, M.H. (2000). Testing critical properties of decision making on the internet. Psychological Science, 10, 399-407. 
Bizer, G.Y., Tormala, Z.L., Rucker, D.D., \& Petty, R.E. (2006). Memory-based versus on-line processing: Implications for attitude strength. Journal of Consumer Research, 16, 269-279.

Blankenship, K.L, \& Wegener, D.T. (2008). Opening the mind to close it: Considering a message in light of important values increases message processing and later resistance to change. Journal of Personality and Social Psychology, 94, 196-213.

Bohner, G., Moskowitz, G., \& Chaiken, S. (1995). The interplay of heuristic and systematic processing of social information. European Review of Social Psychology, 6, 33-68.

Brandl, S.G., Frank, J., Wooldredge, J., \& Watkins, C. (1997). On the measurement of public support for the police: A research note. Policing, 20, 473-480.

Briñol, P., Petty, R. E., \& Barden, J. (2007). Happiness versus sadness as a determinant of thought confidence in persuasion: A self-validation analysis. Journal of Personality and Social Psychology, 93, 711-727.

Briñol, P., Petty, R. E., Valle, C., Rucker, D. D., \& Becerra, A. (2007). The effects of message recipients' power before and after persuasion: A self-validation analysis. Journal of Personality and Social Psychology, 93, 1040-1053.

Brown, B., \& Benedict, W.R. (2002). Perceptions of the police: Past findings, methodological issues, conceptual issues and policy implications. Policing: An International Journal of Police Strategies \& Management, 25, 543-580.

Cacioppo, J.T., Harkins, S.G., \& Petty, R.E. (1981). The nature of attitudes and cognitive responses and their relationships to behavior. In R. Petty, T. Ostrom, \& T. Brock (Eds.), Cognitive responses in persuasion (pp. 31-54). Hillsdale, NJ: Lawrence Erlbaum Associates. 
Cacioppo, J. T., \& Petty, R. E. (1979). The effects of message repetition and position on cognitive responses, recall, and persuasion. Journal of Personality and Social Psychology, 37, 97-109.

Cacioppo, J. T., Petty, R. E., \& Morris, K. (1983). Effects of need for cognition on message evaluation, argument recall, and persuasion. Journal of Personality and Social Psychology, 45, 805-818.

Cacioppo, J.T., Petty, R.E., Kao, C., \& Rodriguez, R. (1986). Central and peripheral routes to persuasion: An individual difference perspective. Journal of Personality and Social Psychology, 51, 1032-1043.

Carlson, K.D., Connerley, \& Mecham, R.L. (2002). Recruitment evaluation: The case for assessing the quality of applicants attracted. Personnel Psychology, 55, 461-490.

Chaiken, S. (1980). Heuristic versus systematic information processing in the use of source versus message cues in persuasion. Journal of Personality and Social Psychology, 39, 7520-766.

Chaiken, S., \& Maheswaran, D. (1994). Heuristic processing can bias systematic processing: Effects of source credibility, argument ambiguity, and task importance on attitude judgment. Journal of Personality and Social Psychology, $66,460-473$.

Clark, J.K.,Wegener, D.T., \& Fabrigar, L.R. (2008). Attitudinal ambivalence and message-based persuasion: Motivated processing of proattitudinal information and avoidance of counterattitudinal information. Personality and Social Psychology Bulletin, 34, 565-577. 
Cooper, J., \& Jones, R.A. (1970). Self-esteem and consistency as determinants of anticipatory opinion change. Journal of Personality and Social Psychology, 14, $312-320$.

DeBono, K.G., \& Harnish, R.J. (1988). Source expertise, source attractiveness, and the processing of persuasive information: A functional approach. Journal of Personality and Social Psychology, 66, 460-473.

Ditto, P.H., \& Lopez, D.F. (1992). Motivated skepticism: Use of differential decision criteria for preferred and nonpreferred conclusions, Journal of Personality and Social Psychology, 63, 568-584.

Eagly, A.H., \& Carli, L.L. (1981). Sex of researchers and sex-typed communications as determinants of sex differences in influenceability: A meta-analysis of social influence studies. Psychological Bulletin, 90, 1-20.

Fabrigar, L., Petty, R. E., Smith, S. M., \& Crites, S. L. (2006). Understanding knowledge effects on attitude-behavior consistency: The role of relevance, complexity, and amount of knowledge. Journal of Personality and Social Psychology, 90, 556577.

Fazio, R.H., \& Zanna, M.P. (1978). Attitudinal qualities relating to the strength of the attitude-behaviour relationship. Journal of Experimental Social Psychology, 14, $398-408$.

Fishbein, M., \& Ajzen (1975). Belief, attitude, intention, and behavior: An introduction to theory and research. Reading, MA: Addison-Wesley.

Fouladi, R.T., McCarthy, C.J., \& Moller, N.P. (2002). Paper-and-pencil or online? Evaluating mode effects on measures of emotional functioning and attachment. Assessment, 9, 204-215. 
Friedrich, J., Fetherstonhaugh, D., Casey, S., \& Gallagher, D. (1996). Argument integration and attitude change: Suppression effects in the integration of one-sided arguments that vary in persuasiveness. Personality and Social Psychology Bulletin, 22, 179-191.

Gosling, S.D., Vazire, S., Srivastava, S., \& John, O.P. (2004). Should we trust web-based studies? A comparative analysis of six preconceptions about internet questionnaires. American Psychologist, 59, 93-104.

Greenwald, A.G. (1968). Cognitive learning, cognitive response to persuasion, and attitude change. In A.G. Greenwald, T.C. Brock, \& T.M. Ostrom (Eds.), Psychological foundations of attitudes (pp.147-170). New York, NY: Academic Press.

Gross, S., Holtz., R., \& Miller, N. (1995). Attitude certainty. In R.E. Petty \& J.A. Krosnick (Eds.), Attitude strength: Antecedents and consequences (pp. 215-245). Mahwah, NJ: Lawrence Erlbaum Associates.

Harkins, S.G., \& Petty, R.E. (1981). The effects of source magnification cognitive effort on attitudes: An information processing view. Journal of Personality and Social Psychology, 40, 401-413.

Haugtvedt, C.P., \& Petty, R.E. (1989). Need for cognition and attitude persistence. Advances in Consumer Research, 16, 33-36.

Haugtvedt, C. P., \& Petty, R. E. (1992). Personality and persuasion: Need for cognition moderates the persistence and resistance of attitude changes. Journal of Personality and Social Psychology, 63, 308-319.

Hay Group (2007, October). A national diagnostic on human resources in policing. Ottawa, ON: Hay Group. 
Heesacker, M., Petty, R. E., \& Cacioppo, J. T. (1983). Field dependence and attitude change: Source credibility can alter persuasion by affecting message-relevant thinking. Journal of Personality, 51, 653-666.

Hinds, L., \& Murphy, K. (2007). Public satisfaction with police: Using procedural justice to improve police legitimacy. Australian and New Zealand Journal of Criminology, 40, 27-42.

HRDC Steering Committee (2000). Strategic human resources analysis of public policing in Canada. Ottawa, ON: Police Sector Council.

Insko, C.A., Lind, A.E., \& LaTour, S. (1976). Persuasion, recall, and thoughts. Representative Research in Social Psychology, 7, 66-78.

Johnson, B.T., \& Eagly, A.H. (1989). Effects of involvement on persuasion: A metaanalysis. Psychological Bulletin, 106, 290-314.

Johnson, H.H., \& Scileppi, J.A. (1969). Effects of ego-involvement conditions on attitude change to high and low credibility communicators. Journal of Personality and Social Psychology, 13, 31-36.

Jones, R. (2004). Recruiting women. The Police Chief, 71. Retrieved October 2, 2008, from http://policechiefmagazine.org/magazine/index.cfm?fuseaction=display _arch\&article_id $=274 \&$ issue_id $=42004$

Jones, D.A., Shultz, J.W., \& Chapman, D.S. (2006). Recruiting through job advertisements: The effects of cognitive elaboration on decision making. International Journal of Selection and Assessment, 14, 167-179.

Jones, L.W., Sinclair, R.C., \& Courneya, K.S. (2003). The effects of source credibility and message framing on exercise intentions, behaviors, and attitudes: An 
integration of the elaboration likelihood model and prospect theory. Journal of Applied Social Psychology, 33, 179-196.

Kiesler, C.A., Collins, B., \& Miller, N. (1969). Attitude change: A critical analysis of theoretical approaches. New York, NY: Wiley.

Kirby, S.D., Ureda, J.R., Rose, R.L., \& Hussey, J. (1998). Peripheral cues and involvement level: Influences on acceptance of a mammography message. Journal of Health Communication, 3, 119-135.

Krantz., J.H., \& Dalal, R. (2000). Validity of web-based psychological research. In M.H. Birnbaum (Ed.), Psychological Experiments on the Internet, (pp. 35-60). San Diego, CA: Academic Press.

Krosnick, J. A., \& Petty, R. E. (1995). Attitude strength: An overview. In R. E. Petty \& J. A. Krosnick (Eds.), Attitude strength: Antecedents and consequences (pp. 1-24). Mahwah, NJ: Lawrence Erlbaum Associates.

Krosnick, J.A., \& Schuman, H. (1988). Attitude intensity, importance, and certainty and susceptibility to response effects. Journal of Personality and Social Psychology, $54,940-952$.

Kruglanski, A. W., \& Thompson, E. P. (1999). Persuasion by a single route: A view from the unimodel. Psychological Inquiry, 10, 83-109.

Landis, J. R. \& Koch, G. G. (1977). The measurement of observer agreement for categorical data. Biometrics, 33, 159-174.

MacKinnon, D.P., Krull, J.L., \& Lockwood, C.M. (2000). Equivalence of the mediation, confounding and suppression effects. Prevention Science, 1, 173-181. 
Martel, L., Caron-Malenfant, E., Vezina, S., \& Belanger, A. (2007). Labour force projections for Canada, 2006-2031. Canadian Economic Observer (no. 11-010). Ottawa, ON : Statistics Canada.

McKeever, J., \& Kranda, A. (2006). Best practices guide: Recruitment and retention of qualified police personnel. Alexandria, VA: International Association of Chiefs of Police.

Michaels, E., Handfield-Jones, H., \& Axelrod, B. (2001). The war for talent. Boston, MA: Harvard Business School Press.

Moore, D.L., \& Reardon, R. (1987). Source magnification: The role of multiple sources in processing of advertising appeals. Journal of Marketing Research, 24, 412-417.

Myers, A. (2006). The police recruitment dilemma, Police Journal, 87, 18-19.

Neimeyer, G.J., Guy, J., \& Metzler, A. (1989). Changing attitudes regarding the treatment of disordered eating: An application of the elaboration likelihood model. Journal of Social and Clinical Psychology, 8, 70-86.

Neimeyer, G.J., MacNair, R., Metzler, A.E., \& Courchaine, K. (1991). Changing personal beliefs: Effects of forewarning, argument quality, prior bias, and personal exploration. Journal of Social and Clinical Psychology, 10, 1-20.

Norusis, M. J. (2006) SPSS 15.0 guide to data analysis. Upper Saddle River, NJ: Prentice Hall.

Orrick, D.W. (2008). Recruitment, retention, and turnover of police personnel. Springfield, IL: Charles C. Thomas Publisher, Ltd.

Petrocelli, J.V., Tormala, Z.L., \& Rucker, D.D. (2007). Unpacking attitude certainty: Attitude clarity and attitude correctness. Journal of Personality and Social Psychology, 92, 30-41. 
Petty, R. E. (1995). Creating strong attitudes: Two routes to persuasion. In T.E. Backer, S.L. David, \& G. Soucey (Eds.), Reviewing the behavioral science knowledge base on technology transfer (pp. 209-224). Rockville, MD: National Institute on Drug Abuse.

Petty, R.E., Baker, S., \& Gleicher, F. (1991). Attitudes and drug abuse prevention: Implications of the Elaboration Likelihood Model of persuasion. In L. Donohew, H. E. Sypher \& W. J. Bukoski (Eds.), Persuasive communication and drug abuse prevention (pp. 71-90). Hillsdale, NJ: Lawrence Erlbaum Associates.

Petty, R. E., \& Briñol, P. (2002). Attitude change: The Elaboration Likelihood Model. In G. Bartels \& W. Nelissen (Eds.), Marketing for sustainability: Towards transactional policy making (pp. 176-190). Amsterdam, NL: IOS Press.

Petty, R. E., Briñol, P., \& Priester, J. R. (2009). Mass media attitude change: Implications of the Elaboration Likelihood Model of persuasion. In J. Bryant \& M. B. Oliver (Eds.), Media effects: Advances in theory and research (3rd ed., pp. 125-164). New York, NY: Routledge.

Petty, R. E., Briñol, P., \& Tormala, Z. L. (2002). Thought confidence as a determinant of persuasion: The self-validation hypothesis. Journal of Personality and Social Psychology, 82, 722-741.

Petty, R. E., \& Cacioppo, J. T. (1977). Forewarning, cognitive responding, and resistance to persuasion. Journal of Personality and Social Psychology, 35, 645-655.

Petty, R. E., \& Cacioppo, J. T. (1979a). Issue involvement can increase or decrease persuasion by enhancing message-relevant cognitive responses. Journal of Personality and Social Psychology, 37, 1915-1926. 
Petty, R. E., \& Cacioppo, J. T. (1979b). Effects of forewarning of persuasive intent and involvement on cognitive responses and persuasion. Personality and Social Psychology Bulletin, 5, 173-176.

Petty, R. E., Cacioppo, J. T. (1984a). Source factors and the elaboration likelihood model of persuasion. Advances in Consumer Research, 11, 668-672.

Petty, R. E., \& Cacioppo, J. T. (1984b). The effects of involvement on response to argument quantity and quality: Central and peripheral routes to persuasion. Journal of Personality and Social Psychology, 46, 69-81.

Petty, R.E., \& Cacioppo, J.T. (1986a). Communication and persuasion: Central and peripheral routes to attitude change. New York, NY: Springer-Verlag.

Petty, R.E., \& Cacioppo, J.T. (1986b). The elaboration likelihood model of persuasion. Advances in Experimental Social Psychology, 19, 123-205.

Petty, R. E., Cacioppo, J. T., \& Goldman, R. (1981). Personal involvement as a determinant of argument- based persuasion. Journal of Personality and Social Psychology, 41, 847-855.

Petty, R. E., Cacioppo, J. T., \& Haugtvedt, C. (1992). Involvement and persuasion: An appreciative look at the Sherifs' contribution to the study of self-relevance and attitude change. In D. Granberg \& G. Sarup (Eds.), Social judgment and intergroup relations: Essays in honor of Muzafer Sherif (pp. 147-174). New York, NY: Springer.

Petty, R. E., Cacioppo, J. T., \& Schumann, D. (1983). Central and peripheral routes to advertising effectiveness: The moderating role of involvement. Journal of Consumer Research, 10, 135-146. 
Petty, R.E., Cacioppo, J.T., Strathman, A.J., \& Priester, J.R. (2005). To think or not to think: Exploring two routes to persuasion (pp. 81-116). In T.C. Brock \& M.C. Green (Eds.), Persuasion: Psychological insights and perspectives. $2^{\text {nd }}$ ed. Thousand Oaks, CA: Sage Publications.

Petty, R. E., Gleicher, F. H., \& Jarvis, B. (1993). Persuasion theory and AIDS prevention. In J. B. Pryor \& G. Reeder (Eds.), The social psychology of HIV infection (pp. 155-182). Hillsdale, NJ: Erlbaum.

Petty, R. E., Haugtvedt, C., \& Smith, S. M. (1995). Elaboration as a determinant of attitude strength: Creating attitudes that are persistent, resistant, and predictive of behavior. In R. E. Petty \& J. A. Krosnick (Eds.), Attitude strength: Antecedents and consequences (pp. 93-130). Mahwah, NJ: Lawrence Erlbaum Associates.

Petty, R. E., Heesacker, M., \& Hughes, J. (1997). Implications of persuasion theory for school psychology. Journal of School Psychology, 35, 107-136.

Petty, R. E., Rucker, D., Bizer, G., \& Cacioppo, J.T. (2004). The elaboration likelihood model of persuasion. In J. S. Seiter \& G. H. Gass (Eds.), Perspectives on persuasion, social influence and compliance gaining (pp. 65-89). Boston, MA: Allyn \& Bacon.

Petty, R.E., Tormala, Z.L., Hawkins, Z.L., \& Wegener, D.T. (2001). Motivation to think about order effects in persuasion: The moderating role of chunking. Personality and Social Psychology Bulletin, 27, 332-344.

Petty, R.E., Unnava, R., \& Strathman, A., (1991). Theories of attitude change. In T. S. Robertson \& H. H. Kassarjian (Eds.), Handbook of consumer behavior (pp. 241280). Englewood Cliffs, NJ: Prentice-Hall. 
Petty, R. E., \& Wegener, D. T. (1999). The Elaboration Likelihood Model: Current status and controversies. In S. Chaiken \& Y. Trope (Eds.), Dual process theories in social psychology (pp. 41-72). New York, NY: Guilford Press.

Petty, R. E., Wegener, D. T., \& Fabrigar, L. R. (1997). Attitude and attitude change. Annual Review of Psychology, 48, 609-647.

Petty, R. E., Wegener, D. T., Fabrigar, L. R., Priester, J. R., \& Cacioppo, J. T. (1993). Conceptual and methodological issues in the Elaboration Likelihood Model of persuasion: A reply to the Michigan State critics. Communication Theory, 3, 336362.

Petty, R.E., Wells, G.L., \& Brock, T.C. (1976). Distraction can enhance or reduce yielding to propaganda: Thought disruption versus effort justification. Journal of Personality and Social Psychology, 34, 874-884.

Petty, R. E., Wheeler, S, C., \& Bizer, G.Y. (1999). Is there one persuasion process or more? Lumping versus splitting in attitude change theories. Psychological Inquiry, 10, 156-163.

Petty, R.E., Wheeler, S.C., \& Bizer, G.Y. (2000). Matching effects in persuasion: An elaboration likelihood analysis (pp.133-162). In G. Maio \& J. Olson (Eds.), Why we evaluate: Functions of attitudes. Mahwah, NJ: Lawrence Erlbaum Associates.

Petty, R. E., Wheeler, S. C., \& Tormala, Z. L. (2003). Persuasion and attitude change. In T. Millon \& M. J. Lerner (Eds.), Handbook of psychology: Volume 5: Personality and social psychology (pp. 353-382). Hoboken, NJ: John Wiley \& Sons.

Pieters, R.G.M., \& Verplanken, B. (1995). Intention-behavior consistency: Effects of consideration set size, involvement, and need for cognition. European Journal of Social Psychology, 25, 531-543. 
Police Sector Council (2005). Results from Ipsos-Reid's reconnecting government with youth 2005. Ottawa, ON: Police Sector Council.

Police Sector Council (2006). Policing environment 2005: Update of the 2000 sector study and implications for HR planning and management today and into the future. Ottawa, ON: Police Sector Council.

Police Sector Council (2007). Research update: Ipsos-Reid's reconnecting with youth 2007, and views on policing 2007 (HR diagnostics). Ottawa, ON: Police Sector Council.

Priester, J. R., \& Petty, R. E. (2003). The influence of spokesperson trustworthiness on message elaboration, attitude strength, and advertising effectiveness. Journal of Consumer Psychology, 13, 408-421.

Public Safety Canada (2008). Police Officers Recruitment Fund - Operating Principles. Retrieved October 27, 2008 from http://www.publicsafety.gc.ca/media/nr/2008/ nr20080314-2-eng.aspx

Rucker, D.D., \& Petty, R.E. (2004). When resistance is futile: Consequences of failed counterarguing for attitude certainty. Journal of Personality and Social Psychology, 86, 219-235.

Rucker, D.D., \& Petty, R.E. (2006). Increasing the effectiveness of communications to consumers: Recommendations based on elaboration likelihood and attitude certainty. Journal of Public Policy and Marketing, 25, 39-52.

Rucker, D. D., Petty, R. E., \& Priester, J. R. (2007). Understanding advertising effectiveness from a psychological perspective: The importance of attitudes and attitude strength. In G. J. Tellis \& T. Ambler (Eds.), The handbook of advertising (pp. 73-88). Thousand Oaks, CA: Sage Publications. 
Rucker, D.D., Petty, R.E., \& Briñol, P. (2008). What's in a frame anyway?: A metacognitive analysis of the impact of one versus two sided message framing on attitude certainty. Journal of Consumer Psychology, 18, 137-149.

Senior, C., Phillips, M.L., Barnes, J., \& David, A.S. (1999). An investigation in the perception of dominance from schematic faces: A study using the World-Wide Web. Behavior Research Methods, Instruments, \& Computers, 31, 341-346.

Sherif, M., \& Hovland, C.I. (1961). Social judgment: Assimilation and contrast effects in communication and attitude change. New Haven, CT: Yale University Press.

Shrout, P.E., \& Bolger, N. (2002). Mediation in experimental and nonexperimental studies: New procedures and recommendations. Psychological Methods, 7, 422445.

Skogan, W.G. (1996). The police and public opinion in britain. American Behavioral Scientist, 39, 421-432.

Tabachnick, B.G., \& Fidell, L.S. (2007a).Using multivariate statistics (5th Ed.). Boston, MA: Pearson.

Tabachnick, B.G., \& Fidell, L.S. (2007b).Experimental design using ANOVA. Belmont, CA: Thomson Higher Education.

Taylor, B., Kubu, B., Fridell, L., Rees, C., Jordan, T., \& Cheney, J. (2005). Cop crunch: Identifying strategies for dealing with the recruiting and hiring crisis in law enforcement. Washington, DC: The Police Executive Research Forum.

Tomsen, C.J., Borgida, E., \& Lavine, H. (1995). The causes and consequences of personal involvement. In R.E. Petty \& J.A. Krosnick (Eds.), Attitude strength: Antecedents and consequences (pp.191-214). Mahwah, NJ: Lawrence Erlbaum Associates. 
Tormala, Z. L., Briñol, P., \& Petty, R. E. (2006). When credibility attacks: The reverse impact of source credibility on persuasion. Journal of Experimental Social Psychology, 42, 684-691.

Tormala, Z. L., Briñol, P., \& Petty, R. E. (2007). Multiple roles for source credibility under high elaboration: It's all in the timing. Social Cognition, 25, 536-552.

Tormala, Z.L., Clarkson, J.J., \& Petty, R.E. (2006). Resisting persuasion by the skin of one's teeth: The hidden success of resisted persuasive messages. Journal of Personality and Social Psychology, 91, 423-435.

Tormala, Z.L., \& Petty, R.E. (2002). What doesn't kill me makes me stronger: The effects of resisting persuasion on attitude certainty. Journal of Personality and Social Psychology, 83, 1298-1313.

Tormala, Z.L., \& Petty, R.E. (2004a). Source credibility and attitude certainty: A metacognitive analysis of resistance to persuasion. Journal of Consumer Psychology, 14, 427-442.

Tormala, Z.L., \& Petty, R.E. (2004b). Resistance to persuasion and attitude certainty: The moderating role of elaboration. Personality and Social Psychology Bulletin, 30, 1446-1457.

Tormala, Z.L., \& Petty, R.E. (2007). Contextual contrast and perceived knowledge: Exploring the implications for persuasion. Journal of Experimental Social Psychology, 43, 17-30.

Tormala, Z.L., \& Rucker, D.D. (2007). Attitude certainty: A review of past findings and emerging perspectives. Social and Personality Psychology Compass, 1, 469-492. 
Updegraff, J.A., Sherman, D.K., Luyster, F.S., \& Mann, T.L. (2007). The effects of message quality and congruency on perceptions of tailored health communications. Journal of Experimental Social Psychology, 43, 249-257.

Visser, P.S., Bizer, G.Y., \& Krosnick, J.A. (2006). Exploring the latent structure of strength-related attitude attributes. In M.P. Zanna (Ed.), Advances in experimental social psychology: Volume 38 (pp. 1-60). New York, NY: Academic Press.

Wang, M., \& Chen, Y. (2006). Age differences in attitude change: Influences of cognitive resources and motivation on responses to argument quantity. Psychology and Aging, 21, 581-589.

Wheeler, S.C., Petty, R.E., \& Bizer, G.Y. (2005). Self-schema matching and attitude change: Situational and dispositional determinants of message elaboration. Journal of Consumer Research, 31, 787-797.

Whetstone, T.S., Reed, J.C., \& Turner, P.C. (2006). Recruiting: A comparative study of the recruiting practices of state police agencies. International Journal of Police Science \& Management, 8, 52-66.

White, M.D., \& Escobar, G. (2008). Making good cops in the twenty-first century: Emerging issues for the effective recruitment, selection and training of police in the United Stated and abroad. Law, Computers, \& Technology, 22, 119-134.

Wood., W. (1982). Retrieval of attitude-relevant information from memory: Effects on susceptibility to persuasion and on intrinsic motivation. Journal of Personality and Social Psychology, 42, 798-810.

Wood, W., Rhodes, N., \& Biek, M. (1995). Working knowledge and attitude strength: An information processing analysis. In R.E. Petty \& J.A. Krosnick (Eds.). Attitude 
strength: Antecendents and consequences (pp. 283-313). Mahwah, NJ: Lawrence Erlbaum Associates.

Worrall, J.L. (1999). Public perceptions of police efficacy and image: The "fuzziness" of support for the police. American Journal of Criminal Justice, 24, 47-66.

Woska, W.J. (2006). Police officer recruitment: A public-sector crisis. The Police Chief, 73. Retrieved October 2, 2008, from http://policechiefmagazine.org/magazine/ index.cfm?fuseaction=display_arch\&article_id=1020\&issue_id=102006 


\section{Appendix A \\ Informed Consent Form (Pilot Study Stage 1)}

The purpose of an informed consent form is to ensure that you understand the purpose of the study as well as the nature of your involvement. This form is to provide you with enough information that you are able to determine whether or not you wish to participate in the study.

Research title: Perceptions of Policing as a Career

Research personnel: For questions or concerns about this study, please contact Dr. Craig Bennell (Associate Professor, Department of Psychology, Carleton University, 613-5202600 ext. 1769) or Rebecca Mugford (Principal Investigator, Carleton University, 613520-2600 ext. 1728, rmugford@ @onnect.carleton.ca). Should you have any ethical concerns about this study, please contact Dr. Avi Parush (Chair, Carleton University Ethics Committee for Psychological Research, Department of Psychology, Carleton University, avi_parush@ carleton.ca, 613-520-2600 ext. 6026) or Dr. Janet Mantler (Chair, Department of Psychology, Carleton University, psychchair@carleton.ca, 613520-2600 ext. 4173).

Purpose: The purpose of this study is to determine the perceived persuasiveness of a number of arguments that can be constructed to support a career in policing.

Task requirements: In this study, you will be provided with a short questionnaire where you will be asked to rate various arguments supporting a policing career in terms of whether you believe the arguments are persuasive or unpersuasive.

Duration and location: This study will take approximately 10 minutes to complete in class.

Anxiety, pain or embarrassment: There are no known risks of you experiencing any anxiety, pain, or embarrassment while participating in this study.

Anonymity and confidentiality: Your participation in the study is anonymous and confidential. After you sign this informed consent form, you will be given an ID number that will not be associated with your name, and the informed consent form will be detached from the questionnaire. The data obtained from this study will be used in aggregate (group) form and only by researchers associated with this project for the purpose of research publications, conference presentations, and/or teaching material.

Right to withdraw: Your participation in this study is entirely voluntary and you will not be provided with any compensation (e.g., extra credit) for your participation. At any point during the study, you have the right to not answer any questions or to withdraw with no penalty whatsoever. Whether or not you decide to participate in this research will have no impact on your course performance. Participation, lack of participation or withdrawal from the study will not be disclosed to the course instructor, and the instructor will not be present in class when this study is being conducted. 
Signatures: I have read the above description of the study, and understand that the data in this study will be used in research publications or for teaching purposes. I agree to participate in this study.

Participant name (print):

Date:

Participant signature :

Witness signature: 
Appendix B

Questionnaire (Pilot Study Stage 1)

Police agencies across Canada are attempting to modernize their recruitment efforts in order to attract more applicants. As a first step in this process, they must determine what potential applicants think about various arguments that can be provided in support of a career in policing. Below are a variety of arguments that support a policing career. Your task is to read each argument carefully and rate them on their persuasiveness (i.e., is this argument something that would be appealing to job-seeking individuals and thus be likely to attract applicants to the policing sector?).

1. Police agencies across Canada offer a new recruit a competitive starting salary averaging approximately 40,000 per year. This starting salary is comparable to that offered by other employment sectors, including education and healthcare.

Not Persuasive

At All

1

$2+3$

$\begin{array}{lllll}4 & 5 & 6 & 7 & 8\end{array}$

Highly

2. By pursuing a career in policing, your employment atmosphere will emphasize the importance of teamwork. That is, police organizations value the importance of making decisions in which each member of the force is involved.

Not Persuasive At All

$1 \quad 2 \quad 3 \quad 4$

56

$7 \quad 8$

Highly

3. By becoming a police officer, you will be provided with countless opportunities to enforce the law in a variety of situations, including traffic violations, assaults, and drug offences.

Not Persuasive At All

$1 \quad 2 \quad 3$

4

56

$7 \quad 8$

Highly

4. By pursuing a career in policing, you will be choosing one of few careers available to you where your number one goal is to always be of direct service to the general public.

Not Persuasive At All

1

2

2

4

5

5

6

7

8

Highly

9 Persuasive 
5. By pursuing a career in the policing field, you will have countless opportunities to help victims of many different crimes, including domestic disturbances, and sexual assaults.

Not Persuasive At All

12

3.4

45

6

$7 \quad 8$

Highly

899 Persuasive

6. By becoming a police officer, you will not just have an ordinary desk job like so many careers out there. Instead you will have a job where the work is exciting and changes everyday.

Not Persuasive

At All

$\begin{array}{llll}1 & 2 & 3 & 4\end{array}$

4

56

$\begin{array}{ll}7 & 8\end{array}$

Highly

7. Policing nowadays is strongly community-oriented. As a police officer, you will have many opportunities to better your community by making it a safer place to live.

Not Persuasive

$\begin{array}{lllllllllll}\text { At All } & 1 & 2 & 3 & 4 & 5 & 6 & 7 & 8 & 9 & \text { Persuasive }\end{array}$

8. By pursuing a career in policing you will be able to fight crime and put the bad guys behind bars.

Not Persuasive

$\begin{array}{lllllllllll}\text { At All } & 1 & 2 & 3 & 4 & 5 & 6 & 7 & 8 & 9 & \text { Persuasive }\end{array}$

9. Once you become a police officer, your job includes having possession of a weapon at all times when on duty.

Not Persuasive

$\begin{array}{lllllllllll}\text { At All } & 1 & 2 & 3 & 4 & 5 & 6 & 7 & 8 & 9 & \text { Persuasive }\end{array}$

10. A career in policing offers you a job that holds with it much employment security. Once you are part of a force, you can rest assured that you have a job that will always be in demand, and do not have to fear being laid off like other jobs out there.

Not Persuasive

$\begin{array}{lllllllllll}\text { At All } & 1 & 2 & 3 & 4 & 5 & 6 & 7 & 8 & 9 & \text { Persuasive }\end{array}$

11. A policing career comes with some of the best medical and dental coverage available for both you and your entire family.

Not Persuasive

At All

$\begin{array}{llll}1 & 2 & 3 & 4\end{array}$

5

Highly

89 Persuasive 
12. Policing is one of the few careers where you will be able to easily retire at a younger age. Not only will you be able to retire younger, but you will be able to do so without any cut in your retirement pension.

Not Persuasive

At All

$\begin{array}{llll}1 & 2 & 3 & 4\end{array}$

56

$7 \quad 8$

Highly

13. By pursuing a career in policing, you will receive one of the best retirement pensions plans available to public sector employees.

Not Persuasive

$\begin{array}{lllllllllll}\text { At All } & 1 & 2 & 3 & 4 & 5 & 6 & 7 & 8 & 9 & \text { Persuasive }\end{array}$

14. By pursuing a career as a police officer, you will be part of a profession which carries with it much prestige and honour.

Not Persuasive

At All

15. As a police officer, you will be provided with many opportunities for advancement in terms of rank and salary. For instance, most agencies will provide you with pay increases at 10,15 and 20 years on the job.

Not Persuasive

$\begin{array}{lllllllllll}\text { At All } & 1 & 2 & 3 & 4 & 5 & 6 & 7 & 8 & 9 & \text { Persuasive }\end{array}$

16. Police organizations value your education. Not only do many police agencies pay for your training once you are hired, but they offer many opportunities for you to continue your education once employed.

Not Persuasive

$\begin{array}{lllllllllll}\text { At All } & 1 & 2 & 3 & 4 & 5 & 6 & 7 & 8 & 9 & \text { Persuasive }\end{array}$

17. Policing nowadays is becoming highly technical and sophisticated. By becoming a police officer, you will have the opportunity to learn about many new state-of-the-art investigative technologies.

Not Persuasive

$\begin{array}{lllllllllll}\text { At All } & 1 & 2 & 3 & 4 & 5 & 6 & 7 & 8 & 9 & \text { Persuasive }\end{array}$

18. By pursuing a career as a police officer, you will have a job that carries with it much status. You will have the ability to exercise your power and authority over others.

Not Persuasive

At All

1

1

2

34

56

$\begin{array}{lll}7 & 8 & 9\end{array}$

Highly

Persuasive 
19. By pursuing a career in policing, you will be provided with many opportunities to create new and lasting friendships with your colleagues.

Not Persuasive

$\begin{array}{lllllllllll}\text { At All } & 1 & 2 & 3 & 4 & 5 & 6 & 7 & 8 & 9 & \text { Persuasive }\end{array}$

20. By becoming a police officer, you will have a job that allows you to travel to many parts of the country.

Not Persuasive

$\begin{array}{lllllllllll}\text { At All } & 1 & 2 & 3 & 4 & 5 & 6 & 7 & 8 & 9 & \text { Persuasive }\end{array}$

21. Police organizations are an equal opportunity employer. By becoming a police officer, you will be part of a workforce that is actively promoting gender equality.

Not Persuasive

$\begin{array}{lllllllllll}\text { At All } & 1 & 2 & 3 & 4 & 5 & 6 & 7 & 8 & 9 & \text { Persuasive }\end{array}$

22. Police organizations are an equal opportunity employer. By becoming a police officer, you will be part of a workforce that is actively promoting and highly values ethnic diversity.

Not Persuasive

$\begin{array}{lllllllllll}\text { At All } & 1 & 2 & 3 & 4 & 5 & 6 & 7 & 8 & 9 & \text { Persuasive }\end{array}$

23. By becoming a police officer, you will be selecting a job where you are highly valued in your community.

Not Persuasive

$\begin{array}{lllllllllll}\text { At All } & 1 & 2 & 3 & 4 & 5 & 6 & 7 & 8 & 9 & \text { Persuasive }\end{array}$

24. Instead of being constrained to the typical 9 to 5 work schedule, you will have the opportunity to work at varying times, allowing for flexibility in your personal schedule so that you can better balance between your work and personal life.

Not Persuasive

$\begin{array}{lllllllllll}\text { At All } & 1 & 2 & 3 & 4 & 5 & 6 & 7 & 8 & 9 & \text { Persuasive }\end{array}$

25. By becoming a police officer, you will be required to wear a uniform while at work, and thus will not have to worry about shopping for work attire. The money that you spend on work clothes can go towards other things that are more important to you.

Not Persuasive

At All

12

34

$5 \quad 6$

7

89

Highly

Persuasive 
26. By becoming a police officer, many agencies will grant you free access to their stateof-the-art fitness centres, which means you will not need to buy an expensive gym pass or equipment for your home.

Not Persuasive

At All

1

2

27. By becoming a police officer, you will become part of a workforce that encourages and highly values employee input in policy development such as shift configurations, uniform design, and community policing strategies.

Not Persuasive

At All

(1)

$1-2$

28. By pursuing a career in policing, you will become part of a workforce that acknowledges the importance of family life.

Not Persuasive

$\begin{array}{lllllllllll}\text { At All } & 1 & 2 & 3 & 4 & 5 & 6 & 7 & 8 & 9 & \text { Persuasive }\end{array}$

29. By becoming a police officer, you will have a job that allows you to become a positive role model for young children.

Not Persuasive

$\begin{array}{lllllllllll}\text { At All } & 1 & 2 & 3 & 4 & 5 & 6 & 7 & 8 & 9 & \text { Persuasive }\end{array}$

30. From traffic, air support, underwater search, and drugs and firearms, you will be exposed to many different career paths as a police officer.

Not Persuasive

$\begin{array}{lllllllllll}\text { At All } & 1 & 2 & 3 & 4 & 5 & 6 & 7 & 8 & 9 & \text { Persuasive }\end{array}$

31. To emphasize the importance of teamwork, physical fitness, and camaraderie, many agencies have a variety of sports teams and extra-curricular activities for you to get involved in.

Not Persuasive

$\begin{array}{lllllllllll}\text { At All } & 1 & 2 & 3 & 4 & 5 & 6 & 7 & 8 & 9 & \text { Persuasive }\end{array}$

32. You will have a career that is unique. It is unlike any other career in that you will face new and challenging situations daily.

Not Persuasive

At All

1

$\sqrt{2}$

23

4

5

5

6

$\begin{array}{lll}7 & 8 & 9\end{array}$

Highly

Persuasive 
33. To be eligible for a career in policing, most agencies only require a high school education. In other words, you do not need to have perfect grades or be highly educated to become a police officer.

Not Persuasive

At All

$\begin{array}{llll}1 & 2 & 3 & 4\end{array}$

56

$\begin{array}{lll}7 & 8 & 9\end{array}$

Highly

34. By becoming a police officer, you will win the respect of your friends and family members. You will be taken seriously if you pursue a career that is highly respected.

Not Persuasive

$\begin{array}{lllllllllll}\text { At All } & 1 & 2 & 3 & 4 & 5 & 6 & 7 & 8 & 9 & \text { Persuasive }\end{array}$

35. By becoming a police officer, you will become part of a workforce that holds high moral and ethical standards.

Not Persuasive

$\begin{array}{lllllllllll}\text { At All } & 1 & 2 & 3 & 4 & 5 & 6 & 7 & 8 & 9 & \text { Persuasive }\end{array}$

36. By becoming a police officer, you will have a job that makes it easy for you to stay active and in shape. This can help you ward off potential health problems when you get older.

Not Persuasive

At All

123

$4 \quad 5 \quad 6$

$7 \quad 8$

Highly

37. A career in policing offers many opportunities to work overtime. This allows you to make extra money when you want it.

Not Persuasive

$\begin{array}{lllllllllll}\text { At All } & 1 & 2 & 3 & 4 & 5 & 6 & 7 & 8 & 9 & \text { Persuasive }\end{array}$

38. A career in policing offers you many ways to increase your income. For instance, you can apply for a job up North for which you can receive isolation pay if you are stationed there.

Not Persuasive

$\begin{array}{lllllllllll}\text { At All } & 1 & 2 & 3 & 4 & 5 & 6 & 7 & 8 & 9 & \text { Persuasive }\end{array}$

39. A career in policing will provide you with a lot of vacation time. Not only will it provide you with much vacation time, but this time will increase as your time on the job increases.

Not Persuasive

$\begin{array}{lllllllllll}\text { At All } & 1 & 2 & 3 & 4 & 5 & 6 & 7 & 8 & 9 & \text { Persuasive }\end{array}$


40. By pursuing a career in policing you will undergo high quality training that allows you to better deal with situations where you or your family is in danger (e.g., if someone breaks into your house).

Not Persuasive

At All

1

2

4

$5 \quad 6$

7

7

8

Highly

9 Persuasive 
Appendix C

Demographics Questionnaire

1. Age :

2. Gender:

Male

Female

3. Do you consider yourself to be a member of a visible minority?

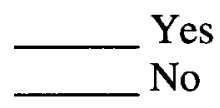

4. If yes, please check which group(s) to which you belong:

Black (e.g., African)

Chinese

South Asian (e.g., Pakistani)

Other Pacific Islanders (e.g., Fijian)

Filipino

South East Asian (e.g., Vietnamese)

West Asians \& Arabs (e.g., Iranian)

Korean

Amer-Indian (e.g., South/Central American Aboriginal)

Person of mixed race/colour

Japanese

Other, please specify:

5. Please identify the school that you are currently attending:

6. Please identify the degree or diploma program in which you are currently enrolled (e.g., B.A. in Criminology, law clerk program, etc.):

7. Current level of study:

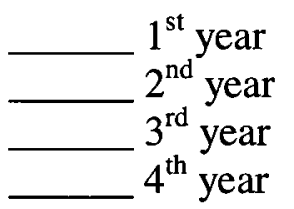

Other (please specify): 
8. Do you have any current or previous law enforcement experience?

Yes
No

9. If yes, please describe your law enforcement experience:

Department served

Time served

Rank within force

Reason for leaving

10. Do you have any family members with any current or previous law enforcement experience?

Yes, please specify (e.g., father, sister, cousin, etc.):

No 


\section{Appendix D \\ Debriefing Form (Pilot Study Stage 1)}

Thank you for your participation in this study. However, before you go, we would like to take a moment to tell you a bit more about our study and why we are interested in examining these sorts of issues.

\section{Why is this research important?}

In the near future, police agencies across Canada will likely experience a substantial shortage in officers. The Police Sector Council (PSC) of Canada has estimated that the annual number of recruits would need to double in 2010 just to maintain the current strength of police officers nation-wide (PSC, 2006). This shortage is likely due to a combination of many factors, including the fact that many employees are retiring, fewer applications are being processed, and that Canadian youth seem less and less interested in a career in the policing field. Indeed, in a recent survey, human resource employees across Canadian police forces indicated that potentially 55 to 75 percent of their senior positions will be vacant within the next five years (HayGroup, 2007). Moreover, only 36 percent of youths in a 2005 national survey indicated that they would even consider a career in law enforcement (PSC, 2005).

\section{What are we trying to learn through this research?}

This study is an initial step towards examining ways in which police agencies can effectively attract more applicants. After we have collected enough responses for this phase of the study, we will construct different recruitment messages on the basis of your ratings. Overall, we believe that arguments that you rate as the most persuasive will foster more positive attitudes towards policing as a career. In contrast, we believe that the arguments you rate as least persuasive will foster less positive attitudes towards policing as a career. Later studies will be conducted to determine the actual effect of these different messages on attitudes towards policing as a career option.

\section{What if I'm interested in the findings of this research?}

For those of you who are interested in the findings of this researcher, please contact the primary researcher, Rebecca Mugford (rmugford@connect.carleton.ca), who can then send you an electronic copy of her final thesis upon completion.

\section{What if I have questions later?}

Once again, we would like to thank you for your participation in this study. As well, we would like to remind you that your information will remain confidential. If you have any questions or comments specifically about this research, please feel free to contact Dr. Craig Bennell (613-520-2600 ext. 1769, craig_bennell@carleton.ca) or Rebecca Mugford (613-520-2600 ext. 1728, rmugford@ connect.carleton.ca). Should you have any ethical or any other concerns about this study, please contact Dr. Avi Parush (Chair, Carleton University Ethics Committee for Psychological Research, Department of Psychology, Carleton University, 613-520-2600 ext.6026, avi_parush@carleton.ca). 


\section{Appendix E \\ Recruitment Messages}

Strong Message

\section{Challenges You May Experience as a Police Officer}

There are certainly some risks you may encounter as a police officer, and some difficulties you will experience throughout your career. For instance:

- Policing is a 24 hours a day job, making it necessary for you to be ready to work evenings, weekends, and sometimes even holidays.

- There will also be times where you may face stressful and dangerous situations while on the job, although these situations are rarer than generally believed.

- Like the majority of other careers out there, paperwork is an inevitable part of police work. However, paperwork would not be the central aspect of your job.

\section{Benefits to Becoming a Police Officer}

There are also many benefits to becoming a police officer that far outweigh the above negative aspects of the job. For instance:

- You will have countless opportunities to help victims of crime, including domestic disturbances and sexual assaults.

- By becoming a police officer, you will not just have an ordinary desk job like so many careers out there. Instead you will have a job where the work is exciting and changes everyday.

- From traffic, air support, underwater search, and drugs and firearms, you will be exposed to many different career paths as a police officer.

- You will also be provided with countless opportunities to travel to many parts of the country.

- Policing offers a great deal of employment security. Once you are part of a force, you can rest assured that you have a job that will always be in demand, and do not have to fear being laid off like other jobs out there.

- Not only do many police agencies pay for your training once you are hired, but they offer many opportunities for you to continue your education once employed.

- A policing career comes with many other advantages as well - including some of the best medical and dental coverage available to both you and your entire family. 
- Policing also offers one of the best retirement pensions available to public sector employees.

- It is one of the few careers where you will be able to easily retire at a younger age. Not only will you be able to retire younger (e.g., when you're 50), but you will be able to do so without any cut in your retirement pension.

These are just a few of the many reasons why policing is a good career choice.

Please proceed to the next page to continue the study.

\section{Weak Message}

\section{Challenges You May Experience as a Police Officer}

There are certainly some risks you may encounter as a police officer, and some difficulties you will experience throughout your career. For instance:

- Policing is a 24 hours a day job, making it necessary for you to be ready to work evenings, weekends, and sometimes even holidays.

- There will also be times where you may face stressful and dangerous situations while on the job, although these situations are rarer than generally believed.

- Like the majority of other careers out there, paperwork is an inevitable part of police work. However, paperwork would not be the central aspect of your job.

\section{Benefits to Becoming a Police Officer}

There are also many benefits to becoming a police officer that far outweigh the above negative aspects of the job. For instance:

- You will have a job that carries with it much status. This will give you the ability to exercise your power and authority over others who will listen to you.

- Becoming a police officer will win you the respect of your friends and family members. You will be taken seriously if you pursue a career that is highly respected.

- You will become part of a workforce that encourages employee input in policy development such as shift configurations, uniform design, and community policing strategies. 
- By pursuing a career in the policing field, you will be able to fight crime and put the bad guys behind bars.

- You will be provided with countless opportunities to enforce the law in a variety of situations, including traffic violations, assaults, and drug offences.

- Another perk to becoming a police officer is that your job includes having possession of a weapon at all times when on duty.

- You'll also be required to wear a uniform while at work so you won't have to worry about shopping for work attire. The money that you save on work clothes can go towards other things that are more important to you.

- Becoming a police officer also offers you ways to increase your income, such as by taking a job up North for which you can receive isolation pay.

- To be eligible for a career in policing, most agencies only require a high school education. In other words, you do not need to have perfect grades or be highly educated to become a police officer.

These are just a few of the many reasons why policing is a good career choice.

Please proceed to the next page to continue the study. 
Appendix F

Thought Listing and Extraneous Factors (Pilot Study Stage 2 and 3)

\section{Thought Listing Measure}

Taking at least 3 minutes but no longer than 10 minutes, please list any thoughts you had about the message while reading it. Please list one thought per box, and don't worry about spelling or grammar, but focus on getting the basic idea of your thought down.

\section{Extraneous Factors}

Please rate the messages you just read in support of policing as a career on the scales below.

The arguments in the message were:

Difficult to Understan

12

Complex

12

3

4

5

6

7

Not

Believable

123

4

5

6

$\begin{array}{llll}7 & 8 & 9 & \text { Believable }\end{array}$




\section{Appendix G \\ Introduction to Messages}

\section{High Relevance, High Credibility}

In response to the imminent staffing crisis just described, police forces across Canada are attempting to recruit police officers.

The following document lays out the challenges and benefits of police work. It was written by Sergeant Steve Smith, a recruiter who has been working as a police officer for 20 years.

\section{High Relevance, Low Credibility}

In response to the imminent staffing crisis just described, police forces across Canada are attempting to recruit police officers.

The following document lays out the challenges and benefits of police work. It was written by Steve Smith, a first year college student who is currently volunteering for his local police department's human resources branch.

\section{Low Relevance, High Credibility}

In response to the potential staffing crisis just described, police forces across Europe are attempting to recruit police officers.

The following document lays out the challenges and benefits of police work. It was written by Sergeant Steve Smith, a recruiter who has been working as a police officer for 20 years.

\section{Low Relevance, Low Credibility}

In response to the potential staffing crisis just described, police forces across Europe are attempting to recruit police officers.

The following document lays out the challenges and benefits of police work. It was written by Steve Smith, a first year college student who is currently volunteering for his local police department's human resources branch. 
Appendix $\mathrm{H}$

Pilot Study Manipulation Checks

\section{Relevance Manipulation Check}

How likely is it that this police staffing crisis will impact you?

$\begin{array}{lllllllllll}\begin{array}{l}\text { Not At All } \\ \text { Likely }\end{array} & 1 & 2 & 3 & 4 & 5 & 6 & 7 & 8 & 9 & \begin{array}{l}\text { Extremely } \\ \text { Likely }\end{array}\end{array}$

\section{Credibility Manipulation Check - High Credibility}

Regardless of how you felt about what Sergeant Steve Smith had to say, how knowledgeable do you think he is about what it's like to be a police officer?

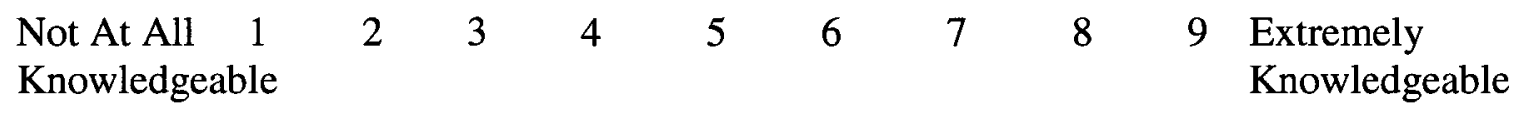

Credibility Manipulation Check - Low Credibility

Regardless of how you felt about what Steve Smith had to say, how knowledgeable do you think he is about what it's like to be a police officer?

$\begin{array}{lllllllllll}\begin{array}{l}\text { Not At All } \\ \text { Knowledgeable }\end{array} & 2 & 3 & 4 & 5 & 6 & 7 & 8 & 9 & \begin{array}{l}\text { Extremely } \\ \text { Knowledgeable }\end{array}\end{array}$




\section{Appendix I \\ Informed Consent Form (Study 1)}

The purpose of an informed consent form is to ensure that you understand the purpose of the study as well as the nature of your involvement. The informed consent form should provide sufficient information such that you have the opportunity to determine whether or not you wish to participate in the study.

Research title: Perceptions of Policing as a Career

Research personnel: For questions or concerns about this study, please contact Dr. Craig Bennell (Associate Professor, Department of Psychology, Carleton University, 613-5202600 ext. 1769) or Rebecca Mugford (Principal Investigator, Carleton University, rmugford@ connect.carleton.ca, 613-520-2600 ext. 1728).

Ethics approval: This research has been approved by Carleton University. Should you have any ethical concerns about this study, please contact Dr. Avi Parush (Chair, Carleton University Ethics Committee for Psychological Research, Department of Psychology, Carleton University, avi_parush@ carleton.ca, 613-520-2600 ext. 6026) or Dr. Janet Mantler (Chair, Department of Psychology, Carleton University, psychchair@carleton.ca, 613 520-2600 ext. 4173.

Task requirements: In this study, you will be asked to read a brief message about policing. Once you have read this, you will be asked to respond to some questions assessing your perceptions of the message. Finally, you will be asked to fill out a brief demographics questionnaire at the end of the study.

Compensation: Once you have signed this form on the next page, you will be asked to provide your e-mail address if you wish to be entered into a draw for $\$ 100$. The winner of this draw will be notified via e-mail once this study has finished. At this time, the winner will be asked to provide their name and mailing address for delivery of the cheque. PSYC 1001 or 1002 students will also be given $0.5 \%$ towards their final grade for their participation.

Duration and location: This study will take approximately 20 minutes to complete and it will take place in class.

Anxiety, pain, and embarrassment: There are no known risks of you experiencing any anxiety, pain, or embarrassment while participating in this study.

Anonymity and confidentiality: Your participation in the study is both anonymous and confidential. After you sign this informed consent form, you will be given an ID number that will not be associated with your name and the informed consent form will be detached from your study materials. The data obtained from this study will be used in aggregate (group) form and only by researchers associated with this project for the purpose of research publications, conference presentations, and/or teaching material. 
Right to withdraw: Your participation in this study is entirely voluntary and you will not be provided with any compensation (e.g., extra credit) for your participation. At any point during the study, you have the right to not answer any questions or to withdraw with no penalty whatsoever. Whether or not you decide to participate in this research will have no impact on your course performance. Participation, lack of participation or withdrawal from the study will not be disclosed to the course instructor, and the instructor will not be present in class when this study is being conducted.

Data protection and disposal: Data collected for this research will be accessible only to the researchers associated with this project. It will be stored in a secure cabinet located in a research lab at Carleton University, which will be locked at all times. All data will be destroyed 5 years after the completion of this project.

Signatures: I have read the above description of the study, and understand the extent of my involvement and that only aggregate data will be used in research publications, conference presentations, and/or for teaching purposes. By signing below, I have indicated that $\mathrm{I}$ have read the informed consent form and agree to participate in this study.

Participant name (print):

Date:

Participant signature:

Participant e-mail:

Witness signature: 


\section{Appendix $\mathbf{J}$}

Attitude and Attitude Certainty Measures (Study 1 and Study 2)

\section{Attitude Measure}

We are interested in knowing how you feel about a career in policing. Please tell us what your attitudes towards policing as a career are on the following scales:

$\begin{array}{lllllllllll}\text { Unfavourable } & 1 & 2 & 3 & 4 & 5 & 6 & 7 & 8 & 9 & \text { Favourable }\end{array}$

$\begin{array}{lllllllllll}\text { Undesirable } & 1 & 2 & 3 & 4 & 5 & 6 & 7 & 8 & 9 & \text { Desirable }\end{array}$

\section{Attitude Certainty Measure}

How confident are you that your attitudes towards policing as a career are correct?

$\begin{array}{lllllllllll}\text { Not at all } & 1 & 2 & 3 & 4 & 5 & 6 & 7 & 8 & 9 & \text { Extremely }\end{array}$

Confident 


\section{Appendix K}

Manipulation Checks (Study 1 and Study 2)

Relevance Manipulation Check

How likely is it that this police staffing crisis will impact you?

$\begin{array}{lllllllllll}\begin{array}{l}\text { Not At All } \\ \text { Likely }\end{array} & 1 & 2 & 3 & 4 & 5 & 6 & 7 & 8 & 9 & \begin{array}{l}\text { Extremely } \\ \text { Likely }\end{array}\end{array}$

Credibility Manipulation Check - High Credibility ${ }^{14}$

Regardless of how you felt about what Sergeant Steve Smith had to say, how knowledgeable do you think he is about what it's like to be a police officer?

$\begin{array}{lllllllllll}\text { Not At All } & 1 & 2 & 3 & 4 & 5 & 6 & 7 & 8 & 9 & \text { Extremely }\end{array}$ Knowledgeable Knowledgeable

Credibility Manipulation Check - Low Credibility ${ }^{15}$

Regardless of how you felt about what Steve Smith had to say, how knowledgeable do you think he is about what it's like to be a police officer?

$\begin{array}{lllllllllll}\text { Not At All } & 1 & 2 & 3 & 4 & 5 & 6 & 7 & 8 & 9 & \begin{array}{l}\text { Extremely } \\ \text { Knowledgeable }\end{array} \\ \text { Knowledgeable } & & & & & & & & \end{array}$

\section{Quality Manipulation Check}

How would you rate the quality of the arguments used by the recruiter to support policing as a career? $\begin{array}{lllllllllll}\begin{array}{l}\text { Extremely } \\ \text { Weak }\end{array} & 1 & 2 & 3 & 4 & 5 & 6 & 7 & 8 & 9 & \begin{array}{l}\text { Extremely } \\ \text { Strong }\end{array} \\ \end{array}$

\footnotetext{
${ }^{14}$ Study 1 only

${ }^{15}$ Study 1 only
} 


\section{Appendix L \\ Debriefing Form (Study 1)}

Thank you for your participation in this study. However, before you go, we would like to take a moment to tell you a bit more about our study and why we are interested in examining these sorts of issues.

\section{Why is this research important?}

In the near future, police agencies across Canada will likely experience a substantial shortage in officers. The Police Sector Council (PSC) of Canada has estimated that the annual number of recruits would need to double in 2010 just to maintain the current strength of police officers nationwide (PSC, 2006). This shortage is likely due to a combination of many factors, including the fact that many employees are retiring, fewer applications are being processed, and that Canadian youth seem less and less interested in a career in the policing field. Indeed, in a recent survey, human resource employees across Canadian police forces indicated that potentially 55 to 75 percent of their senior positions will be vacant within the next five years (Hay Group, 2007). Moreover, only 36 percent of youths in a 2005 national survey indicated that they would even consider a career in law enforcement (PSC, 2005).

\section{What are we trying to learn through this research?}

In order to determine the effect of different message, source, and recipient factors on attitudes towards a career in policing, we provided participants with different recruitment messages where we varied the quality of the arguments supporting policing as a career (weak or strong), the credibility of the recruiter (low or high) and the personal relevance of the message (low or high). The overall goal of this research is to see if attitudes towards policing differ across these groups. For example, some of the questions that we hope to answer include: Does it matter if the recruiter is seen as an expert on a policing career? Do those who see the policing crisis as more personally relevant to them as a Canadian citizen pay more attention to the arguments in the message than the expertise of the source, and does this influence attitudes towards policing as a career? This was done as a first step towards determining the relative importance of these different aspects of a police recruitment message.

\section{What if I'm interested in the findings of this research?}

For those of you who are interested in the findings of this research, please contact the primary researcher, Rebecca Mugford (rmugford@connect.carleton.ca), who can then send you an electronic copy of her final thesis upon completion.

\section{What if I have questions later?}

Once again, we would like to thank you for your participation in this study. As well, we would like to remind you that your information will remain confidential. If you have any questions or comments specifically about this research, please feel free to contact $\mathrm{Dr}$. Craig Bennell (613-520-2600 ext. 1769, craig_bennell@carleton.ca) or Rebecca Mugford (613-520-2600 ext. 1728, rmugford@connect.carleton.ca).Should you have any ethical concerns about this study, please contact Dr. Avi Parush (Chair, Carleton University 
Ethics Committee for Psychological Research, Department of Psychology, Carleton University, 613-520-2600 ext. 6026). 


\author{
Appendix M \\ Study 1 Power and Effect Size Tables
}

M-1

Power and effect size estimates for all main and interaction effects for attitudes towards policing as a career

\begin{tabular}{lcc}
\hline \multicolumn{1}{c}{ Effect } & Power & Partial $\eta^{2}$ \\
\hline Relevance & .44 & .01 \\
Quality & .43 & .01 \\
Credibility & .05 & .00 \\
Relevance x Quality & .05 & .00 \\
Relevance x Credibility & .05 & .00 \\
Quality x Credibility & .05 & .00 \\
Relevance x Quality x Credibility & .19 & .01 \\
\hline
\end{tabular}

M-2

Power and effect size estimates for all main and interaction effects for attitude certainty

\begin{tabular}{lcc}
\hline \multicolumn{1}{c}{ Effect } & Power & Partial $\eta^{2}$ \\
\hline Relevance & .05 & .00 \\
Quality & .13 & .00 \\
Credibility & .08 & .00 \\
Relevance x Quality & .05 & .00 \\
Relevance x Credibility & .13 & .00 \\
Quality x Credibility & .09 & .00 \\
Relevance x Quality x Credibility & .39 & .01 \\
\hline
\end{tabular}


M-3

Power and effect size estimates for all main and interaction effects for total number of relevant thoughts

\begin{tabular}{lcc}
\hline \multicolumn{1}{c}{ Effect } & Power & Partial $\eta^{2}$ \\
\hline Relevance & .18 & .00 \\
Quality & .23 & .00 \\
Credibility & .05 & .01 \\
Relevance x Quality & .23 & .01 \\
Relevance x Credibility & .06 & .00 \\
Quality x Credibility & .19 & .01 \\
Relevance x Quality x Credibility & .13 & .00 \\
\hline
\end{tabular}

M-4

Power and effect size estimates for all main and interaction effects for thought favourability

\begin{tabular}{lcc}
\hline \multicolumn{1}{c}{ Effect } & Power & Partial $\eta^{2}$ \\
\hline Relevance & .37 & .01 \\
Quality & .99 & .11 \\
Credibility & .11 & .00 \\
Relevance x Quality & .21 & .01 \\
Relevance x Credibility & .13 & .00 \\
Quality x Credibility & .12 & .00 \\
Relevance x Quality x Credibility & .06 & .00 \\
\hline
\end{tabular}




\section{Appendix N \\ Sets of Arguments for Three Argument Conditions}

Strong Arguments

Set 1

- Policing offers a great deal of employment security. Once you are part of a force, you can rest assured that you have a job that will always be in demand, and do not have to fear being laid off like other jobs out there.

- You will also be provided with countless opportunities to travel to many parts of the country.

- Not only do many police agencies pay for your training once you are hired, but they offer many opportunities for you to continue your education once employed.

Set 2

- You will have countless opportunities to help victims of crime, including domestic disturbances and sexual assaults.

- From traffic, air support, underwater search, and drugs and firearms, you will be exposed to many different career paths as a police officer.

- It is one of the few careers where you will be able to easily retire at a younger age. Not only will you be able to retire younger (e.g., when you're 50), but you will be able to do so without any cut in your retirement pension.

Set 3

- By becoming a police officer, you will not just have an ordinary desk job like so many careers out there. Instead you will have a job where the work is exciting and changes everyday.

- A policing career comes with many other advantages as well - including some of the best medical and dental coverage available to both you and your entire family.

- Policing also offers one of the best retirement pensions available to public sector employees. 


\section{Weak Arguments}

Set 1

- You will have a job that carries with it much status. This will give you the ability to exercise your power and authority over others who will listen to you.

- Becoming a police officer will win you the respect of your friends and family members. You will be taken seriously if you pursue a career that is highly respected.

- Becoming a police officer also offers you ways to increase your income, such as by taking a job up North for which you can receive isolation pay.

Set 2

- To be eligible for a career in policing, most agencies only require a high school education. In other words, you do not need to have perfect grades or be highly educated to become a police officer.

- Another perk to becoming a police officer is that your job includes having possession of a weapon at all times when on duty.

- You'll also be required to wear a uniform while at work so you won't have to worry about shopping for work attire. The money that you save on work clothes can go towards other things that are more important to you.

Set 3

- You will become part of a workforce that encourages employee input in policy development such as shift configurations, uniform design, and community policing strategies.

- By pursuing a career in the policing field, you will be able to fight crime and put the bad guys behind bars.

- You will be provided with countless opportunities to enforce the law in a variety of situations, including traffic violations, assaults, and drug offences. 
Please indicate on the scales provided below, how open you are to a career in each of the following fields:

\section{Education:}

$\begin{array}{lllllllllll}\begin{array}{l}\text { Not at all } \\ \text { Open }\end{array} & 1 & 2 & 3 & 4 & 5 & 6 & 7 & 8 & 9 & \begin{array}{l}\text { Extremely } \\ \text { Open }\end{array}\end{array}$

\section{Healthcare:}

$\begin{array}{lllllllllll}\begin{array}{l}\text { Not at all } \\ \text { Open }\end{array} & 1 & 2 & 3 & 4 & 5 & 6 & 7 & 8 & 9 & \begin{array}{l}\text { Extremely } \\ \text { Open }\end{array}\end{array}$

\section{Skilled Trades:}

$\begin{array}{lllllllllll}\begin{array}{l}\text { Not at all } \\ \text { Open }\end{array} & 1 & 2 & 3 & 4 & 5 & 6 & 7 & 8 & 9 & \begin{array}{l}\text { Extremely } \\ \text { Open }\end{array}\end{array}$

\section{Policing:}

$\begin{array}{lllllllllll}\begin{array}{l}\text { Not at all } \\ \text { Open }\end{array} & 1 & 2 & 3 & 4 & 5 & 6 & 7 & 8 & 9 & \begin{array}{c}\text { Extremely } \\ \text { Open }\end{array} \\ \end{array}$

\section{Retail:}

$\begin{array}{lllllllllll}\begin{array}{l}\text { Not at all } \\ \text { Open }\end{array} & 1 & 2 & 3 & 4 & 5 & 6 & 7 & 8 & 9 & \begin{array}{l}\text { Extremely } \\ \text { Open }\end{array} \\ \end{array}$

\section{Government:}

$\begin{array}{lllllllllll}\begin{array}{l}\text { Not at all } \\ \text { Open }\end{array} & 1 & 2 & 3 & 4 & 5 & 6 & 7 & 8 & 9 & \begin{array}{l}\text { Extremely } \\ \text { Open }\end{array}\end{array}$

\section{Non-profit Sector:}

$\begin{array}{lllllllllll}\begin{array}{l}\text { Not at all } \\ \text { Open }\end{array} & 1 & 2 & 3 & 4 & 5 & 6 & 7 & 8 & 9 & \begin{array}{l}\text { Extremely } \\ \text { Open }\end{array}\end{array}$

\section{Military:}

$\begin{array}{lllllllllll}\begin{array}{l}\text { Not at all } \\ \text { Open }\end{array} & 1 & 2 & 3 & 4 & 5 & 6 & 7 & 8 & 9 & \begin{array}{l}\text { Extremely } \\ \text { Open }\end{array} \\ \end{array}$




\section{Appendix $\mathbf{P}$ \\ Behavioural Intention Questions}

Please respond to the questions below on the scales provided.

More Information:

How interested are you in obtaining more information about career opportunities in the field of policing?

$\begin{array}{lllllllllll}\text { Not at all } & 1 & 2 & 3 & 4 & 5 & 6 & 7 & 8 & 9 & \text { Extremely }\end{array}$ Interested

Visiting Websites:

How likely is it that you will seek out more information about policing as a career sometime in the future by visiting recruitment websites?

$\begin{array}{lllllllllll}\begin{array}{l}\text { Not at all } \\ \text { Likely }\end{array} & 1 & 2 & 3 & 4 & 5 & 6 & 7 & 8 & 9 & \begin{array}{l}\text { Extremely } \\ \text { Likely }\end{array}\end{array}$

Contacting Agency:

How likely is it that you will seek out more information about policing as a career sometime in the future by directly contacting a police agency?

$\begin{array}{lllllllllll}\text { Not at all } & 1 & 2 & 3 & 4 & 5 & 6 & 7 & 8 & 9 & \text { Extremely }\end{array}$ Likely Likely

\section{Apply in the Future:}

How likely is it that you will apply for a career in policing sometime in the future?

$\begin{array}{lllllllllll}\text { Not at all } & 1 & 2 & 3 & 4 & 5 & 6 & 7 & 8 & 9 & \text { Extremely }\end{array}$ Likely Likely 


\section{Appendix Q \\ Study 2 Power and Effect Size Tables}

Q-1

Power and effect size estimates for all main and interaction effects for attitudes while controlling for openness to policing as a career

\begin{tabular}{lcc}
\hline \multicolumn{1}{c}{ Effect } & Power & Partial $\eta^{2}$ \\
\hline Relevance & .17 & .00 \\
Quality & .05 & .00 \\
Quantity & .10 & .00 \\
Relevance x Quality & .06 & .00 \\
Relevance x Quantity & .05 & .00 \\
Quality x Quantity & .05 & .00 \\
Relevance x Quality x Quantity & .23 & .00 \\
\hline
\end{tabular}

Q-2

Power and effect size estimates for all main and interaction effects for attitude certainty while controlling for openness to policing as a career

\begin{tabular}{lcc}
\hline \multicolumn{1}{c}{ Effect } & Power & Partial $\eta^{2}$ \\
\hline Relevance & .11 & .00 \\
Quality & .25 & .01 \\
Quantity & .11 & .00 \\
Relevance x Quality & .08 & .00 \\
Relevance x Quantity & .16 & .00 \\
Quality x Quantity & .25 & .01 \\
Relevance x Quality x Quantity & .08 & .00 \\
\hline
\end{tabular}


Q-3

Power and effect size estimates for all main and interaction effects for total number of relevant thoughts while controlling for openness to policing as a career

\begin{tabular}{lcc}
\hline \multicolumn{1}{c}{ Effect } & Power & Partial $\eta^{2}$ \\
\hline Relevance & .12 & .00 \\
Quality & .15 & .00 \\
Quantity & .09 & .00 \\
Relevance x Quality & .07 & .00 \\
Relevance x Quantity & .22 & .01 \\
Quality x Quantity & .11 & .00 \\
Relevance x Quality x Quantity & .12 & .00 \\
\hline
\end{tabular}

Q-4

Power and effect size estimates for all main and interaction effects for thought favourability while controlling for openness to policing as a career

\begin{tabular}{lcc}
\hline \multicolumn{1}{c}{ Effect } & Power & Partial $\eta^{2}$ \\
\hline Relevance & .16 & .00 \\
Quality & .96 & .06 \\
Quantity & .40 & .01 \\
Relevance x Quality & .05 & .00 \\
Relevance x Quantity & .09 & .00 \\
Quality x Quantity & .21 & .01 \\
Relevance x Quality x Quantity & .06 & .00 \\
\hline
\end{tabular}

